\title{
The role of gender in medical specialty choice and general practice preferences
}

Citation for published version (APA):

Maiorova, T. (2009). The role of gender in medical specialty choice and general practice preferences. [Doctoral Thesis, Maastricht University]. Datawyse / Universitaire Pers Maastricht. https://doi.org/10.26481/dis.20090529tm

Document status and date:

Published: 01/01/2009

DOI:

10.26481/dis.20090529tm

Document Version:

Publisher's PDF, also known as Version of record

\section{Please check the document version of this publication:}

- A submitted manuscript is the version of the article upon submission and before peer-review. There can be important differences between the submitted version and the official published version of record.

People interested in the research are advised to contact the author for the final version of the publication, or visit the DOI to the publisher's website.

- The final author version and the galley proof are versions of the publication after peer review.

- The final published version features the final layout of the paper including the volume, issue and page numbers.

Link to publication

\footnotetext{
General rights rights.

- You may freely distribute the URL identifying the publication in the public portal. please follow below link for the End User Agreement:

www.umlib.nl/taverne-license

Take down policy

If you believe that this document breaches copyright please contact us at:

repository@maastrichtuniversity.nl

providing details and we will investigate your claim.
}

Copyright and moral rights for the publications made accessible in the public portal are retained by the authors and/or other copyright owners and it is a condition of accessing publications that users recognise and abide by the legal requirements associated with these

- Users may download and print one copy of any publication from the public portal for the purpose of private study or research.

- You may not further distribute the material or use it for any profit-making activity or commercial gain

If the publication is distributed under the terms of Article $25 \mathrm{fa}$ of the Dutch Copyright Act, indicated by the "Taverne" license above, 
The role of gender in medical specialty choice and general practice preferences

Tanja Maiorova 
CC Copyright, Tanja Maiorova, Maastricht 2009 Druk: Datawyse bv / Universitaire Pers Maastricht Cover illustration: Pallieter Hutschemakers, idee Timo Ekhart ISBN 978-90-5278-831-9 


\title{
The role of gender in medical specialty choice and general practice preferences
}

\author{
PROEFSCHRIFT \\ ter verkrijging van de graad van doctor aan \\ de Universiteit Maastricht, \\ op gezag van de Rector Magnificus, Prof. mr. G.P.M.F. Mols, \\ volgens het besluit van het College van Decanen, \\ in het openbaar te verdedigen \\ op vrijdag 29 mei 2009 om 12:00 uur \\ door \\ Tanja Maiorova \\ geboren op 8 oktober 1979 te Moskou
}

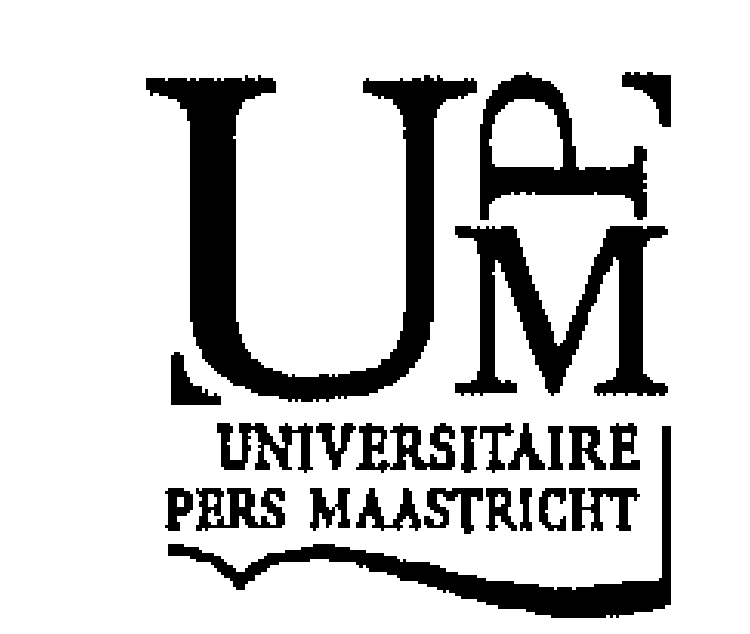




\section{Promotores}

Prof. dr. A. Scherpbier

Prof. dr. J. van der Zee

\section{Copromotor}

Dr. F. Stevens

\section{Beoordelingscommissie}

Prof. dr. J.A. Knottnerus (voorzitter)

Prof. dr. J. Cohen-Schotanus, UMC Groningen

Prof. dr. T. Lagro-Janssen, UMC St. Radboud Nijmegen

Prof. dr. A.C. Nieuwenhuijzen-Kruseman

Prof. dr. C.P.M. van der Vleuten 


\section{Het Zeil}

Een eenzaam zeil kruist op de golven

Van de onmetelijke zee...

Wat zoekt het? Welk doel wil het volgen?

Wat liet het achter op de ree?

Het is een speelbal van de winden,

De mast buigt heen en weer en zucht...

Geluk probeert het niet te vinden

Noch is het er voor op de vlucht!

Rondom het zeil azuren stromen,

De gouden zon daarboven staat...

Dwars, vraagt het of er storm kan komen

Alsof in stormen rust bestaat!

Michail Lermontov 


\section{Contents}

\section{Chapter 1 Introduction}

Chapter 2 Gender-Related Differences in General Practice Preferences: Longitudinal Evidence from the Netherlands $1982-2001$

Chapter 3 Gender shift in realisation of preferred type of GP practice: longitudinal survey over the last 25 years

Chapter 4 Differences between faculties of medicine in the numbers of their medical graduates entering general practice training and general practice orientation of their curricula. A longitudinal descriptive study

Chapter 5 The impact of clerkships on students' specialty preferences. What do undergraduates learn for their profession?

Chapter 6 Shortage in general practice despite the feminisation of the medica workforce: a seeming paradox? A cohort study

Chapter 7 Discussion

Summary

Samenvatting

Dankwoord

Curriculum Vitae 


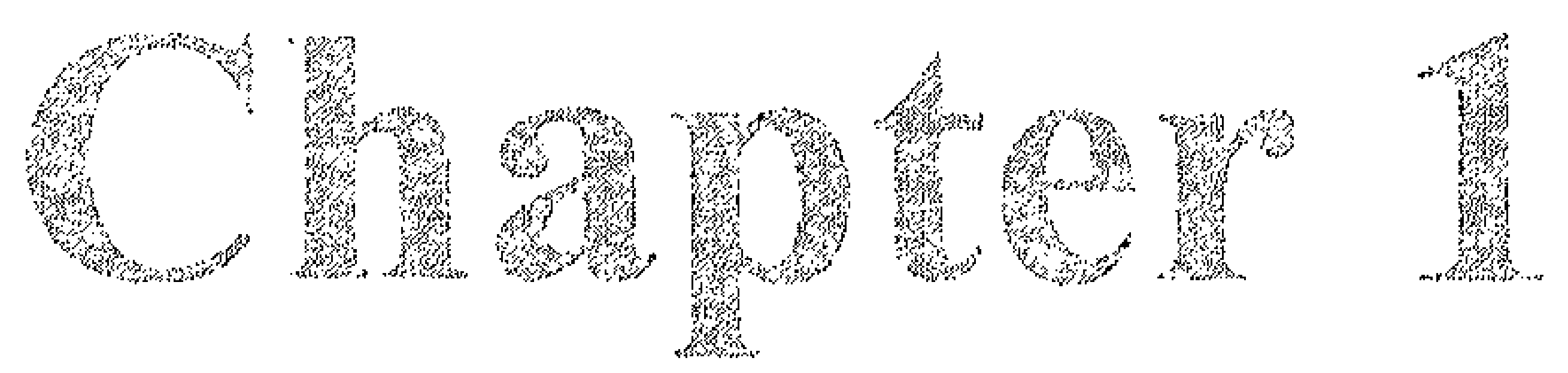

\section{Introduction}




\section{Chapter 1}

The central issue in this thesis is the career preference of male and female general practitioners (GPs): what type of practice is preferred by new male and female GPs? What do students value the most in opting for a career in general practice and are the preferences of these students different from those of students who choose other medical specialties? The answers to these questions are important for health manpower development in medicine and in general practice in particular. Health policy makers are continuously trying to maintain an even balance between the demand for and supply of health care professionals, because a mismatch may lead to either a surplus or a shortage of health professionals [1-5]. Health care demands are ever changing and highly susceptible to external, societal and demographic influences. Important quantitative and qualitative factors on the supply side are the expected number of graduates, potential drop out and changes in students' preferences and favoured specialities. It is impossible to know exactly in advance how the labour market will develop. It is even less well known what factors affect this. Questions concerning avoidance of a mismatch between supply and demand, such as how to balance demand and supply, and how to train a sufficient number of doctors to meet future needs, are important but difficult to answer satisfactorily. So far predictions have been based primarily on population growth, on the expected numbers of medical graduates and demographic factors that influence the size of the medical workforce [6]. Nevertheless, many other factors play a role as well.

General practice is a domain that has the full attention in health policy. In the Netherlands, this is mainly related to the GP's central position in the health care system as gatekeeper to specialised health care services. Most patients' health problems are first presented to their GP and only some $6 \%$ of cases are referred to a medical specialist in the hospital [7]. This implies that the GP, as a generalist in health care, is expected to be an expert and advisor concerning a wide range of health problems, presented by people from all age groups and social and cultural backgrounds. Traditionally, Dutch GPs worked in single-handed practices, as generalists serving a number of patients, usually a mix of people with private and public insurance [8]. Times have changed, however, and so has primary health care. Since 2006/7, almost all inhabitants of the Netherlands have the same basic health insurance coverage. Furthermore, GPs are faced with new and higher patient demands and pressure from developments in specialised health care in hospitals and elsewhere. These changes inevitably affect the content and organisation of and ideas about work in primary health, which in turn will impact on the GP work force.

Societal changes also influence health care in general and primary health care in particular. The three important developments which may have influence on the organisation and the image of primary health are: (1) increasing numbers of female doctors leading to the feminisation of the medical profession, which will be the focus of the research, (2) the democratisation of society leading to more egalitarian doctor-patient relationships and (3) the changing demographic composition of the general population, with a larger proportion of elderly patients and new tasks in general practice. 
Apart from being affected by these societal changes, general practice is undergoing organisational changes, including an increase in the number of group practices and a concomitant decrease in the number of single-handed practices and the replacement of retiring older GPs by a new generation of young doctors with different views on work and medical practice.

Demographic factors, perception of tasks and doctor-patient relationships, organisation of general practice and feminisation also affect the image of general practice together with medical students' interest in general practice as a career.

The important question for this thesis is the practice preferences of young general practitioners and the popularity of general practice among medical students on background of the feminisation in medicine. After a brief discussion of the social developments related to the general practice context, the research questions addressed in this thesis will be described.

\section{Feminisation of the medical profession}

All over the world a steady feminisation of the medical profession can be observed [914]. In the Netherlands in $2008,65 \%$ of all medical students were female [15]. Currently, female medical students outnumber their male counterparts in many other countries as well $[16,17][18]$. While there are still more male than female doctors in Western Europe, reflecting the situation in the past when male medical students outnumbered their female colleagues, the proportion of female doctors continues to rise [13]. How will this impact on the practice of medicine?

In Eastern Europe, in Russia in particular, the medical profession differs significantly from that in the West in its traditionally predominantly female labour force. Around $70 \%$ of doctors in Russia are female and were so in the past. What these figures obscure, however, is that despite female predominance, women are under-represented in prestigious specialities in Russia [19]. In Western Europe too women generally do not hold the high positions $[20,21]$. According to some authors, feminisation of certain occupational niches (health care, education, law) may herald a gradual decline in the status accorded to that profession $[19,22,23]$. In other words, whether perceived as positive or negative, feminisation may lower the established prestige of a medical specialty. This may relate to women being more likely to work part time, giving more attention to family life and seeming less dedicated to their profession.

The feminisation in medicine reflects developments in society at large. In recent decades the distinctions between 'typical' male and female professions have blurred. Women have increasingly entered traditional male professions, changing working conditions as they did so. In medicine in particular increasing numbers of women are fostering work environments that allow doctors to balance a career and family life [17]. While many women in medicine may work full time, the majority of female doctors opt for jobs which allow sufficient time for their personal life, flexibility in working hours 


\section{Chapter 1}

and opportunities to combine work and family life [24]. Not only women, but also men increasingly want to work fewer hours in order to obtain a more even balance between work and family obligations [25-27]. Nowadays many male professionals, also in medicine, are equally in favour of opportunities for part time work and want more time for leisure activities and/or their family [28]. There is evidence that both the men and the women of the new generation of doctors, the so-called generation X, born between 1965 and 1980, prefer a lifestyle where they are in control, with more time for their personal life and flexible schedules $[29,30]$. This is in sharp contrast to the ideas of the older generation of baby boomers, born between 1945 and 1964, who have a leaning towards a strong work ethic and long working hours [24].

It should be noted here that nowhere in the European Union are more people working part time than in the Netherlands. In 2002, $43 \%$ of all jobs in the Netherlands were part time jobs. At that time, the EU average was as low as $18 \%$ [31]. So there is a much stronger tendency to work part time among the Dutch population than in other countries. Undoubtedly, this will affect the medical labour force too. In the Netherlands in 1996, $26 \%$ of medical specialists were working part time [32]. And this number is only expected to rise.

\section{Changing preferences and work attitude of young GPs}

With the continuous increase in the number of female doctors, the preferences of young GPs are changing. As men and women generally hold dissimilar views of work and career, gender differences in doctors' career preferences are becoming an important issue in health manpower. Many women take on dual responsibilities: on the one hand work and on the other hand looking after their home and children. As noted before, this fosters a preference for part-time work and flexible working hours. Women are more frequently employed as non-principals compared to men, and child care is a frequent reason for that. [33] Women also show a stronger preference for working in partnerships. Nowadays, the majority of GPs is working in group practices instead of solo practices $[9,34]$. In $2007,78 \%$ of Dutch GPs worked in a partnership, while ten years earlier it was $60 \%$ [35]. The question is whether the labour market will be able to respond adequately to these changing preferences by offering sufficient suitable medical positions. If the labour market fails to rise to this challenge, there is a good chance that many GPs will fail to find a practice setting they like and, consequentially, turn their back on general practice $[1,2,36,37]$. They may look for another medical speciality or, worse, leave the medical profession altogether. However, at present, little is known about how demand and supply will develop. There are good reasons to conduct an inquiry into this issue of supply and demand. Besides the increasingly crucial and complex role of the GP in primary health care, there is an additional economic reason to look into this: the justification of societal investments in postgraduate training of GPs. 
Summarizing, developments in general practice reflect general feminization trends. General practice is attracting more women than men and the majority of the new generation of GPs is female [37]. The likely effect will be a demand for more part-time jobs, more arrangements for parental leave, regular working hours, and so on. For the coming years, GP shortages are already being predicted as a consequence of an increasing demand for service and the growing complexity in the provision of primary health care. It is not unlikely that many vacancies will be filled by GPs working part time and "...society may reap lower returns for its investment in medical education." [17] Data on medical students' preferences can assist in adequate planning and help prevent shortages of GPs in the long run. In the next paragraphs we discuss other developments like demographical changes, new tasks in general practice and changing relations with patients which might impact the perception of general practice and career decisions among medical graduates.

\section{New tasks: from "cure" to "care"}

The ageing (or 'greying') of the population is a familiar social phenomenon in Europe. It refers to the increasing proportion of older people in the population as a whole, which is mainly due to higher life expectancy and low birth rates [38]. Inevitably, this will affect the patient population that is seen in general practice. The group of persons aged 75 years or over consults their doctor frequently and has high co-morbidity [39]. The number of patients with chronic diseases and physical limitations will increase and GPs will have more frequent and more intensive contacts with elderly people. Even today, elderly persons with chronic diseases make up a large proportion of patients in general practice [40]. In other words, as a consequence of increased life expectancy, more elderly persons will have to cope with more (chronic) health problems for a longer period. Low admission rates in hospitals and short lengths of stay will further increase (and therefore change) the demand for GP services, with a concomitant increase in the GP's workload [40]. Due to the increase in elderly patients, chronic diseases and prevention tasks, there has been a marked shift from "cure" to "care". At the intersection of cure and care GPs play a central role.

A parallel development is that the GP plays a more central role in the prevention and treatment of lifestyle diseases [41] . Although prevention has always been a typical task for GPs, for example the prevention of smoking or alcohol abuse, in recent years more and more attention is paid to "new" lifestyle problems such as obesity in young people. Screening and monitoring of these patients has become one of the tasks of the GP, because in the long run these patients are at risk of developing diabetes mellitus type 2 and/or cardiovascular diseases [42].

Finally, in recent decades the Netherlands has become a country in which more and more inhabitants are from different cultural backgrounds. Also for these people, with their variety in backgrounds, standards and values, the GP is the gatekeeper to health 


\section{Chapter 1}

care. Moreover, the first generation of persons who came to the Netherlands from Turkey and Morocco in the 1960s to work here is reaching the age where they need more care [40] . GPs are the first to accommodate these demographic and health care related developments. Hence, GPs will continue to see their tasks change. The new tasks might also reflect on the impression of general practice that medical students receive during their clerkships and, indirectly their career choices towards general practice. On the other side, these new tasks create a new kind of demand in health care which is to be fulfilled with medical graduates. How coming generations of male and female students will respond to these changing demands in health care remains to be seen.

\section{Doctor-patient relationships}

Another societal development with a strong impact on the work of GPs and related to the feminization in medicine is the increasing democratisation of health care. The increasing presence of women in medicine seems to promote a more democratic style of communication with patients, which fosters collaborative relationships [43]. Until the 1960s, doctor-patient relationships were usually one-directional, hierarchical and paternalistic $[44,45]$. The doctor was the medical expert; the patient was a lay person who only had to comply with the doctor's advice and treatment in order to get well. Since the late 1960s and early 1970s, doctor-patient relationships have become more egalitarian. One reason is that society as a whole has become more egalitarian, with less social distance between doctor and patient [44]. This does not necessarily mean that patients act more egalitarian by asking more questions or making more remarks on the treatment. Yet, patients have become better educated and are better informed about their health problems. Patient involvement in decision making appears to have increased over time [42] and today it is becoming increasingly customary for GPs to have a legal obligation to obtain patients' informed consent for treatment [46]. Though, in a Dutch study on the hypertension patients it was argued that doctor-patients relationship did not become more egalitarian, but rather more task-oriented due to the evidence-based medicine and protocolized care [47].

Changed doctor-patient relationships can have positive effects, such as improved communication and improved patient care. However, there are some negative consequences as well. Although GPs are still highly trusted, patients expect more from their doctor, whose workload tend to increase [40]. In fact, $60 \%$ of referrals appears to be related to pressure put upon GPs [45].

Summarizing, demographic developments and more egalitarian relationships between doctors and patients provoke qualitative as well as quantitative changes in GPs' tasks. Not only is it possible that more doctors will be needed to cope with higher patient demand, it is equally possible that, with changes in the nature of demand, the doctor's work, required work experience and work perception will change as well [40]. This has consequences for the image and impression of general practice where medical students 
often base their future specialty preferences. Next, we will discuss general practice as a career choice of medical students, beginning with the postgraduate training required to become a general practitioner.

\section{Career preferences of medical students}

Notwithstanding overall high commitment to and interest in medicine, the majority of today's medical students prefer to regard the medical profession as a 'regular' job with regular working hours and a secure work-life balance $[32,48]$. A controllable lifestyle has become an important consideration in career choices. Current generation of students frequently prefer uncomplicated working conditions, ample leisure time and high earnings, if possible in part-time jobs [24].

\section{Postgraduate training and the image of general practice}

GP training is much shorter than the training of most hospital-based specialties, which might make it more attractive to young people. In 1974 vocational training in general practice was first introduced in the Netherlands [49]. Until then, a medical graduate could set up in independent practice as a GP without any further training. Soon, professional developments made a one- year training programme compulsory. In 1974, all Dutch medical schools provided a compulsory one-year vocational training programme in general practice for the first time. In 1988, the programme was extended to two years, and in 1994 a three-year training programme was compulsory for medical graduates who wanted to enter general practice [50]. The extension of the training programme reflects the professionalization of general practice as a medical specialty, as well as the increasing importance of primary health care. In recent years, government policy has focused on strengthening primary health care [51]. This has resulted in many GP group practices, where sub-specialised general practitioners work together, supported by allied health professionals, such as nurse practitioners [34]. It is obvious that this changes the GP's professional environment and also the behaviour of individual practitioners. Through the years, primary care as provided by GPs has shifted from individualised, idiosyncratic, 'experience-based' medicine to team-based, rational, scientific, 'evidence-based' medicine [52]. This shift was supported by the outcomes of epidemiological studies, which provided a strong basis for the development of guidelines for 'good' medical practice, which are being published in rapid succession. Knowledge of the 'state of art' in effective diagnostic procedures and therapeutic interventions has become a prerequisite for delivering good quality care and is an essential element of the GP's medical expertise. Similar to hospital-based specialties, general practice requires 'lifelong learning' [53]. The image of general practice has changed. The GP used to be a family doctor who was on call every day 24-hours a day. Nowadays, general practice is more like a regular job (at least in the Netherlands) and doctors are on call on a limited number of occasions [54]. In this way, general practice offers ample opportunities for a 


\section{Chapter 1}

controllable lifestyle. This could be the reason why marital status is positively related to a primary care career choice [55- 59] as family demands often lead to the preference of a flexible lifestyle.

Taking increasing numbers of women in medicine and more controllable lifestyle opportunities into account, general practice could be expected to become more popular among medical students. However, the interesting paradox is that in some countries it is still difficult to recruit general practice trainees. This is particularly the case in the US and England [56-59]. It raises the question as to how career choices are made by medical students. One of the reasons for the lower popularity of general practice could be that medical students often believe that a GP is a basic generalist whose main task it is to refer patients to the hospital. Moreover, status and income may play a different role in different countries, which is reflected in the professional community's view of general practice as a profession. In Australia and the US general practice is widely regarded as a lower status, lower income branch of the medical profession. In these countries the earnings aspect is an important factor in career decisions. There is evidence that in the UK the situation is different; financial considerations are not regarded as important in decisions whether to enter into general practice or not [60]. There is also evidence that in the US a preference for a surgical or supporting (hospital) specialty is positively related to high income and prestige motivations. Low income and les prestige expectations are related to choosing a career in primary care and general practice [61-63]. The fact that 'high achievers' (students who have high school grades, attend extra courses and take intercalated degrees) are more motivated by status and expected income in choosing their future career has been demonstrated by a number of studies in the USA $[56,64,65]$.

As a consequence of decreasing numbers of students choosing general practice, primary care departments in some countries are putting more efforts into stimulating students to opt for their specialty [66]. It is, however, still not clear, how to influence medical students' career choices. This brings us to the question of factors influencing career decisions. There are two groups of factors that are known to affect students' career choices: (a) internal factors, such as age, gender, parent's occupation and standard of living, early interest, personality characteristics, and (b) external factors, such as clerkship experiences, role models, characteristics of the medical curriculum. Internal factors, intrinsically related to a person, influence attitudes and preferences for postgraduate training and work. External factors mainly play a role during undergraduate medical education and shape the final career decision. Clerkship experiences and role models are examples of important external factors that influence career choices. 


\section{Internal factors influencing career preferences}

Gender as such is known to play a role in choosing a career. There is evidence that men and women choose different career paths due to the nature of human needs $[57,67]$. Women are more influenced than men by practical considerations relating to family circumstances and child care responsibilities [60, 68, 69]. Because of this, women are less likely to choose hospital specialities. Also their choices are less definite than those made by men. This reflects women's uncertainty whether their domestic and family circumstances will be compatible with hospital training [60]. Women's lower income expectations may further reflect anticipation of reduced work hours to meet family demands [69]. There is evidence that compared to men women more strongly favour contacts with patients, convenient working hours and rather few shifts [70]. Technical challenges, earning potential and prestige are important to men, while residency conditions, part-time work and flexibility are important for women [69].

Early interest in primary care as a positive predictor of a speciality choice in primary care $[58,71,72]$. Having a physician as a parent is negatively related to choosing a primary care career $[57,73]$. This may reflect the fact that students with a physician parent (and thus high economic status) have high income and status expectations. Medical education, including postgraduate training, takes quite a long time. The training period of a GP is relatively short, which is attractive to those who want to graduate as soon as possible.

Finally, students also make negative choices, based on characteristics of a speciality they do not like. These are made independent of culture or health care system and develop because of discrepancies between expectations and real work conditions. Some students choose a career in the hospital or in primary care because they dislike the other opportunity. Also, reasons for students to change their preference towards general practice were sometimes related to disillusionment with hospital medicine [73].

\section{External factors influencing career preferences}

Many studies have shown that student's clerkship experiences affect the likelihood that they will select particular specialities [72-75]. Ambulatory care experiences and community exposure were significantly associated with the intentions to pursue a generalist specialty [58] [76]. Not only clerkship experiences but also extra courses in primary care have a positive effect on career plans. Increased interest in primary care during medical school was strongly associated with the electives taken in primary care [71]. These positive effects of community exposure can partly be explained by the establishment of effective and satisfying relationships with patients. Consequently, the suggested way to increase the number of graduated general physicians has been to focus on outpatient settings to keep the interest of the generalist-oriented students $[77,78]$.

Role modelling is another important mechanism for encouraging medical students to choose a particular medical speciality. Exposure to role models in a particular clinical 


\section{Chapter 1}

field is strongly associated with a medical student's choice [74, 78-80]. Role models have the greatest effect at graduation, the stage when professional interactions can influence speciality choices [81]. In primary care the role models have mostly a motivating effect on the majority of students [82].

Teaching models. Medical schools can differ in how they teach medicine. In some schools emphasis is put on community-based medical education; in other schools more on hospital-based, clinical education. There is evidence that the primary care orientation of a curriculum increases the number of students choosing primary care as a career. The degree to which the school is orientated towards primary care will affect whether students choose this option $[76,83-85]$.

\section{Problem statement and research questions}

As outlined above, health services have to sustain the balance between demand and supply in the primary care work force. Supply, i.e. the number of GPs and their availability on the market is the focus of this thesis.

The rationale of this study is that past and current developments in medicine and general practice (such as aging of population, new tasks in the health care, doctor-patient relationships, image and perception of general practice and feminisation of medicine in particular) have an impact on students' speciality preferences and on their later medical careers in general practice. Different factors that influence career choices highlight opportunities for directing and predicting students' speciality choices. Little is known, however, on which factors play a decisive role in choosing a specific speciality and what attracts students in a certain specialty. Insights into current developments in the medical workforce are important for health care policy making. Analysing career pathways and preferences of graduated GPs may help to forecast the labour market situation in primary care. As the context of demands in primary health care changes, there should be an adequate supply of young doctors. Knowledge of what aspects of general practice do attract medical students will help to find the balance between the demand and supply in health care. Research into speciality choices of undergraduates will pinpoint the characteristics of general practice worth emphasising to attract students to this speciality.

Many stages in a medical career are crucial for becoming a medical professional. In this thesis two studies are reported which focus on two stages of a career in general practice: (a) after graduation, when newly graduated GPs decide which type of practice setting they prefer and (b) the clerkships, in which undergraduate students for the first time are fully exposed to different specialities in a comparable manner. A link between these two studies will be made by exploring the influence of the medical curriculum on a student's decision to pursue a career in general practice. The problem statement for this thesis is: 
What career paths do male and female GPs follow from medical student to the realisation of their initial practice preferences?

The following research questions are addressed:

1. What kinds of work arrangements do newly graduated GPs prefer and were they able to realise their preferences in the past 25 years? How do these preferences differ for men and women?

2. Does the undergraduate medical curriculum relate to students' decisions to pursue a career in general practice?

3. What are the decisive factors in medical students' career choices, and what is the role of gender in decision-making regarding future specialisation?

The first question addresses work preferences of recently graduated GPs and whether they succeed in realising their preferences on the labour market. As above mentioned, there is an increasing share of female GPs. Newly graduated GPs tend to prefer part time work, less time on call and more time for their private life. In this light we will explore whether general practice preferences are different for men and women and how these preferences have changed in recent decades. We analyse longitudinal data of all Dutch GPs registered between 1982 and 2000. In view of the feminisation of the medical profession and changing practice preferences, the question is whether male and female GPs were able to realise their preferences. Also, reasons for leaving general practice will be explored for male and female GPs. Insights into the long-term impact of changing male-female ratios on career preferences contribute to a better understanding of factors playing a role in the supply side of the GP workforce.

The second question is whether the undergraduate medical curriculum relates to students' final career choice for general practice. Previous research has shown that a primary-care oriented curriculum stimulates medical students to enter postgraduate training in primary care. We will explore this hypothesis, comparing the share of students choosing general practice in the eight Dutch medical faculties.

In order to answer the third question, we conducted a longitudinal cohort study in which we surveyed medical students on their career preferences, in particular the likelihood of their becoming a GP. Despite the fact that clinical experiences are known to influence medical career preferences, it remains unclear which aspects of these experiences make students favour some specialities and reject others. We described factors mentioned above explaining career choices before and after clerkships because this is a crucial period for students to decide which speciality they will choose for their postgraduate training. Special attention is paid to the role of gender in career choices. To explore whether the effect of the clerkship in general practice is specific or generic, a comparison will be made with clerkships in internal medicine and surgery. 


\section{Chapter 1}

\section{References}

1. Young, R. and B. Leese, Recruitment and retention of general practitioners in the UK: what are the problems and solutions? Br J of Gen Prac, 1999. 49: p. 829-833.

2. Hingstman, L. and L. Van der Velden, Behoefteraming Huisartsen 1997 - 2010 [Estimating the need of general practitioners 1997 - 2001]. 1998, NIVEL: Utrecht.

3. Ontwikkeling capaciteit huisartsenzorg 2000-2004-2012. Een tussenraportage met beleidscenario's. [Development in the capacity of general practice 2000-2004-2012. A report with scenario's]. 2004, Capaciteitsorgaan: Utrecht.

4. Mathie, A., The Primary Care Workforce: An Update for the New Millenium. 2000: London: Royal College of General Practitioners.

5. GP shortage 'critical'. 2002, BBC NEWS; Health: www.bbc.com.

6. Van der Velden, L. and L. Hingstman, Vraag en aanbod huisartsen. Bronnenoverzicht en ramingen 2000-2010. [ Demand and supply of general practitioners. Resources review and estimations 2000-2010].2001, NIVEL: Utrecht.

7. Fleming, D., The European study of referrals from primary to secondary care. 1993, Maastricht University. [Thesis].

8. Van den Hombergh, P., et al., Saying 'goodbye' to single-handed practices; what do patients and staff lose or gain? Fam Prac, 2005. 22(1): p. 20 -7.

9. Government Statistical Service. Statistics for general medical practitioners in England: 1994 2004, in Statistical Bulletin. 2005, Department of Health Publications: London.

10. Brooks, F., Women in general practice: responding to the sexual division of labour? Soc Sci and Med, 1998. 47(2): p. 181-93.

11. Denekens, J., The impact of feminisation on general practice. Acta Clinica Belgica, 2002. 57(1): p. 5-10.

12. Lawrence, J., P. Poole, and S. Diener, Critical factors in career decision making for women medical graduates. Med Educ, 2003. 37(4): p. 319-27.

13. McKinstry, B., et al., The feminization of the medical work force, implications for Scottish primary care: a survey of Scottish general practitioners. BMC Health Services Research, 2006. 6: p. 56.

14. Boerma, W.G.W. and A.v.d. Brink-Muinen, Gender-related differences in the organization and provision of services among general practitioners in Europe. Medical Care, 2000. 38: p. 993-1002.

15. Cenraal Bureau voor de Statistiek: Hoger onderwijs, ingeschrevenen naar studierichting en leeftijd.[Cenral Office for the Statistics] www.cbs.nl 2008.

16. Lambert, E. and E. Holmboe, The relationship between specialty choice and gender of U.S. medical students, 1990-2003. Acad Med, 2005. 80(9): p. 797-802.

17. Levinson, W. and N. Lurie, When most doctors are women: what lies ahead? Annals of Internal Medicine, 2004. 141(6): p. 471-474.

18. British Medical Association. The demography of medical schools: a discussion paper. British Medical Association, 2004.

19. Harden, J., "Mother Russia' at Work: gender divisions in the medical profession. European journal of women's studies, 2001. 8(2): p. 181-199.

20. Riska, E., Towards gender balance: but will women physicians have an impact on medicine? Soc Sci and Med, 2000. 52(2): p. 179-87.

21. Van Wijk, F., Vrouwen rukken op, behalve in de top. Arts \& Auto, 2003. 13: p. 32-33.

22. Remennik, L., 'Women with a Russian Accent in Israel: on the gender aspects of immigration. European Journal of Women's Studies, 1999. 6(4): p. 441-461.

23. Women docs 'weakening' medicine. 2004, BBC NEWS: Health. 
24. Jovic, E., J. Wallace, and J. Lemaire, The generation and gender shifts in medicine: an exploratory survey of internal medicine physicians. BMC Health Services Research, 2006. 6(1): p. 55.

25. Vaughan, C., Career choices for generation X (Editorial). BMJ, 1995. 311: p. 525-526.

26. Lugtenberg, M., et al., Internal medicine specialists' attitudes towards working part-time: a comparison between 1996 and 2004. BMC Health Services Research, 2006. 6: p. 126.

27. Cohen-Schotanus, J., et al., Tien jaar arts: een longitudinaal onderzoek naar de loopbaan van artsen die hun studie begonnen in Groningen. [Ten years being a doctor: a longitudinal research on the careers of doctors who have studied in Groningen]. Ned Tijdschr Geneeskd, 2002. 146: p. 2474-8.

28. Shanley, B., et al., Factors influencing career development of Australian general practitioners. Australian Family Physician, 2002. 31(1): p. 49-54.

29. Dorsey, E., D. Jarjoura, and G. Rutecki, Influence of controllable lifestyle on recent trends in specialty choice by US medical students. JAMA, 2003. 290(9): p. 1173-1178.

30. Buddeberg-Fischer, B., et al., Swiss residents' arguments for and against a career in medicine. BMC Health Services Research, 2006. 6: p. 98.

31. Part-time work in Europe. 2007, European Foundation for the Improvement of Living and Working Conditions. Dublin.

32. Heiligers, P. and L. Hingstman, Career preferences and the work-family balance in medicine: gender differences among medical specialists. Soc Sci and Med, 2000. 50(9): p. 1235-1246.

33. Baker, M., J. Williams, and R. Petchey, GPs in principle but not in practice: a study of vocationally trained doctors not currently working as principals. BMJ, 1995. 310: p. 1301-04.

34. Kenens, R., H. Hofhuis, and L. Hingstman, Inventarisatie mono- en multidisciplinaire samenwerkingsverbanden in de eerste lijn: een eerste verkenning. [Analysis of mono- and multi disciplinary team work in primary care: the first survey]. NIVEL, 2006.

35. Hingstman, L. and R. Kenens, Cijfers uit de registratie van huisartsen: peiling 2007. [Numbers from the registration of general practitioners in 2007]. 2007, NIVEL: Utrecht. p. 14.

36. Planning the Medical Workforce. Second report of the Medical Manpower Standing Advisory Committee. 1995, The Stationary Office, Department of Health: London.

37. Primary Care: Delivering the Future. 1997, The Stationary Office, Department of Health: London.

38. Carone, G. and D. Costello, Can Europe Afford to Grow Old?, in International Monetary Fund Finance and Development magazine. 2006.

39. Bakker de, D., et al., Jaarrapport 2000. [A year report 2000]. 2001, Landelijk Informatie Netwerk Huisartsenzorg: Utrecht.

40. van den Berg, M., et al., De werkbelasting van de huisartsen. [Workload of the general practitioners]. Tweede nationale studie naar ziekten en verrichtingen in de huisartspraktijk. 2004, NIVEL: Utrecht.

41. Cardol, M., et al., Huisartsenzorg: wat doet de poortwachter?[General Practice Care: what is the role of the gatekeeper?] Tweede nationale studie naar ziekten en verrichtingen in de huisartspraktijk. 2004, Utrecht: NIVEL.

42. Sociaal en Cultureel Rapport 2006. Investeren in vermogen. [ Investing in the capacity]. 2006, Sociaal en Cultureel Planbureau: Den Haag.

43. Roter, D., J. Hall, and Y. Aoki, Physician gender effects in medical communication: a metaanalystic review. JAMA, 2002. 288(6): p. 756-64.

44. Gallagher, E. and C. Searl, Content and context in health professional education. 2007.

45. Campen van, C., S. Kooiker, and J. Timmermans, In het zicht van de toekomst. Zorg. Sociaal en Cultureel rapport 2004. [ In the light of the future. Care. Social and Cultural report 2004]. 2004, Sociaal en Cultureel Planbureau.: Den Haag.

46. Van den Brink-Muinen, A., et al., Has patients' involvement in the decision-making process changed over time? Health Expect, 2006. 9(4): p. 333-42. 


\section{Chapter 1}

47. Bensing, J., et al., Shifts in doctor-patient communication between 1986 and 2002: a study of videotaped General Practice consultations with hypertension patients BMC Family Practice 2006. 7: p. 62.

48. Bickel, J. and A. Brown, Generation X: Implications for Faculty Recruitment and Development in Academic Health Centers. Acad Med, 2005. 80(3): p. 205-10.

49. Runia, E. and R. van Herk, De verwezenlijking van de beroepsopleiding tot huisarts, 1956-1973.[ Establishment of the General Practice vocational training, 1956-1973]. H \& W, 1991. 34(4): p. 117-23.

50. Kramer, A., Acquisition of clinical competence during postgraduate training in general practice. 2003, Maastricht University: Maastricht. p. 158. [Thesis]

51. Intentieverklaring versterking eerstelijnszorg. [Intentions to strengthen the Primary Care]. 2004, Ministerie Volksgezondheid, Welzijn en Sport: Den Haag.

52. Campbell, S., et al., Improvements in quality of clinical care in English General Practice 19982003: longitudinal observational study.BMJ, 2005. 331: p. 1121.

53. Slawson, D.C. and A.F. Shaughnessy, Teaching evidence-based medicine: should we be teaching information management instead? Acad Med, 2005. 80(7): p. 685-9.

54. Sixma, H., De huisarts: Heer van stand tot middenklasser?[A general practitioner: a man from the high class to the middle class]. 199134 (3) 111-116. H \& W, 1991. 34: p. 111-116.

55. Newton, D., M. Grayson, and T. Whitley, What predicts medical student career choice? J Gen Intern Med, 1998. 13: p. 200-3.

56. Henderson, M., D. Hunt, and J. Williams, General internists influence students to choose primary care careers: the power of role modelling. Am J Med Sci, 1996. 101: p. 648-53.

57. Gorenflo, D., M. Ruffin, and K. Sheets, A multivariate model for specialty preference by medical students. J Fam Pract, 1994. 39: p. 570-6.

58. Kassebaum, D., P. Szenas, and M. Schuchert, Determinants of the generalist care intentions of 1995 graduating medical students. Acad Med, 1996. 71: p. 198-209.

59. Schieberl, J., et al., Factors associated with choosing a primary care career. West J Med, 1996. 164(6): p. 492-6.

60. Lambert, T., et al., Career preferences of doctors who qualified in the United Kingdom in 1993 compared with those of doctors qualifying in 1974, 1977, 1980, and 1983. BMJ, 1996. 313: p. 1924.

61. Kiker, B. and M. Zeh, Relative income expectations, expected malpractice premium costs, and other determinants of physician specialty choice. J Health Soc Behav, 1998. 39(2): p. 152-67.

62. Newton, D., M. Grayson, and T. Whitley, What predicts medical student career choice? J of Gen Intern Med, 1998. 13: p. 200-3.

63. Rosenthal, M., et al., Income expectations of first-year students at Jefferson Medical College as a predictor of family practice specialty choice. Acad Med, 1992. 67: p. 328-331.

64. Murdoch, M., et al., Evaluating the psychometric properties of a scale to measure medical students' career-related values. Acad Med, 2001. 76: p. 157-65.

65. Fincher, R., L. Lewis, and L. Rogers, Classification model that predicts medical students' choices of primary care or non-primary care specialties. Acad Med, 1992. 67: p. 324-7.

66. Schroeder, S., Training an appropriate mix of physicians to meet the nation's needs. Academic Medicine, 1993. 68(2): p. 118-22.

67. Ek, E., E. Ek, and S. Mackay, Undergraduate experience of surgical teaching and its influence on career choice. Aust N Z J Surg, 2005. 75(8): p. 713-718.

68. Cameron, R., et al., Comparison of career patterns of male and female graduates of one Australian medical school. Teaching and Learning in Medicine, 1995. 7(4): p. 218-224.

69. Baxter, N., R. Cohen, and R. McLeod, The impact of gender on the choice of surgery as a career. Am J of Surg, 1996. 172: p. 373-6. 


\section{Introduction}

70. Du Moulin, M., R. Heymans, and G. Noordenbos, Gender factors in the selection of training for a medical specialty. NTVG, 2000. 144: p. 129-33.

71. $\mathrm{Xu}, \mathrm{G}$., et al., Factors associated with changing levels of interest in primary care during medical school. Acad Med, 1999. 74: p. 1011-5.

72. Schwartz, M., et al., Medical student interest in internal medicine. Initial report of the Society of General Internal Medicine Interest Group Survey on Factors Influencing Career Choice in Internal Medicine. Ann of Intern Med, 1991. 114: p. 6-15.

73. Morrison, J. and T. Murray, Career preferences of medical students: influence of a new four-week attachment in general practice. Br J of Gen Prac, 1996. 46: p. 721-5.

74. Solomon, D. and D. Di Pette, Specialty choice among students entering the fourth year of medical school. Am J of Med Sci, 1994. 308: p. 284-8.

75. Rabinowitz, H., The relationship between medical student career choice and a required third-year family practice clerkship. Fam Med, 1988. 20: p. 118-21.

76. Howe, A. and G. Ives, Does community-based experience alter career preference? New evidence from a prospective longitudinal cohort study of undergraduate medical students. Medical Education, 2001. 35: p. 391-7.

77. Linzer, M., et al., Admission, recruitment, and retention: finding and keeping the generalistoriented student. SGIM Task Force on Career Choice in Primary Care and Internal Medicine. J of Gen Intern Med 1994. 9: p. 14-23.

78. Campos-Outcalt, D., et al., The effects of medical school curricula, faculty role models, and biomedical research support on choice of generalist physician careers: a review and quality assessment of the literature. Acad Med, 1995. 70: p. 611-619.

79. Hunt, D., et al., Medical student career choice; do physical diagnosis preceptors influence decisions? Am J of Med Sci, 1995. 310: p. 19-23.

80. Martini, C., et al., Medical school and student characteristics that influence choosing a generalist career. JAMA, 1994. 272(9): p. 661-668.

81. Basco, W. and J. Reigart, When do medical students identify career-influencing physician role models? Acad Med, 2001. 76: p. 380-2.

82. $\mathrm{Xu}, \mathrm{G}$., et al., Comparisons among three types of generalist physicians: personal characteristics, medical school, experiences, financial aid, and another factors influencing career choice. Adv in Health Sci Educ, 1997. 1(3): p. 197-207.

83. Scott, I., et al., Why would I choose a career in family medicine?: Reflections of medical students at 3 universities. Can Fam Physician, 2007. 53(11): p. 1956-7.

84. Koenig, J., Comparison of medical school performances and career plans of students with broad and with science-focused premedical preparation. Acad Med, 1992. 67: p. 191-6.

85. Saigal, P., et al,, Factors considered by medical students when formulating their specialty preference in Japan: findings from a qualitative study. BMC Medical Education, 2007. 7: p. 31. 


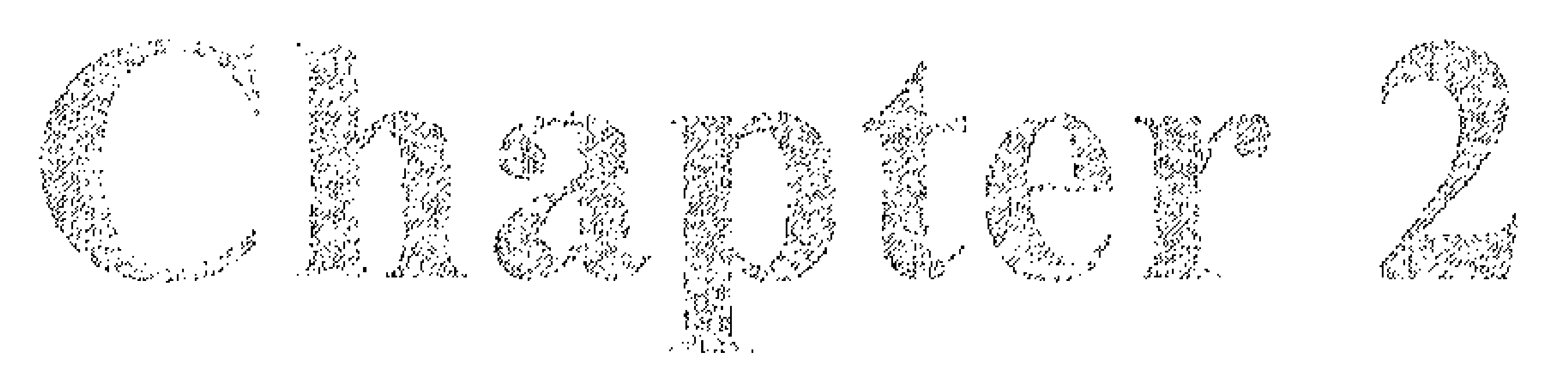

\section{Gender-related differences in general practice preferences: longitudinal evidence from the Netherlands 1982 - 2001}

Tanja Maiorova

Fred Stevens

Albert Scherpbier

Lud van der Velden

Jouke van der Zee

Health Policy, 2005, 72 (1): 73-80 
Chapter 2

\begin{abstract}
The proportion of female doctors is increasing. Yet, there is little evidence that demonstrates changing career preferences over a long period, nor do we know the long-term impact of changing male-female ratios in medicine. We explored this within the GP profession. By means of a longitudinal cohort study (postal questionnaires) among all graduated GPs in the Netherlands between 1982 and 2001 we explored trends in career preferences and investigated whether practice preferences of men and women differ over the years.

Preference of becoming a GP has significantly decreased among men. GPs prefer group practice more than solo practice. Female doctors were more likely to prefer a small practice and to associate. Men prefer to take over an established practice. Main reasons to abstain from practicing as a GP for men were having found another job or not having found a practice according to their preferences. Main reasons for women were having decided for another job and family life. We conclude that male and female GPs select differently on practice setting. Preferences change through the years but tend to converge. Gender differences are likely due to the circumstance that career choices for men are more influenced by fluctuating labour markets, while female choices are more based on family circumstances. We expect that as more women will become a GP the demand for small group practices will increase. Also, as many female GPs abstain from practicing after having finished a vocational GP training program it will be essential to create work facilities to keep them available for the GP labour market.
\end{abstract}

Keywords: general practitioners; gender; practice preferences; longitudinal; vocational training. 
General practice preferences

\section{Introduction}

All over Europe the share of female doctors in health care is increasing. In most countries the number of women studying medicine even exceeds that of men. Consequently, as men and women generally have dissimilar views on work and careers, gender differences in career preferences of physicians is increasingly becoming an important health manpower issue. Due to the 'feminisation' of the medical workforce, general practice is one of the specialties that have to contend with difficulties. While early in the 1980s the forecasted supply of GPs was looked upon as sufficient for the next decades, this was considered differently at the end of the 1990s. In several countries, and in particular in the United Kingdom and the Netherlands concerns have been expressed about recruiting doctors to general practice [1-5]. UK research, for example, showed that early commitment to full-time principalship has fallen and that fewer young doctors are choosing for general practice as a medical career $[6,7]$. Evidently, gender plays a role in this, as fall in choice of general practice has been greater among men than among women [8]. Research further shows that men and women have different professional roles in general practice. Women are more frequently than men employed as assistants instead of as principals. Overall reasons not preferring to be a principal, however, are similar. Yet women report domestic responsibilities and child care more frequently than men [9]. Everywhere in Europe, a steady feminisation of general practice and of the medical profession in general, is taking place. Evidently, this will have a qualitative impact on medical work [10]. It will influence doctor - patient interactions, interprofessional relationships and practice performance. Yet, in some countries, and in particular in the Netherlands and the UK, also a quantitative effect is expected. It is not unlikely that shortages of GPs in the near future will occur [11]. In the Netherlands this may be due to the relatively low numbers of practicing GPs, and high numbers of doctors working part-time. Up until now, however, shortage predictions are still somewhat uncertain, as long term trends in practice preferences have not been analysed, due to lack of data. Previous research into practice preferences of graduated GPs was usually confined to samples and/or to the analysis of one or a just a few yearly cohorts $[3,6,7,9,12-15]$. Expanding on these studies, we use a data base that includes all GPs graduated in the Netherlands since 1982. With this large and comprehensive data set we are able to provide long-term insights into career preferences of doctors having completed a GP vocational training program. We can see what the influence has been of changing malefemale ratios in practice preferences over a period of nearly twenty years, also taking into account increasing patient demands and the availability of preferred practices in the Netherlands [16].

In the Netherlands virtually the whole population is registered with a GP who provides primary care services and who is the gatekeeper to other, more specialised medical services for the patient. GPs in the Netherlands are largely self-employed, and have great involvement as doctors of first contact. Most GPs share a practice with other GPs. The Netherlands have a low GP density. The average number of patients of a Dutch GP is 


\section{Chapter 2}

2300, which is quite high compared to GPs in most other European countries [17]. Dutch GPs work 60 hours a week on average and are paid on capitation basis and feefor-service. It is not allowed to start a GP practice in the Netherlands without formal approval by the government. One also needs a contract with an insurance company for reimbursement.

In this article we explore whether general practice preferences of men and women differ and have changed since 1982, and if so, whether such changes alter through the years. This is an important question, because insights in long-term developments can contribute to our understanding of factors that play a role in career choices of male and female GPs. It also provides information that enables us to forecast better the need for GPs and sort of practices in the future. Our data allow to explore the following specific research questions:

1. Do graduated male and female GPs differ in their preferences of work arrangements (practice form, practice size and practice establishment)?

2. How have these male/female preferences developed between 1982 and 2001 ?

3. Do male and female GPs differ in reasons to abstain from becoming a GP?

Based on insights from previous research, we expect that, compared to female GPs, men more frequently will prefer larger practices and to work in a solo practice. Longitudinally we expect that preferences of men and women will converge, but still will be different through the years,. Finally, compared to men, we expect that female GPs will abstain from general practice more frequently because of higher interference with family life $[7,15,16,18]$.

\section{Methods}

The data source for this article, provided by the Netherlands Institute of Health Services Research (NIVEL) in Utrecht, consists of data of all GPs in the Netherlands. In 1980 a first questionnaire was sent to all registered Dutch GPs to assess their actual employment status. In subsequent years, questionnaires were only sent to those who just had finished their GP vocational training program. They were asked to fill in the questionnaire in January, the year following their GP graduation. The doctors included in the present study had qualified as a GP in The Netherlands between 1982 and 2001. GPs kept receiving a similar questionnaire every year until they finally had settled in a general practice, or had given up finding a suitable position (abstained). Topics in the questionnaire were personal attributes (age, gender, university of medical education and general practice graduation) and present occupational involvement. This included: (a) practice form: working solo, in partnership or in a group practice; (b) size of practice/number of patients: $<1500 ; 1500-<2000 ; 2000-2500$; (c) practice establishment: taking over a practice from another GP, association with other GP, or new establish- 
ment. Those who had given up finding a practice of their preference were asked the reasons of abstaining. The overall mean response rate through the years was 94 percent.

\section{Results}

\section{Total number of newly trained GPS}

Figure 1 shows the yearly numbers of graduated male and female GPs between 1982 and 2001, including those who have abstained or have settled instantly after graduation $\left(\mathrm{N}=7234^{1}\right)$. While the percentage of male physicians exceeds that of female graduates up until 1996, from 1997 on the male - female ratio changes in favor of women, and increases to 62 percent women in 2001. Between the early 1980s and the late 1990s we see an overall decrease in the number of male graduates, and since the early 1990s a slight increase of female GPs. In other words, we see more a 'demasculinisation' of the graduating GP population than of a 'feminization'.

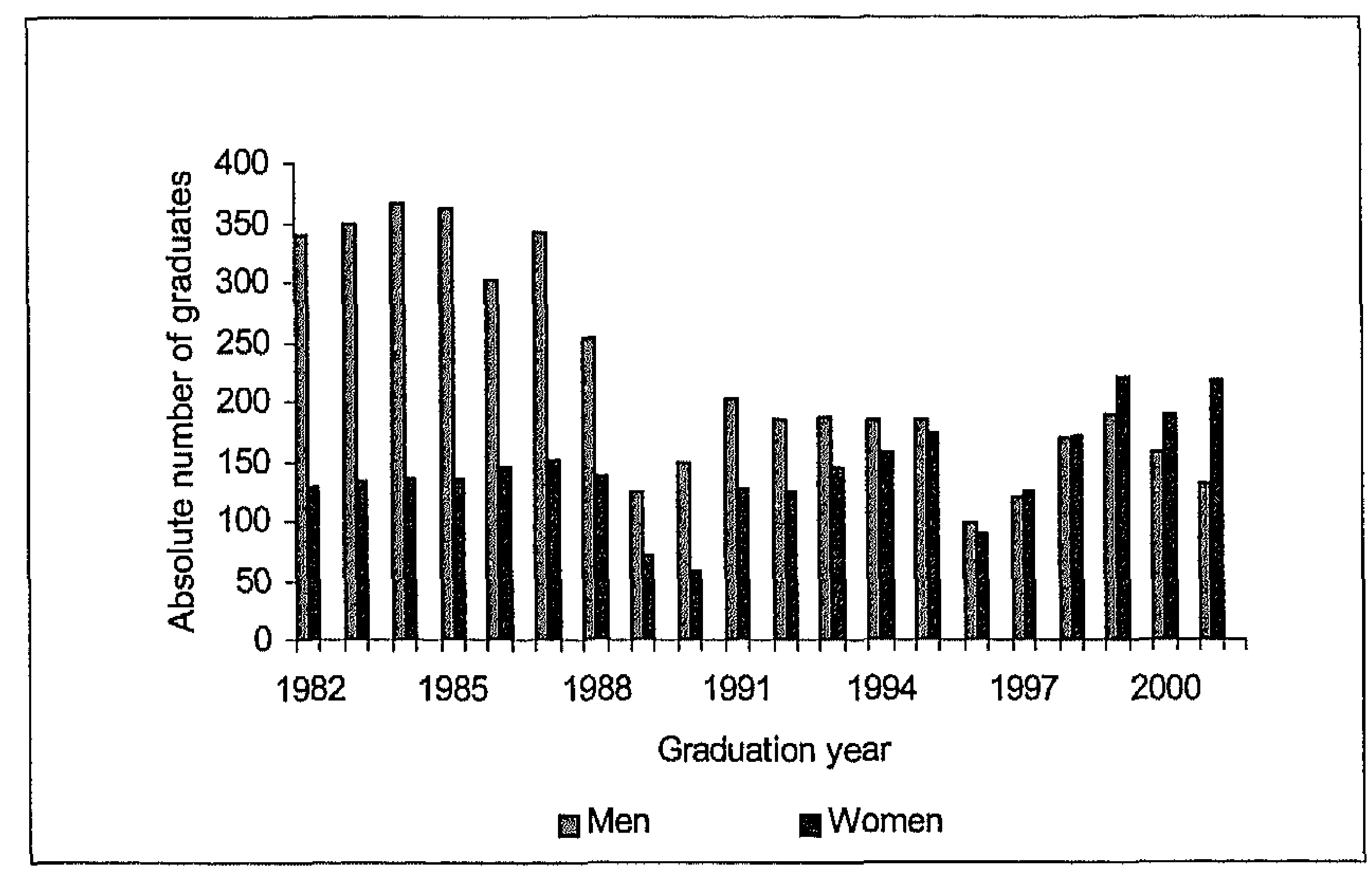

Figure 1. The number of graduates $1982-2001$

\footnotetext{
${ }^{1}$ GPs who instantly had settled or abstained after graduation were not included in further analyses. Their data were only used in this paragraph to present total male-female ratios of graduates 1982-2001.
} 
Chapter 2

\section{Male- female ratio}

The total number of GP participants searching for a practice between 1982 and 2001 is 3750 , of whom 2313 were men and 1437 (38\%) were women. This number of participants per year ranged between 77 (1991) and 255 (1996), depending on the number of qualifiers, length of vocational training, and number of GPs who have found a practice right away after graduation.

\section{Practice organization: solo versus group practice}

Figures $2 \mathrm{a}$ and $2 \mathrm{~b}$ show that among graduated GPs trying to find a practice, doctors generally prefer group or duo practice more than solo practice. It also appears that there is a decrease in preferences for a solo practice. This decrease is more substantial for men than for women $\left(\chi^{2}=378,22, \mathrm{df}=38 ; \mathrm{p}<.001\right.$ and $\left.\chi^{2}=106,72, \mathrm{df}=38 ; \mathrm{p}<.001\right)$. Preference for solo practice, which already was low, decreased even more through the years. In the 1980s and early 1990s, between 10 and 20 percent of men prefer a solo practice, which slowly decreases to $3-15$ percent in late 1990s. In the 1980s only 1 to 8 percent of women prefer a solo practice, which decreases to zero in 2001. This decrease in solo practice preference among searching doctors is probably due to the fact that those who prefer such a practice were able to find one sooner and easier than those who prefer a group practice.

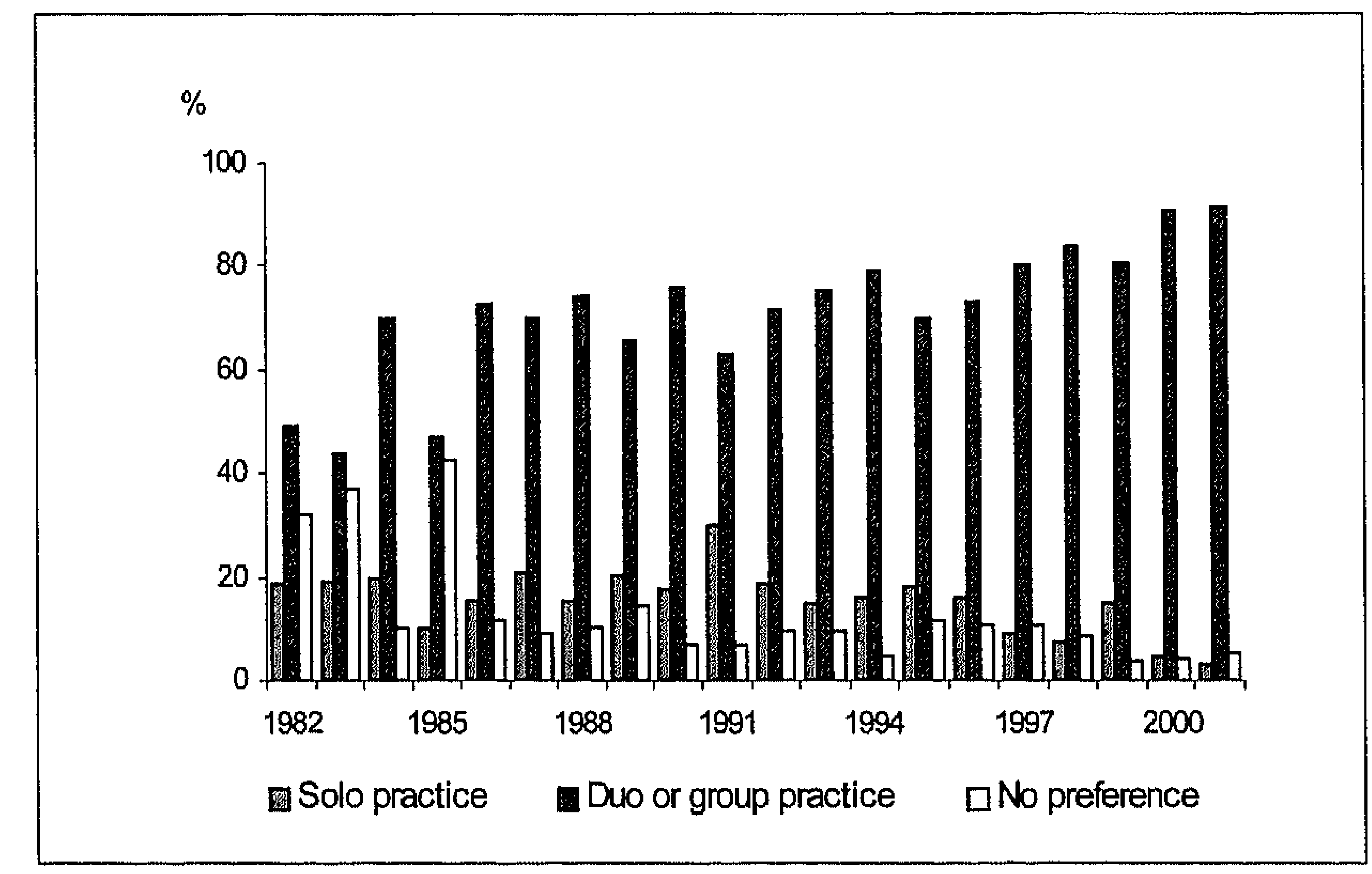

Figure 2a. Practice form preference of men, $N=2835$ 


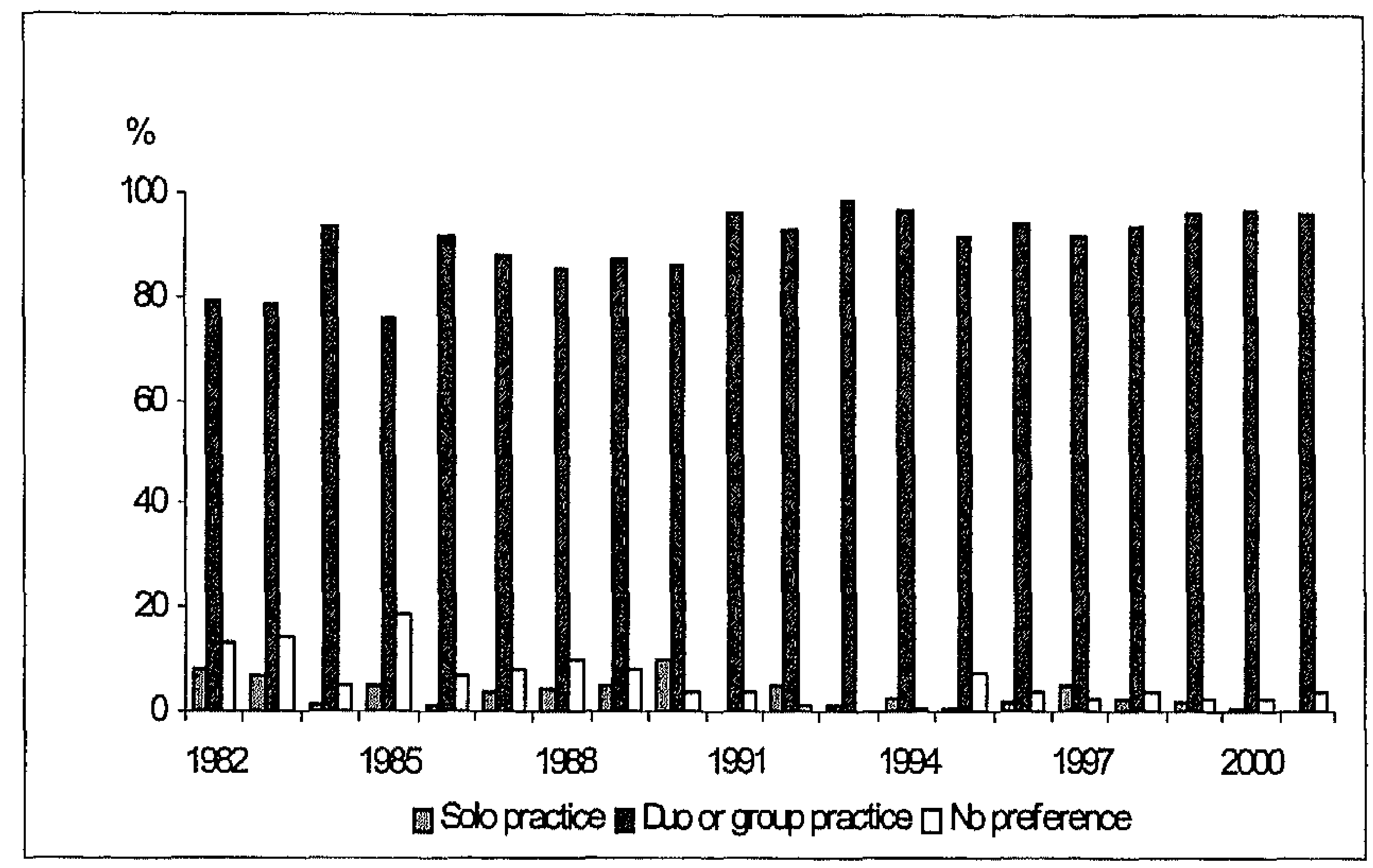

Figure 2b. Practice form preference of women, $N=1796$

\section{Size of practice}

As figures $3 \mathrm{a}$ and $3 \mathrm{~b}$ show, we found substantial differences in the practice size preferences of men and women $\left(\chi^{2}=180,79, \mathrm{df}=57 ; \mathrm{p}<.001\right.$ and $\left.\chi^{2}=134,91, \mathrm{df}=57 ; \mathrm{p}<.001\right)$. Through the years, about 16 percent of graduated female GPs prefer a practice of less than 1500 patients, compared to only 2 percent of men. Compared to female GPs male doctors more frequently prefer a practice of at least 2500 patients (average about 31 percent versus 9 percent, respectively). Medium-sized practices were frequently preferred by both men and women. But also within this category men prefer a somewhat larger practice than women (2000 to 2499 patients versus 1500 to 1999 patients). Comparing patterns of preferences of male and female GPs over the years shows that these are a little less stable for men than for women. Between 1985 and 1991 medium-sized practices were more popular than larger ones. Between 1991 and 1996 this had changed. After 1996, however, medium-sized practices increased in popularity again.

We also explored gender differences in practice size preferences, separately for solo practice and group practice preferences. For both practice forms men prefer a larger practice and women a smaller one. In other words, practice size preferences are independent of the preference of working on one's own or together with somebody else. 


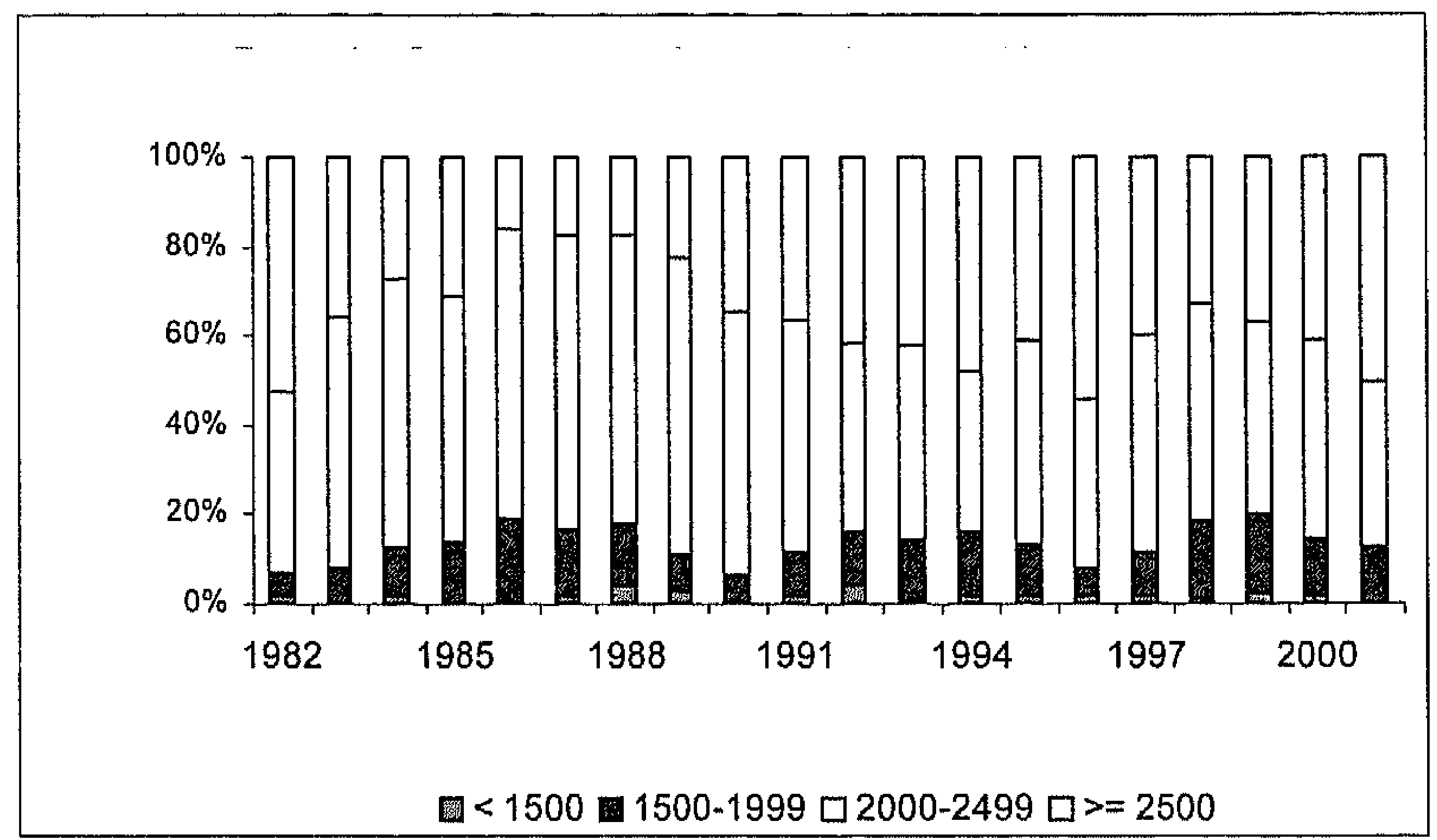

Figure 3a. Practice size preferences of men, $\mathrm{N}=2313$

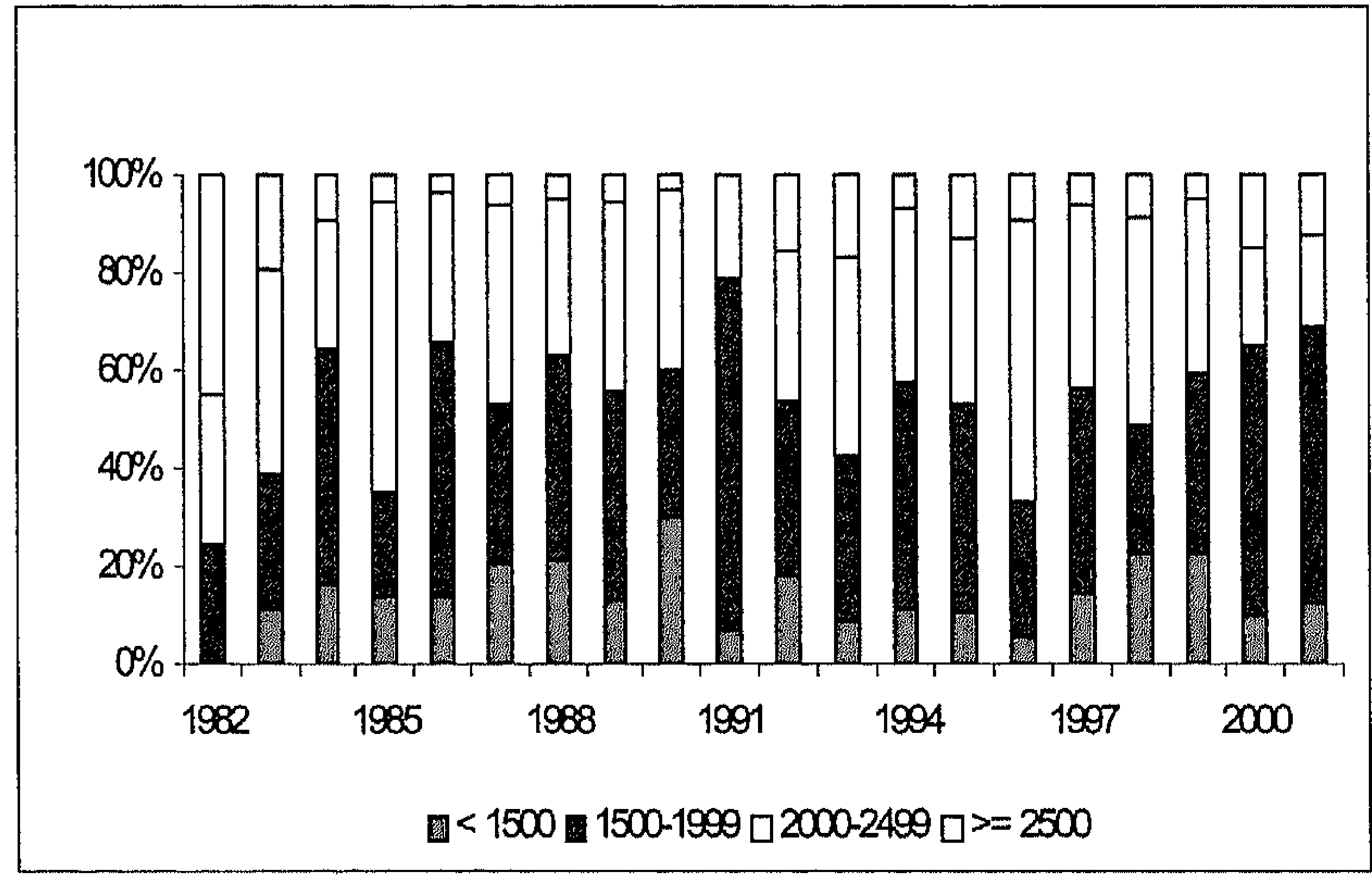

Figure $3 b$. Practice size preference of women, $N=1437$

\section{Practice establishment}

Independent establishment is neither the priority for men nor for women (figure $4 \mathrm{a}$ and 4b). Preference for free establishment decreased in the mid 1980s. This is mainly due to changes in practice setting policies in $1985^{2}$. In the 1990s preference for free establishment dropped and never rose to that same level again in following years. Figures $4 \mathrm{a}$ and

${ }^{2}$ From 1985 on it was no longer allowed to start a general practice without official approval. 
$4 \mathrm{~b}$ further show that men prefer taking over an existing general practice, while women prefer more to associate with already established physicians $\left(\chi^{2}=676,86, \mathrm{df}=57\right.$; $\mathrm{p}<.001$ for men and $\chi^{2}=282,71, \mathrm{df}=57 ; \mathrm{p}<.001$ for women).

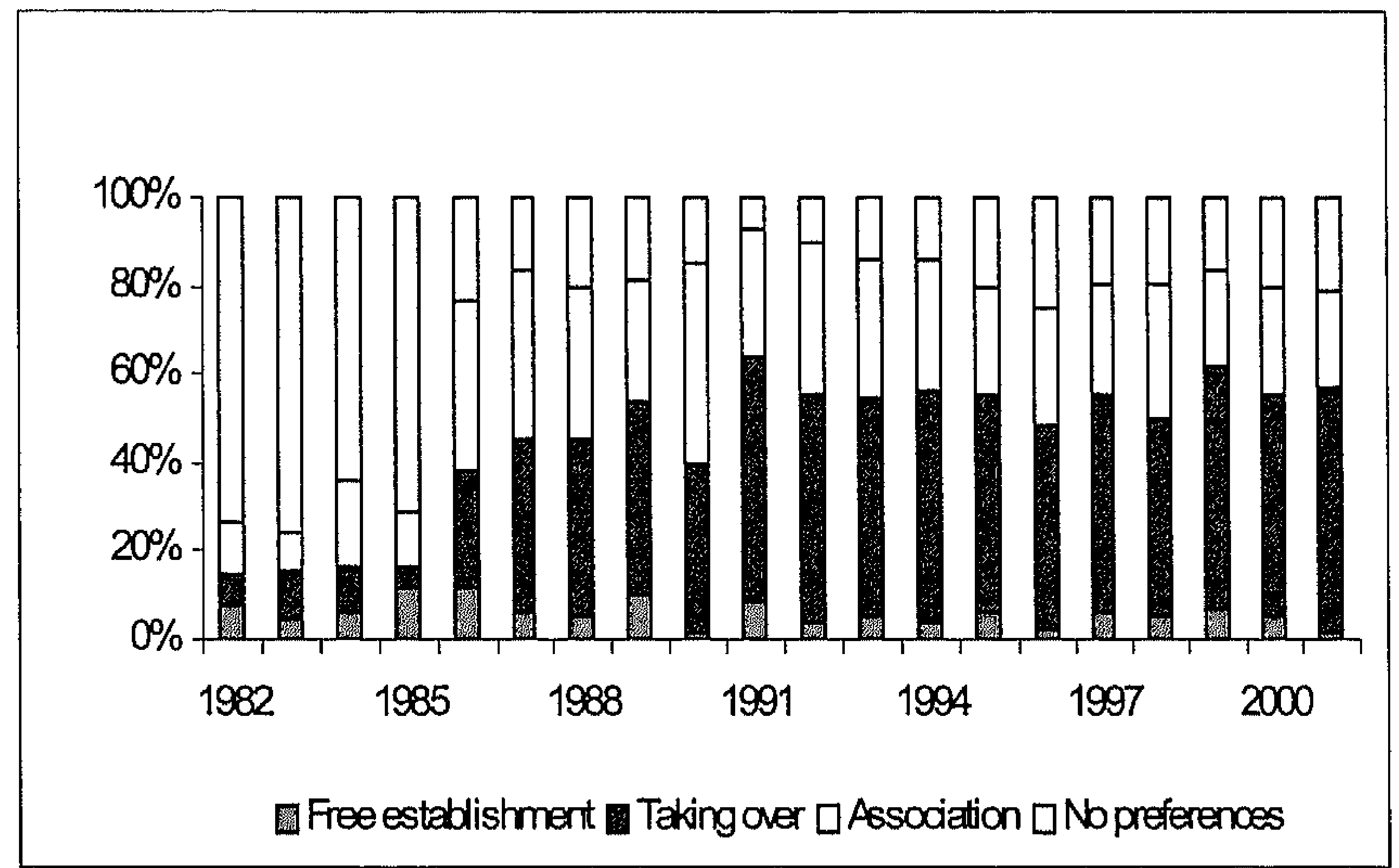

Figure 4a. Practice establishment preferences of men, $N=2233$

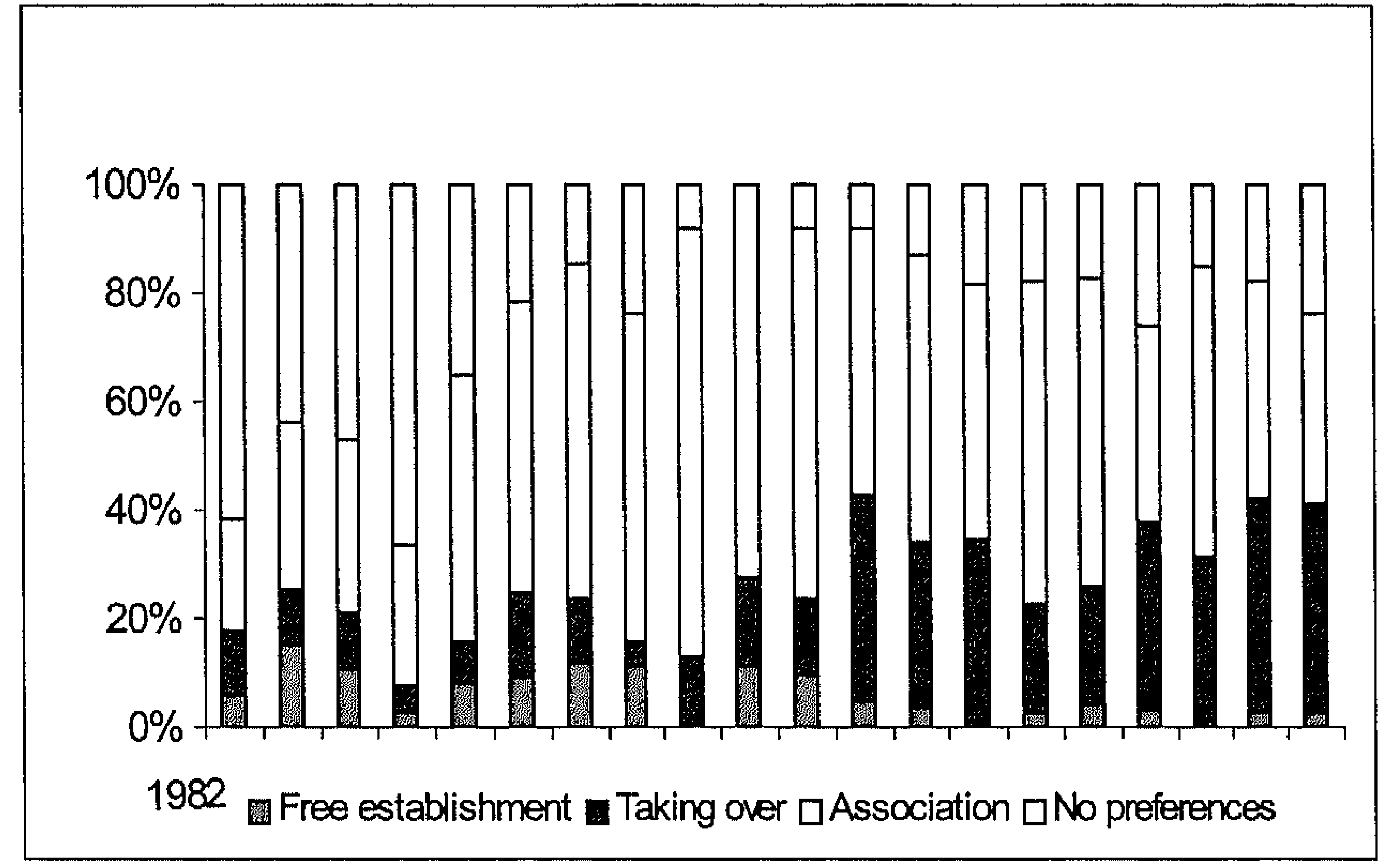

Figure 4a. Practice establishment preferences of women, $N=1368$ 


\section{Chapter 2}

\section{Abstainers}

Between 1982 and 2001 on average 18 percent $(N=691)$ of graduated GPs refrained from finding a job in their specialty, notwithstanding having finished vocational training recently. Most frequent reasons mentioned by men were having found another job or function $(51 \%)$, financial reasons $(9 \%)$, or having found no practice according to the preferences $(29 \%)$. Also for women the main reason to refrain from seeking a general practice corresponding to their preference was having found another job or function $(42 \%)$. The second most important reason mentioned by women, however, were family circumstances ( $28 \%$ for women versus $6 \%$ for men). More men $(78 \%)$ than women $(75 \%)$ were not able to realize their plans. Curiously, more women $(19 \%)$ than men $(15 \%)$ never had serious plans to work as a GP at all, even from the beginning on. The alternative job chosen, instead of becoming a GP, was also gender-bound: men were more likely to work in hospitals as a resident ( $11 \%$ vs. $6 \%)$, as an occupational physician $(32 \%$ vs. $18 \%)$ or as a military doctor $(5 \%$ vs. $0 \%)$. Women somewhat more frequently choose for nursing home physician ( $29 \%$ vs. $24 \%$ ), to work in a consultation bureau for young children ( $12 \%$ vs. $2 \%)$, or to start as a locum ( $6 \%$ vs. $3 \%)$.

\section{Discussion}

Since the mid 1990s a majority of newly trained GPs in the Netherlands are women. Although female physicians attend the same educational program and specialise just as much as male doctors, women use different criteria to select from career options. General practice is a less popular choice for medical graduates and has to contend with important changes in preferred practices. In this article we have compared practice preferences of male and female doctors who have completed general practice vocational training in the Netherlands since 1982. Our research questions, whether there is a difference in practice preferences between men and women and whether these preferences converge through the years can positively be answered. Among women preference for working solo has consistently been at a rather low level through the years, while preference for a group practice has been higher for women than for men $[9,15]$. For men the relatively higher preference for solo practice in the 1980s decreased towards a near similar low level as for women. Since 1982 both men and women prefer a group practice or partnership more than a solo practice, which is consistent with findings from cross-national comparison [19].

Gender differences in preferred practice size turned out to remain on the same level. Consistent with previous research male GPs prefer larger practices more than women do. Thus, while during two decades preference for a group practice converged, graduated male and female GPs still select differently on size of practice. The difference in choice of practices forms and size of practices between men and women has possibly to do with their preference for a part-time job. Relying on the results from previous studies 
$[19,15]$, the popularity of part-time jobs among women suggests a preference for sharing work with colleagues in duo- or group practices and a smaller patient population. In the longitudinal comparison of preferred practice sizes we also found in time varying preference patterns for men and more stable preferences for women. We assume that these differences are due to the fact that career preferences of graduated male GPs are influenced by fluctuating labour market circumstances. Male doctors appear to find it more difficult to choose a satisfying medical career [15]. Female choices, however, may be more affected by family constraints. We concur with Vaughn's [1] notion that "Women have always fitted their work into their lives, and an increasing number of men are attracted by this option." As more women will become a GP we expect that the demand for smaller group practices will increase.

Finally, compared to their male colleagues, female GPs prefer more often to associate with another GP than to take over an already established practice. This suggests that women favour sharing responsibilities in organising and managing a practice rather than to be exclusively in charge. However, our data of recent years indicate a convergence of male and female practice establishment preferences.

Regarding our third research question on reasons to abstain from practicing as a GP, we found that most men and women did so because they were not able find the practice of their preference. But while many men decided this way because of having found another interesting job, not finding a preferred practice or just because of financial reasons, women mentioned limitations due to family constraints as important second reason. This finding is consistent with results from previous UK research that out of hours commitment, and difficulty in combining work with family commitments were ranked as most important factors for not practicing as a principal, and the more recent move of women towards locum work $[7,9]$. Also, while more men than women reported not having been able to realise their initial plans, more women than men reported never to having been serious to work as a GP at all. The views elicited from our female respondents that many did not find the practice of their preference, were limited in their choice because of family reasons, or even never had serious plans to become a GP point to the serious underlying issue of the presence of an underused pool of vocationally trained GPs, especially among women. The loss of women from the GP specialty is expensive and wasteful both for the teaching institutes involved as for individuals abstaining. The fact that more women are becoming physician and that a great number of these women will enter a GP vocational training program makes it essential to create facilities to keep them available for the GP labour market.

This study has several limitations. One is, that preferences for work are only known of those who were searching for a position and were not settled immediately after graduation. Those who had abstained or settled right away after graduation were not further asked on practice preferences. A second limitation is, that during the years answer categories of some of the questions in the questionnaire have been changed due developments in GP practice organisation modes. This has reduced the answer options that could be used for some of the analyses. Notwithstanding these limitations, our results, 
Chapter 2

based on an analysis of nearly 20 years of GP graduates, underscore previous findings on gender differences in career preferences.

Our results underscore earlier concerns expressed on future qualitative and quantitative shortage problems of GPs in relation to changing career preferences of male and of female doctors. Evidently, this problem applies to other countries as well. It is important to take these changing work preferences of GPs into account in health care policies and create lifestyle-friendly options for general practice. 
General practice preferences

\section{References}

1. Vaughan, C., Career choices for generation X (Editorial). British Medical Journal, 1995; 311 : 525-26.

2. Allen, I., Career preferences of doctors (Editorial). British Medical Journal, 1996; 313:2.

3. Taylor, D.H.J. and B. Leese, Recruitment, retention, and time committment change of general practitioners in England and Wales, 1990-4: a retrospective study. British Medical Journal, 1997; 314: 1806 .

4. Velden, L.F.J.v.d., P. Heiligers, and L. Hingstman, Vaarwel praktijk [Goodbye practice]. Medisch Contact, 2002; 57.

5. Leliefeld, Toekomstig evenwicht [Future balance]. Medisch Contact, 2002; 57.

6. Goldacre, M.I., J.M. Davidson, and T.W. Lambert, Career choices at the end of the preregistration year of doctors who qualified in the United Kingdom in 1996. Medical Education, 1999; 33: 882-89.

7. Lambert, T.W., J. Evans, and M.J. Goldacre, Recruitment of UK-trained doctors into general practice: findings from national cohort studies. British Journal of General Practice, 2002; 52: 36472.

8. Goldacre, M.J., Career choices of junior doctors. Medical Education, 2000; 34: 700-07.

9. Baker, M., J. Williams, and R. Petchey, GPs in principle but not in practice: a study of vocationally trained doctors not currently working as principals. British Medical Journal, 1995; 310: 130104.

10. Bensing, J.M., A. Van den Brink - Muinen, D.H. Bakker, Gender differences in practice style: a Dutch study of general practitioners. Medical Care, 1993; 31: 219-29.

11. The primary care workforce - An update for the new Millenium. 2000; London.

12. Lambert, T.W. and M.J. Goldacre, Career destinations and views in 1998 of the doctors who qualified in the United Kingdom in 1993. Medical Education, 2002; 36: 193-8.

13. Lambert, T.W., et al., Graduate status and age at entry to medical school as predictors of doctor's choice of long-term career. Medical Education, 2001; 35: 450-4.

14. Goldacre, M.J. and T.W. Lambert, Stability and change in career choices of junior doctors: postal questionnaire surveys of the United Kingdom qualifiers of 1993. Medical Education, 2000; 34: 700-7.

15. Johnson, N., et al., The career outcomes for doctors completing general practice vocational training 1990-1995. British Journal of General Practice, 1998; 48:1755-8.

16. Van der Velden, L. and L. Hingstman, Vraag en aanbod huisartsen. Bronnenoverzicht en ramingen 2000-2010. [ Demand and supply of general practitioners. Resources and estimations]. 2001, NIVEL: Utrecht.

17. Boerma, W.G.W., F.A.M.J.M.d. Jong, and P.H. Mulder, Health care and general practice across Europe. 1994, Utrecht: NIVEL, Netherlands Institute of Primary Health Care/Dutch College of General Practititoners.

18. Bowler, I. and N. Jackson, Experiences and career intentions of general practice registrars in Thames deaneries: postal survey. British Medical Journal, 2002; 324: 464-5.

19. Boerma, W.G.W. and A.v.d. Brink-Muinen, Gender-related differences in the organization and provision of services among general practitioners in Europe. Medical Care, 2000; 38: 993-1002. 


\section{Chapter 3}

\section{Gender shift in realisation of preferred type of GP practice: longitudinal survey over the last 25 years}

Tanja Maiorova

Fred Stevens

Lud van der Velden

Albert Scherpbier

Jouke van der Zee

BMC Health Sevices Research, 2007, 7 (1):111 


\title{
Chapter 3
}

\begin{abstract}
Background

An increasing number of newly trained Dutch GPs prefer to work in a group practice and as a non-principal rather than in a single-handed practice. In view of the greater number of female doctors, changing practice preferences, and discussions on future workforce problems, the question is whether male and female GPs were able to realise their initial preferences in the past and will be able to do so in the future.
\end{abstract}

Aim

To analyse long-term trends in the realisation of the preference for working in a group practice and as a non-principal among GPs in the Netherlands

\section{Methods}

We have conducted longitudinal cohort study of all GPs in the Netherlands seeking a practice between 1980 and 2004. The Netherlands Institute of Health Services Research (NIVEL) in Utrecht collected the data used in this study by means of a postal questionnaire. The overall mean response rate was $94 \%$.

\section{Results}

Over the past 20 years, an increasing proportion of GPs, both male and female, were able to achieve their preference for working in a group practice and/or in a non-principal position. Relatively more women than men have settled in group practices, and more men than women in single-handed practices; however, the practice preference of men and women is beginning to converge. Dropout was highest among the GPs without any specific practice preference.

\section{Conclusions}

The overwhelming preference of male and female GPs for working in group practices is apparently being met by the number of positions (principal or non-principal) available in group practices. The preference of male and female GPs regarding the type of practice and job conditions is expected to converge further in the near future. 


\section{Background}

Several decades ago, the single-handed practice was the common European GP setting. Through the years, this has changed in favour of group practices [1]. In this study we analysed trends in the preference for group or single-handed practices, and the realisation of this preference, among newly qualified GPs in the Netherlands over the last 25 years.

Previous research indicated two important developments concerning the practice preferences of young GPs. First, younger generations of GPs prefer other working conditions and other practice settings than older GPs, settings that provide more opportunity for leisure time, flexibility, and the sharing of practice responsibilities [2]. Secondly, all over Europe a steady feminisation of general practice, and of the medical profession in general, is taking place [3-8]. The likely result is a reduction of GPs' working hours together with a stronger preference for working in a group practice, locum (nonprincipal) work, and opportunities to combine work and family life [8, 9]. Although men used to be more motivated by financial incentives than women, newly trained male GPs also prefer to work less than full-time and increasingly support flexible office hours in order to accommodate family and home responsibilities [2, 10]. Even though men and women may differ in their preferred form of medical practice, there are trends in common, namely, increasingly more recently qualified GPs prefer: (a) a group practice to a single-handed practice, (b) part-time over full-time employment [10-13] and (c) more preference for non-principal position.

In the light of these changing practice preferences, we do not know whether newly qualified GPs are and were able to realise their plans and initial preferences. There may be an increasing mismatch between the type of practice left by retiring GPs and the type preferred by newly trained ones. This mismatch could result in workforce problems if young GPs have to settle in a non-preferred type of practice, which may lead to the decision not to settle at all and to drop out $[2,14-16]$.

Previous research into practice preference and realisation among newly qualified GPs was often confined to samples and/or to the analysis of one or a just a few yearly cohorts. In this study, we analysed trends in practice choices and realisation of preferences from 1980 onwards. Longitudinal data shed light on how the relation between preference and realisation has developed through the years. Insights into these long-term trends regarding the GP workforce in the Netherlands can contribute to our understanding of preferred careers of male and female GPs, and can help to better forecast the balance of need and supply of GPs in the future for other countries too. 
Chapter 3

We first analyse long-term trends in preferences for single and group practice and for principal and non-principal position. Then we investigate whether newly graduated GPs were able to realise their preference, and finally, what were the characteristics of those who dropped out of the profession.

We addressed the following questions:

1. How has the preference for single-handed and group practice and for principal and non-principal position developed over time among male and female GPs?

2. Were GPs able to realise their practice preference and if so, was this similar for men and women?

3. What preferences did the GPs have who have dropped out of the profession?

\section{GPs in the Netherlands}

In the Netherlands, virtually the entire population is registered with a GP who provides primary care services and who is the gatekeeper to other, more specialised medical services. GPs in the Netherlands are largely self-employed, and nowadays most work in group practices. The percentage of GPs working in a group practice increased from $28 \%$ in 1980 to $73 \%$ (66\% of all male GPs, $93 \%$ of all female GPs) in $2005[17,18]$. There has been a reduction in total numbers of GPs seeking a practice caused by the decreasing number of students entering general practice. The Netherlands has a rather low GP density, with the average GP list being 2053 patients in 1999, compared with 1663 patients in the UK, and 1523 patients as the European average [17, 19, 20].

Similar to GPs in the UK, Dutch GPs work 51 hours a week on average on a full-time basis. Dutch GPs who work as locum, or non-principal, in a group practice are usually employed by the GP who runs the practice. While GPs in the UK are usually reimbursed on a combination of allowance, capitation, and quality payments, Dutch GPs were (up till 2006) paid on capitation (sick fund patients) and on fee-for-service basis (privately insured patients); this private/public remuneration system was replaced by a mixed capitation fee-for-services system in 2006. No major change to remuneration of GPs in The Netherlands has taken place between 1980 and 2005.

\section{Methods}

\section{Data}

The data used in this study were collected by the Netherlands Institute of Health Services Research (NIVEL) in Utrecht, which collects data on all GPs in the Netherlands. In 1980 a first questionnaire was sent to all registered Dutch GPs to assess their actual employment status. In subsequent years, questionnaires were sent to only those who had 
recently qualified. They were asked to fill in the questionnaire in January, the first year following qualification. GPs kept receiving a similar questionnaire every year, until they finally had settled in a general practice, or had given up finding a suitable position (abstained). Topics in the questionnaire were the person's sex, practice type preference, and current position (working in a group or in a single-handed practice, a principal or a non-principal position). Through the years, the overall mean response rate was fairly stable about $94 \%$.

The number of practice-seeking GPs each year includes both who have qualified the same year and have been looking for a position for more than one year.

\section{Variables}

The preference for practice type was defined as the number of GPs who were looking for a position in (a) a single-handed practice, (b) a group practice, (c) a non-principal position or (d) had no particular practice type preference.

Realisation of preference was defined as the percentage of practice-seeking GPs who had found a position consistent with their initial practice choice. The possible types of settlement were: (a) a principal in a single-handed practice, (b) a principal in a group practice, (c) a non-principal and (d) did not settle at all.

\section{Analysis}

A descriptive, longitudinal analysis was conducted, including almost the complete population of GPs graduated between 1980 and 2004.

As the data set was not a sample, but included the whole population of GPs who qualified between 1980 and 2004, we abstained from statistical testing. We analysed longterm realisation of practice preference merely among GPs who qualified in 1980 to 1999. It can take several years before GPs finally find a permanent position in a practice. On this reason we considered that the data for GPs who qualified in 2000 to 2004 would not accurately reflect the realisation of practice preferences.

\section{Results}

\section{Preferences of practice-seeking GPS}

For many years, the preference for a single-handed practice among male GPs was stable at about $17 \%$, and only in the last 5 years did this preference drop to $6 \%$ (see Figure 1 ). Preference for a principal position in a group practice increased from $51 \%$ early 1980 s to $80 \%$ more recently. A substantial proportion of male GPs had no particular preference, or was undecided about this in the 1980 s (30\%). This has since changed, with only $10 \%$ of male GPs expressing no preference for working in a single/group practice from 
1995 onwards. A non-principal position preference was negligent and increased up to $5 \%$ in $2000-04$.

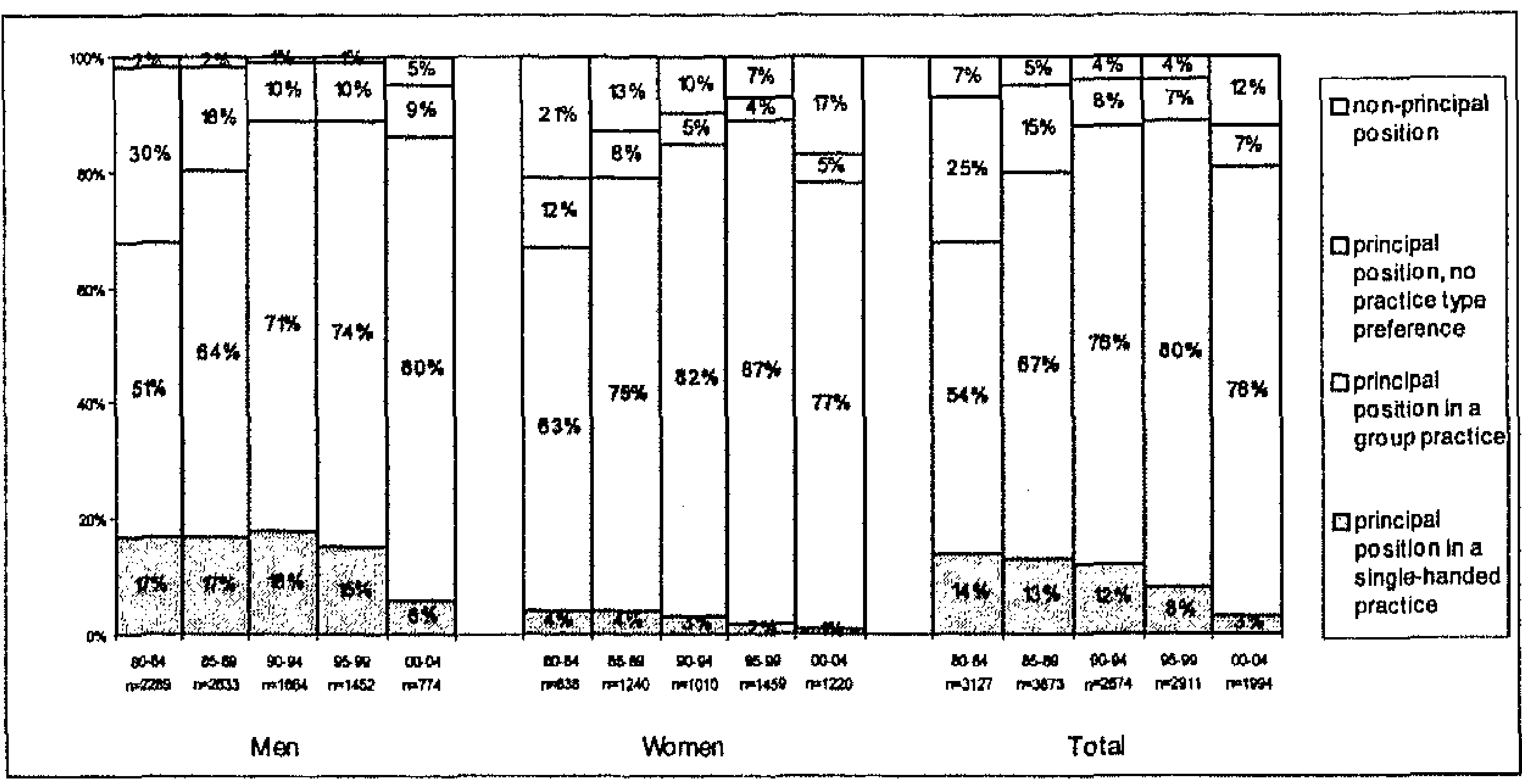

Figure 1. Practice type preference by Dutch GPs, according to gender and period (1980-2004)

Similar trends were observed among female GPs for single-handed practices and for non-principal positions. Single-handed practice was never popular among female GPs, and the proportion of women seeking such practices declined from $4 \%$ to $1 \%$ over the study period. There was and is a strong preference for working as a principal in a group practice: $63 \%$ of female GPs preferred this type of practice in the early 1980 s and $87 \%$ in the period 1995-99. The proportion of female GPs without a specific preference dropped from $12 \%$ to $5 \%$, most likely in favour of a preference for working in a group practice. The proportion of women favouring a non-principal position diminished at first, and has increased in 2000-04 to $17 \%$.

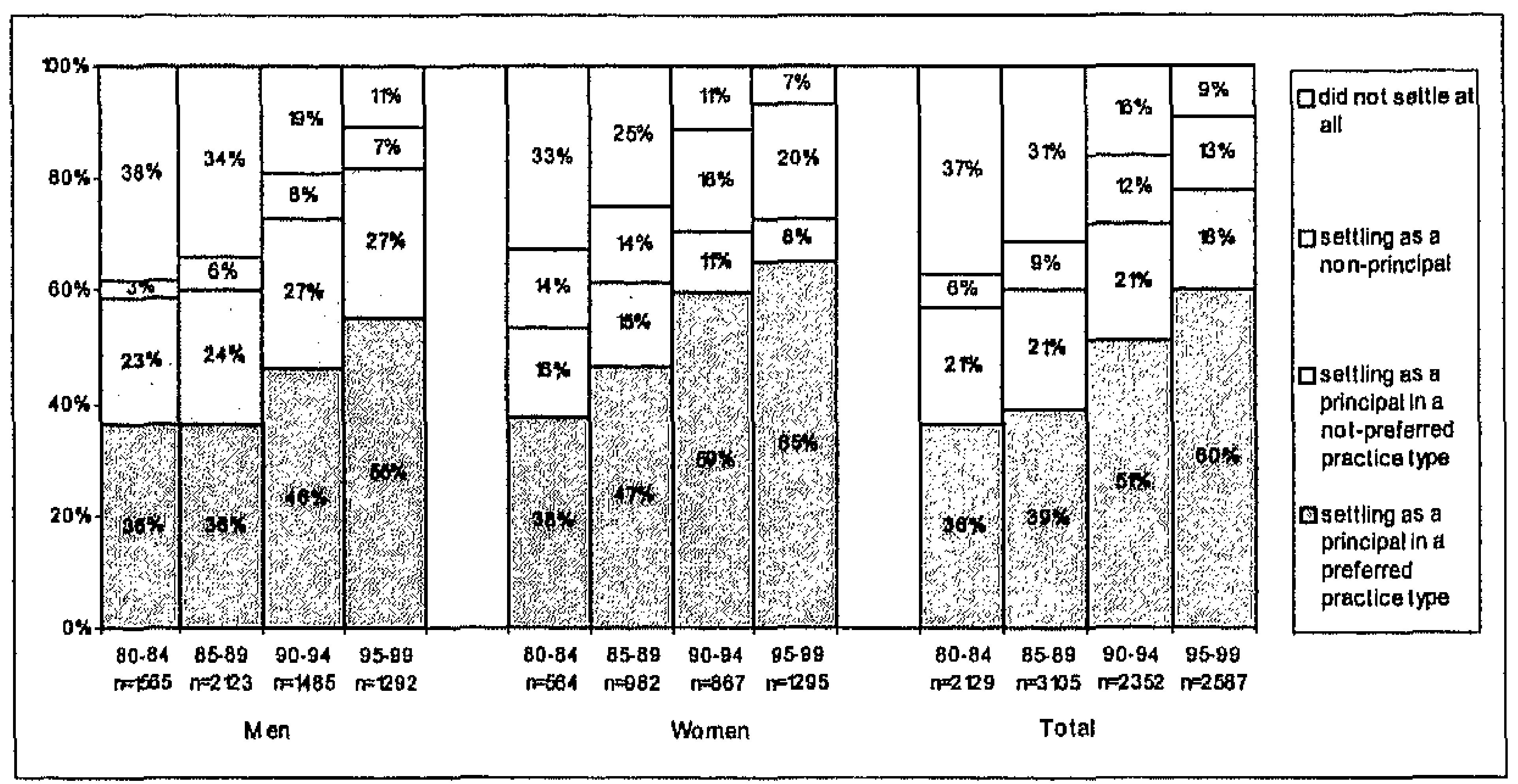

Figure 2. Realised practice type, for Dutch GPs preferring a position as a principal, according to gender and period (1980-1999) 


\section{Realisation of practice preference: GPs with a preference for a principal position}

Figure 2 shows the total number of GPs who were looking for a principal position in either a single-handed or in a group practice. In the 80 s $36 \%$ of GPs who were looking for a principal position in a single-handed or a group practice was able to realise their preference. This percentage has increased to $60 \%$ in the period 1995-99. From 1985 on, women were slightly more successful than men in realising their preferences. There is a consistently increasing percentage of GPs, higher among women than among men (20\% versus $7 \%$ in 1995-99), who settled as a non-principal, while looking for a principal position. The share of GPs who did not settle at all had fallen from $37 \%$ in 1980-84 to $9 \%$ in 1995-99. Relatively more male than female dropped out of the profession.

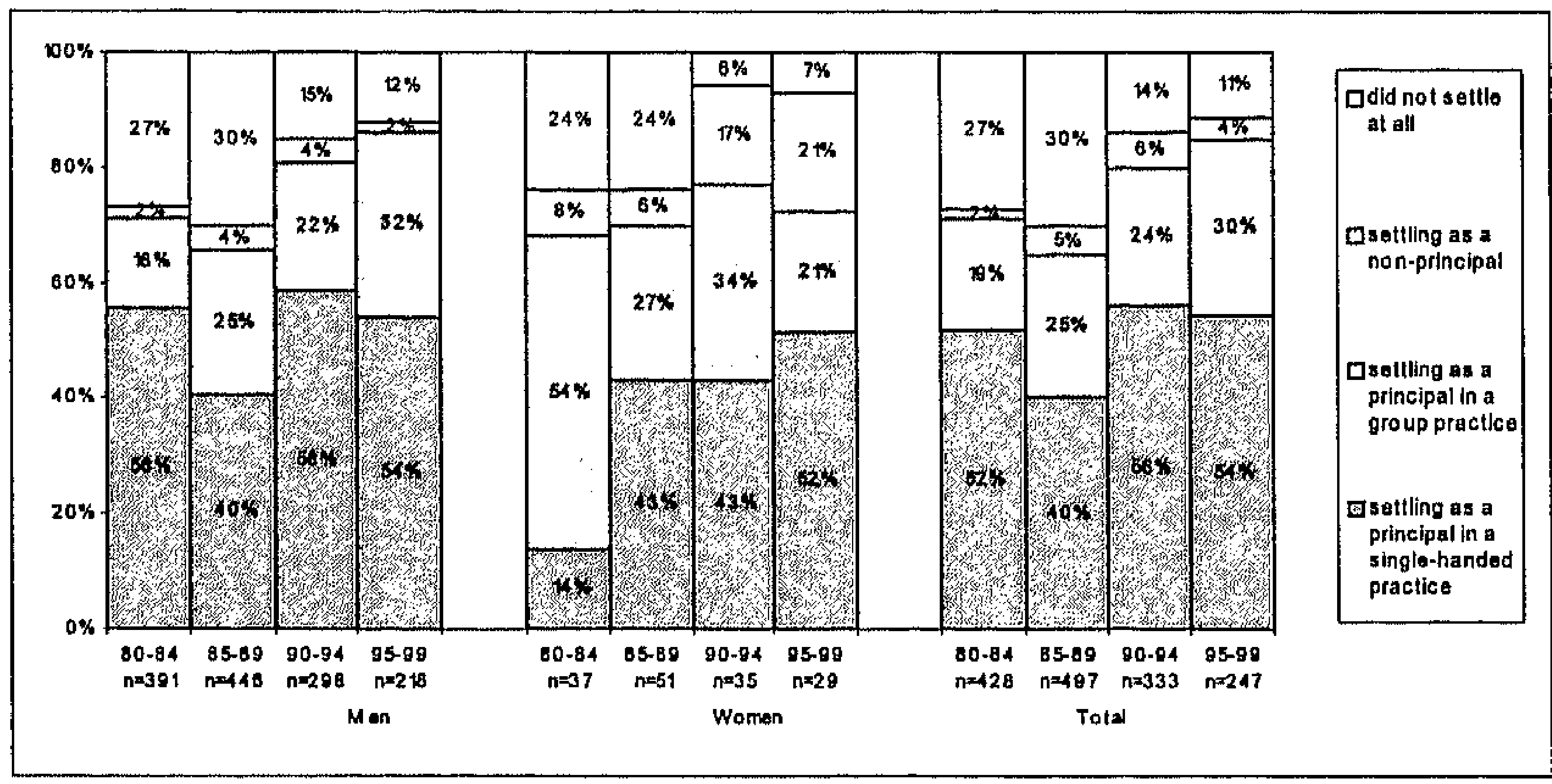

Figure 3. Realised practice type, for Dutch GPs preferring a position as a principle in a single-handed practice, according to gender and period (1980-1999)

\section{Realisation of practice preference: GPs with a preference for a principal position in a single-handed practice}

Figure 3 shows the proportion of GPs who initially preferred to work in a single-handed practice. The mean proportion of male GPs who realised their preference fluctuated between 1980 and 1999 , with an average of $55 \%(\min 34 \%, \max 72 \%$ ). The percentage of female GPs who realised their preference for a single-handed practice increased from $14 \%(1980-84)$ to $52 \%$ (1995-99). Women tended to work in a group practice. Their preference may have changed in favour of a group practice or they may still prefer a single-handed practice but have opted for a second-best solution. . This trend was also observed among men: in 1980-1984 16\% had a position in a group practice and in 1995$9932 \%$. Relatively more women than men had a locum (non-principal) position in a practice, and this proportion increased from $8 \%(1980-84)$ to $21 \%(1995-99)$. 


\section{Chapter 3}

The percentage of the GPs who dropped out of the profession was initially rather high and decreased for both men (from $27 \%$ to $12 \%$ ) and women (from $24 \%$ to $7 \%$ ) in the last decade.

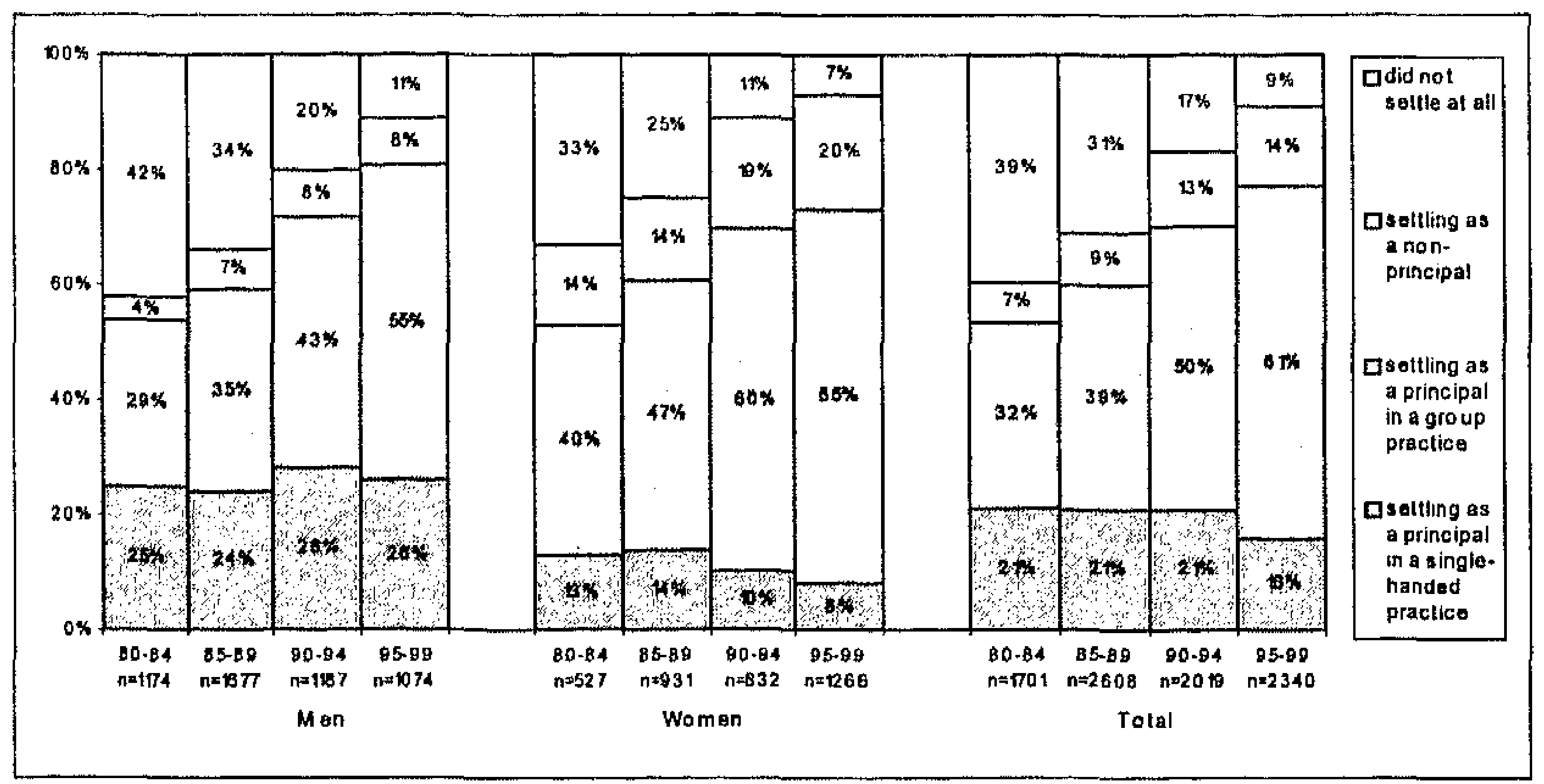

Figure 4. Realised practice type, for Dutch GPs preferring a position as a principal in a group practice, according to gender and period (1980-1999)

\section{Realisation of practice preference: GPs with a preference for a principal position in a group practice}

Among GPs who expressed a preference for working in a group practice as a principal, female GPs were more likely than male GPs to find a position in such a practice; however, over the years the proportions have become more equal: $55 \%$ male and $65 \%$ female (figure 4). The proportion of men who settled in a group practice has continued to increase from $29 \%$ in $1980-84$ to $55 \%$ in $1995-99$. Nowadays, the proportion of female GPs who have a non-principal position has increased, from $14 \%$ in $1980-84$ to $20 \%$ in 1995-99.

The number of dropouts among those who preferred a group practice was at first rather high ( $42 \%$ for men and $33 \%$ for women). This percentage has declined rapidly in the period between 1995 and 1999 (11\% and 7\% respectively). 


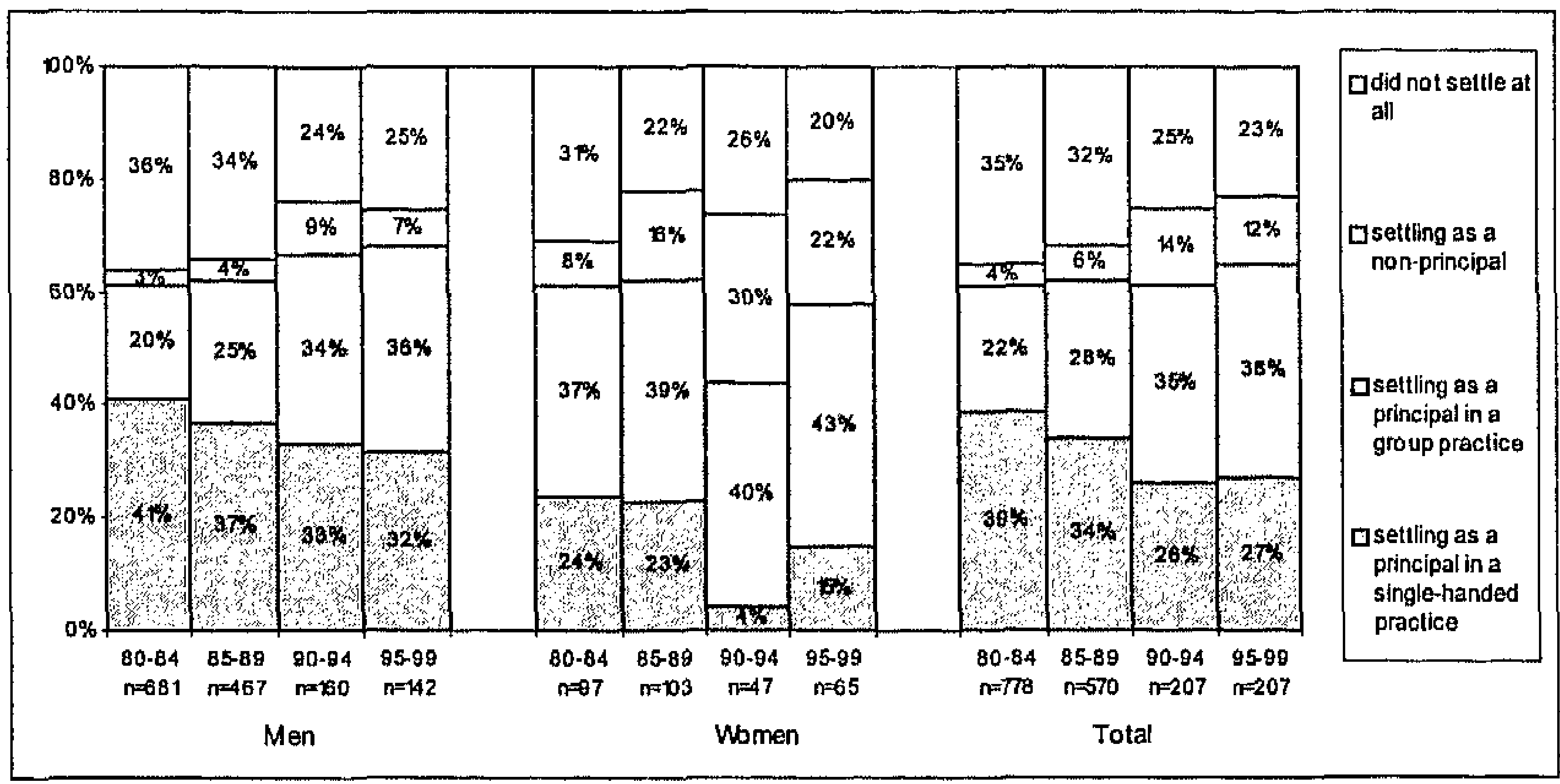

Figure 5. Realised practice type, for Dutch GPs preferring a position as a principal without preference for the practice type, according to gender and period (1980-1999)

\section{Realisation of practice preference: GPs with a preference for a principal position without practice type preference}

The trends are similar to GPs who had particular preferences. A higher proportion of both men and women have settled in a group practice in recent years (figure 5). Relatively more men than women worked in a single-handed practice, and relatively more women than men settled in a group practice and held a non-principal position.

The dropout rate was higher among both male and female GPs who had no expressed preference for working in a single-handed or group practice than it was among GPs who had such a preference. Although the dropout rate has decreased over the past 20 years, it is still relatively high: $25 \%$ for men and $20 \%$ for women in $1995-99$.

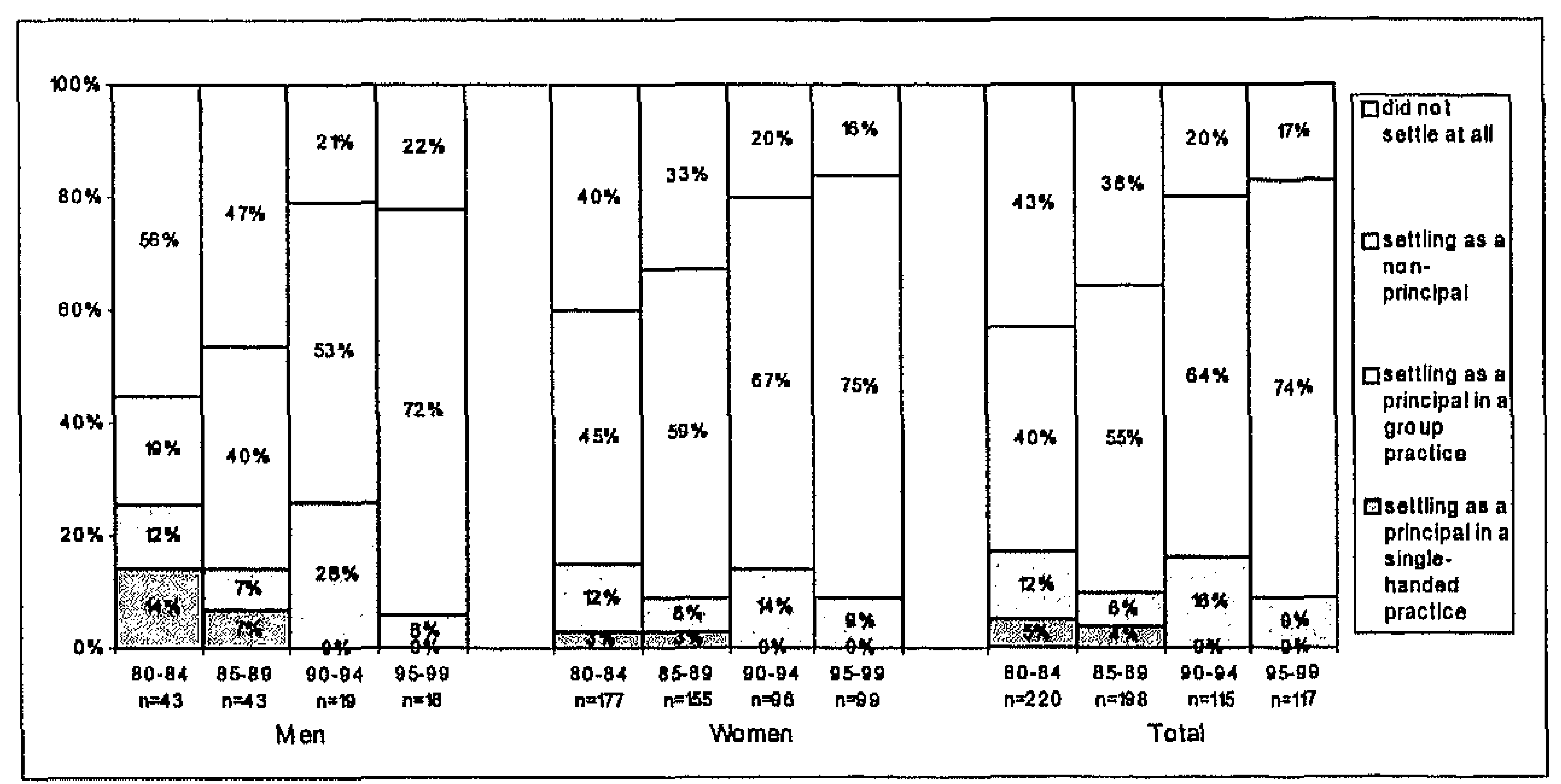

Figure 6. Realised practice type, for Dutch GPs seeking a position as a non-principal, according to gender and period (1980-1999) 
Chapter 3

\section{Realisation of practice preferences: GPs seeking a non-principal position}

Increasing percentage of GPs (higher among women than men) settled as a nonprincipal according to their preference: $40 \%$ in the early 1980 s and $75 \%$ in the late 1990s (figure 6). Through the years, there was a higher percentage GPs who settled as a principal in a group practice than in a single-handed practice. The share of GPs who did not settle has significantly decreased.

\section{Discussion}

In this study we investigated long-term trends in the newly qualified GPs concerning the following issues: (a) GP preference for working in a single -handed or group practice, principal or non-principal position (b) realisation of this preference, (c) the destination of GPs without a specific preference for practice type, and (d) drop-out.

Our findings show that over the last 25 years the preference for working in a singlehanded practice has strongly decreased so as to be virtually extinct, not only among female GPs but also among male GPs. The preference among male GPs for working in a group practice either as a principal or non-principal has increased steadily over the years, such that now both male and female GPs have an overwhelming preference for working in a group practice. There could be a number of explanations for this perspective. Firstly, currently, Dutch GPs choose often a sub-specialisation to offer an enhanced care and take over some tasks from the hospital physicians. This aim is easier to reach when joining together in a group practice. Secondly, present need for more time for family life applies not only to women but also to men. A study from Canada showed that female and male physicians do not differ significantly in their work hours or orientation towards patient care [21]. Although in the Netherlands, men still work longer hours than women, this development could take place in the future. Another explanation may involve gender identity, which has become an issue in recent years. The stereotypes of typical male and female physicians' orientations towards job arrangements have changed. Even though men and women still hold different work and family values and interests, the gap between their lifestyle attitudes has become smaller. Consequently, for the coming years we expect that (a) group practices will continue to be the most favoured practice setting among GPs seeking to establish themselves in a practice, and (b) male and female preference for this type of practice will continue to converge. More women than men hold a non-principal position, although the proportion of both male and female GPs who have such positions increased over the study period. Similar results were obtained in a Scottish study [8]. With a few exceptions, men realise positions more frequent in a single-handed practice, and women in a group practice, regardless of their original practice choice. This was also true for GPs who had no specific preference for a practice type. It seems that women choose jobs that best facilitate achieving a satisfactory work-family balance and/or that they are more flexible than 
men regarding the choice of practice. Our finding that female GPs are also more likely to hold a non-principal position in a group practice is in line with this. Further research into gender differences in practice setting is needed.

We found that the number of GPs who dropped out has decreased steadily over the years. Drop-out rates remained more stable in those GPs without a specific preference. The lack of a clear preference for a specific type of practice continues to form a serious risk of dropping out. In the 1980s dropout rates (that is not settling as a GP at all) were rather high (between $30 \%$ and $40 \%$ ) and did not differ much between categories of GPs (males, females, with and without preference for a specific type of practice). This changed in the 1990s, with there being a decrease in dropout rates among GPs with an expressed preference for a type of practice. Dropout rates remained stable in those GPs without a specific preference. This finding somewhat contradicts expectations, because one would suppose that GPs without a preference would be more flexible in taking a position in a certain type of practice. However, as became evident from our results, this group is, surprisingly, more inclined to step out of the profession. The most frequent job alternatives were an occupational physician and a nursing home physician [13].

A question is whether these Dutch developments are relevant to other European countries. We believe that this to be the case: the proportion of female doctors is increasing all over Europe [21]. The overall influx of women into medicine has highlighted issues concerning flexibility and the work-family balance. It is also evident that a singlehanded practice is unsuitable for combining work and family duties. This might become a problem in countries with a high proportion of single-handed practices, and may lead to decreased general practice coverage and to a shortage in GPs.

Will a mismatch in demand and supply of practices result in a workforce crisis? Recent evidence shows that in England the number of GPs increased by 1.5\% a year between 1994 and 2004, and at the same time there was a decrease in single-handed practices and an increase in larger group practices [6]. This shift is also taking place in the Netherlands. However, notwithstanding an increase in the availability of group practices in the Netherlands, similar to the UK situation, GPs are not distributed evenly across the country [22]. The number of male GPs seeking a position in a group practice is increasing rapidly, and more men are taking positions in group practices, even if they initially preferred a single-handed practice. Apparently, the number of vacant partnerships is also likely to increase. As the older generation of GPs reaches retirement, a number of practices will become vacant, so we do not envisage there being insufficient positions available. Given the demand for GP coverage, former single-handed practices may well be developed into group practices, to meet the current demand of newly qualified GPs for such positions, as found in this study. In the light of our research findings, a workforce crisis seems unlikely. Changing male and female GPs preferences for working in a group practice will go together with a greater availability of such practice settings. Any discrepancy between demand and supply will be mainly due to the uneven spread of GPs across the country. A far more serious problem, however, is the rather large number of trained GPs who do not find a position. Even though the number of dropouts has 


\section{Chapter 3}

decreased over the years, this problem needs urgent attention and further investigation of its background.

We had access to a unique longitudinal data set, consisting of information about all GPs who qualified in the Netherlands over the last 25 years. The main limitation of our study is that recently qualified GPs who immediately found a position in a practice were not included, as they did not have to answer the questions on their preferences. This group counts on average $6 \%$. Despite this limitation, our results substantiate previous concern about future qualitative and quantitative problems in the supply of GPs in relation to changing career preferences of male and of female doctors. It is important to take these changing work preferences of GPs into account in health care policies.

\section{Conclusion}

Mismatches between GP practice preference and realisation have become less common in the last few years. Both male and female GPs have an overwhelming preference for working in a group practice and this preference is being met. The preference of male and female GPs regarding the type of practice and job conditions is expected to converge further in the future.

The friction between preference and realisation was more pressing in the 1980 s, as a substantial dropout rate among newly qualified GPs might indicate. A considerable proportion of GPs are now able to realise their practice preference, while the dropout rate has decreased.

Though our data only show relations and do not allow for casual explanations, it seems that the 'yield' of the postgraduate GP training has improved. In the future, dropout rates could be reduced if Dutch medical schools were to pay attention to future GPs without a specific practice preference, as this may be an indicator of a lukewarm interest in the profession. 


\section{References}

1. Van den Hombergh P, Engels Y, van den Hoogen H, van Doremalen J, van den Bosch W, Grol R: Saying 'goodbye' to single-handed practices; what do patients and staff lose or gain? Family practice 2005, 22(1):20 -27.

2. Young R, Leese B: Recruitment and retention of general practitioners in the UK: what are the problems and solutions? British Journal of General Practice 1999, 49:829-833.

3. Brooks F: Women in general practice: responding to the sexual division of labour? Social Science\&Medicine 1998, 47(2):181-193.

4. Denekens J: The impact of feminisation on general practice. Acta Clinica Belgica 2002, 57(1):510.

5. Lawrence J, Poole P, Diener S: Critical factors in career decision making for women medical graduates. Medical Education 2003, 37(4):319-327.

6. Service GS: Statistics for general medical practitioners in England: 1994 - 2004. In: Statistical Bulletin. London: Department of Health Publications; 2005.

7. Levinson W, Lurie N: When most doctors are women: what lies ahead? Annals of internal medicine 2004, 141(6):471-474.

8. McKinstry B, Colthart I, Eliott K, Hunter C: The feminization of the medical work force, implications for Scottish primary care: a survey of Scottish general practitioners. BMC Health Services Research 2006, 6:56

9. Baker M, Williams J, Petchey R: GPs in principle but not in practice: a study of vocationally trained doctors not currently working as principals. British Medical Journal 1995, 310:1301-1304.

10. Shanley B, Schulte K, Chant D, Jasper A, Wellard R: Factors influencing career development of Australian general practitioners. Australian Family Physician 2002, 31(1):49-54.

11. Graham F, De La Harpe D: Implications of the increasing female participation in the general practice workforce in Ireland. Irish Medical Joumal 2004, 97(3):82-83.

12. Janes R, Elley R, Dowell A: New Zealand rural general practitioners 1999 survey. Part 2: Gender issues. New Zealand Medical Joumal 2004, 2:1191.

13. Mayorova T, Stevens F, Scherpbier A, Van der Velden L, Van der Zee J: Gender-related differences in general practice preferences: longitudinal evidence from the Netherlands $1982-2001$. Health Policy 2005, 72:73-80.

14. Health Do: Planning the Medical Workforce. Second report of the Medical Manpower Standing Advisory Committee. In. London: DoH; 1995.

15. Health Do: Primary Care: Delivering the Future. In. London: The Stationary Office; 1997.

16. Hingstman L, Van der Velden L: Behoefteraming Huisartsen 1997 - 2010 [Estimating the need of general practitioners 1997 - 2001]. In. Utrecht: NIVEL; 1998.

17. Boerma WGW: Profiles of General Practice in Europe. Utrecht: NIVEL; 2003.

18. Kenens R, Hingstman L: Cijfers uit de registratie van huisartsen, peiling 2005. In. Utrecht: NIVEL; 2005.

19. Van der Zee J, Kroneman M, Boerma W: De Nederlandse huisarts in Europees perspectief [The Dutch General Practitioner in European perspective]. Huisarts \& Wetenschap 2004, 47(6):266273.

20. Organisation WH: European health for all, database. In. Copenhagen: WHO-Regional Office for Europe; 2002.

21. Jovic E, Wallace J, Lemaire J: The generation and gender shifts in medicine: an exploratory survey of internal medicine physicians. BMC Health Services Research 2006, 6(1):55.

22. Sibbald B, Young R: The general practitioner workforce 2000. Workload, job satisfaction, recruitment and retention. In. Manchester: National Primary Care Research and Development Centre, University of Manchester; 2001. 


\section{Chapter 4}

Differences between faculties of medicine in the numbers of their medical graduates entering general practice training and general practice orientation of their curricula. A longitudinal descriptive study

\footnotetext{
Tanja Maiorova

Fred Stevens

Lud van der Velden

Jouke van der Zee

Paul Zwietering

Albert Scherpbier
}

Submitted to Nederlandse Tijdschrift Voor Geneeskunde 


\title{
Chapter 4
}

\begin{abstract}
Purpose

The purpose of this article is to analyze differences between medicine faculties in share of

graduates entering GP training, and to assess the degree of orientation toward general practice (GP) of the undergraduate curricula of the eight Dutch medical faculties. It is also explored whether there is a relationship between the share of GP topics and primary care orientation of the curriculum and students' decisions to pursue a career in general practice.

Design
\end{abstract}

The study was conducted as a retrospective cohort study.

\section{Methods}

On the basis of different longitudinal data sets it was assessed what percentage graduates per

faculty entered the GP training program each year between 1989 and 2001 . Next, by means of a questionnaire the coordinators of general practice education in the undergraduate curriculum of the eight Dutch faculties of medicine were asked to indicate the degree of orientation toward general practice and primary care in the 6-years medicine curriculum. Based on these data faculties were ranked according to the degree of general practice orientation. It was further explored if the general practice orientation was related to the percentage of students entering general practice.

\section{Results}

The number of graduates varied between 1682 and 2443 depending on the university in the

period 1989-2001. On average, $23.5 \%$ of the students entered general practice training. The medical faculties of Maastricht, Nijmegen and Amsterdam (VU) showed the strongest orientation toward general practice. General practice orientation of the curriculum only showed a slight correlation with the percentage of students entering general practice training in the early nineties.

\section{Conclusion}

Slight differences between faculties were found in share of graduates entering a GP training program. Although curricula differ in primary care orientation this was not associated with the percentage of students entering general practice training, except in the early nineties. Student-centered educational approaches may be related to students choosing a career in general practice. Limitations of the study are discussed. 


\section{Introduction}

Do the eight Dutch faculties of medicine differ in the numbers of their graduates who enter and successfully complete general practice training and is it possible to identify a measurable association with curriculum characteristics? There is evidence from the literature that students' specialty choices depend largely on career considerations, the labour market, and specialty-related factors [1-3]. The effects of a certain specialty on lifestyle and working conditions, such as working hours, workload, possibility to work part time, as well as personality strongly impact on specialty choices [4-6]. It is also known that a stronger general practice component in the medical curriculum can encourage students to undertake a training scheme in general practice [7].

Students generally come into contact with general practice for the first time during the general practice clerkship $[8,9]$. These experiences can be expected to influence their career choices after graduation $[10,11]$. Previous studies have examined specialty choices and career preferences of medical students at Dutch faculties of medicine [3, 12-14], but these studies did not target differences between faculties in the numbers of graduates entering and successfully completing general practice training nor at how these differences might be explained by the general practice orientation of the curriculum.

In the study reported in this article, we used descriptive longitudinal data from different sources to make a comparison between the Dutch faculties of medicine with regard to the numbers of their graduates entering and completing general practice training. Additionally, we ascertained how much of the faculties' curriculum content was related to general practice and we explored whether there was an association with the numbers of students opting for general practice.

We sought to answer three research questions:

1. Do faculties of medicine differ in the numbers of their medical graduates who undertake and successfully complete general practice training?

2. Do the curricula of faculties of medicine differ in structure and magnitude of general practice-related curriculum content?

3. Are differences between the faculties of medicine in general practice orientation of the curriculum associated with the number of students entering general practice training schemes? 


\section{Method}

\section{Study design and data collection}

The number of students entering and completing general practice training.

We used two types of data:

We obtained data on the annual numbers of students graduating from the faculties of medicine during the period 1989/90-2000/01 from reports from the Association of Universities in the Netherlands (VSNU) and reports from Statistics Netherlands (CBS).

We obtained data per university on the annual numbers of medical graduates entering general practice training and the numbers successfully completing training from Registration Commission for General Practice and Nursing Homes (HVRC).

We collected data on all students graduating during the period 1989/90-2000/01 who entered general practice training schemes between $1989 / 90$ and 2007. HVRC data comprised faculty of medicine and year of graduation. Linkage of these data to the annual numbers of graduates (VSNU/CBS) yielded annual percentages, per medical faculty, of graduates entering general practice training. The following formula was used to calculate this:

Percentage of medical graduates from faculty of medicine $\mathrm{Y}$ in year $\mathrm{X}$ who entered general practice training $=$

$\frac{\text { all graduates from university } \mathrm{Y} n \text { year } \mathrm{X} \text { who entered general practice training }}{\text { all medical graduates from faculty } \mathrm{Y} \text { in year } \mathrm{X}} \times 100 \%$

\section{General practice-related curriculum content}

Because it was not possible to obtain reliable data on general practice-related curriculum content for the period 1989-2001, we used expert opinion as a proxy measure. For this purpose we contacted the coordinators of general practice education of the eight Dutch faculties of medicine early in 2008 and asked them to complete a questionnaire on the coverage of general practice topics in the curriculum and the extent of students' contacts with general practice. In order to examine curriculum differences in general practice orientation we collected the following data:

- duration of the general practice clerkship;

- number of full time equivalents of staff time allocated to undergraduate general practice education divided by the number of first-year students;

- number of days in the first three years of the curriculum on which students have contacts in general practice; 
- general practice electives (number of positions for students and number of weeks per elective);

- active versus passive participation of students during the general practice clerkship;

- input from the department of general practice in the curriculum, estimated on the basis of [1] contribution to education, [2] curriculum content related to general practice, [3] influence on general practice-related curriculum content via the administration of the faculty of medicine, [4] satisfaction with general practice-related content, [5] representation of the department of general practice on education bodies of the faculty of medicine (Cronbach's alpha $=0.92$ ).

Based on the mean faculty scores on these data, the general practice orientation of the curricula of the faculties of medicine was ranked from strongest [1] to weakest [8].

\section{Results}

Numbers of students entering and completing general practice training between 1989 2001.

Table 1 shows that between 1989 and 2001 the numbers of medical graduates per faculty of medicine varied between 1682 and 2443. The mean overall percentage of graduates pursuing general practice training was $23.5 \%$. Between 1989 and 1995 more graduates entered general practice training than between 1995 and 2001. The highest percentages were found for the faculties of medicine in Groningen, Nijmegen, and Maastricht, while the percentages were lowest for the faculties of Leiden and Amsterdam (Free University and University of Amsterdam) and intermediate for the faculties of Rotterdam and Utrecht. 


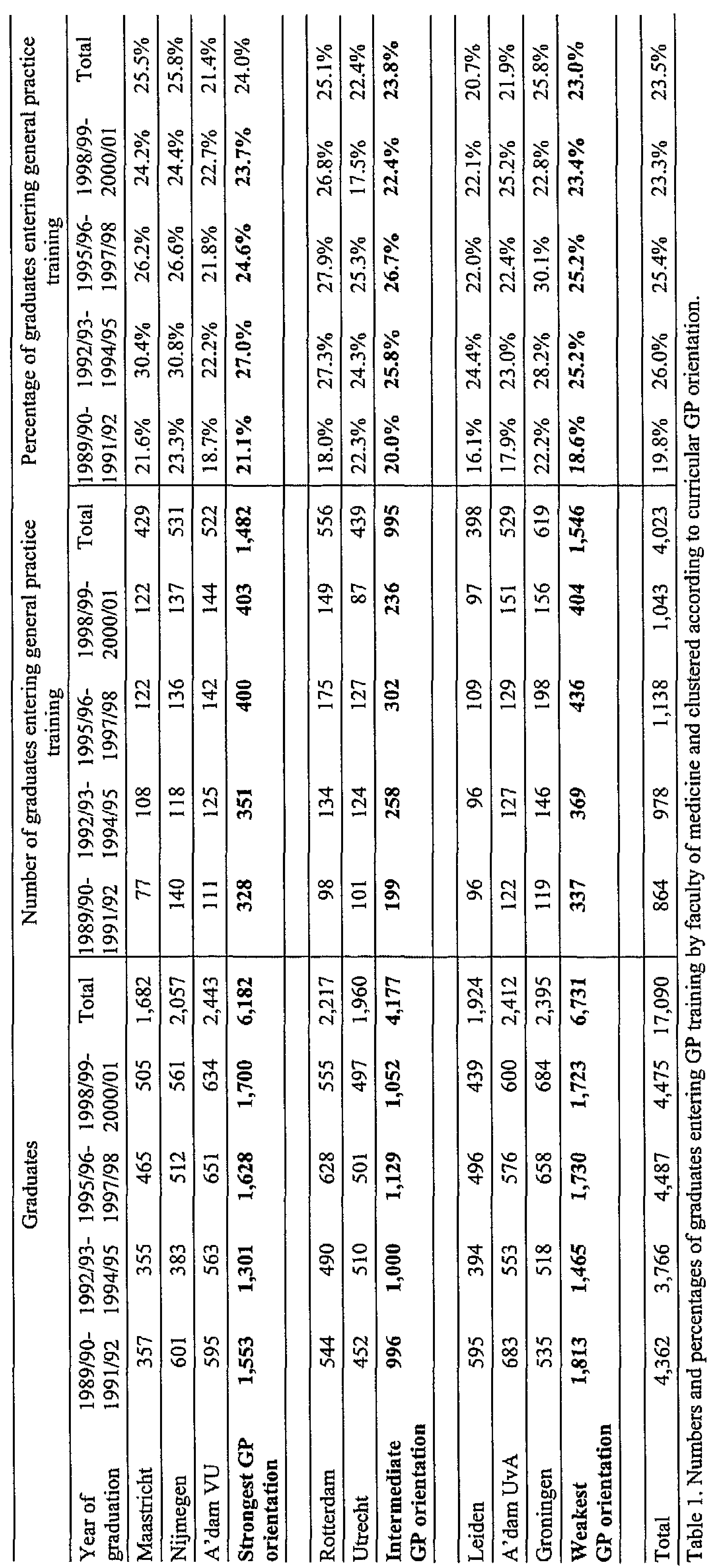




\section{General practice orientation of the undergraduate medical curriculum}

The ranking based on the seven parameters (Table 2) of orientation towards general practice was divided into three categories: strongest general practice orientation (Maastricht, Nijmegen, Free University, Amsterdam); intermediate general practice orientation (Rotterdam, Utrecht); and weakest general practice orientation (Leiden, University of Amsterdam, Groningen).

\begin{tabular}{|c|c|c|c|c|c|c|c|c|}
\hline & \multicolumn{3}{|c|}{ Strongest GP orientation } & \multicolumn{2}{|c|}{$\begin{array}{l}\text { Intermediate GP } \\
\text { orientation }\end{array}$} & \multicolumn{3}{|c|}{ Weakest GP orientation } \\
\hline & Maastricht & Nijmegen & $\mathrm{VU}$ & Rotterdam & Utrecht & Leiden & UvA & Groningen \\
\hline \multicolumn{9}{|l|}{ Objective data } \\
\hline $\begin{array}{l}\text { Ratio no. fte's for teach- } \\
\text { ing/no. of first-year students } \\
* 100 \\
\text { (Ranking) }\end{array}$ & $\begin{array}{l}2.9 \\
\text { (1) }\end{array}$ & $\begin{array}{l}2.2 \\
(2)\end{array}$ & $\begin{array}{l}1.9 \\
(3)\end{array}$ & $\begin{array}{l}0.3 \\
(7.5)\end{array}$ & $\begin{array}{l}1.3 \\
(4)\end{array}$ & $\begin{array}{l}.008 \\
(5.5)\end{array}$ & $\begin{array}{c}0.8 \\
(5.5)\end{array}$ & $\begin{array}{l}0.3 \\
(7.5)\end{array}$ \\
\hline $\begin{array}{l}\text { Clerkship duration in weeks } \\
\text { (Ranking) }\end{array}$ & $\begin{array}{l}10 \\
(1)\end{array}$ & $\begin{array}{c}8 \\
(2)\end{array}$ & $\begin{array}{c}6 \\
(3.5)\end{array}$ & $\begin{array}{c}4 \\
(7)\end{array}$ & $\begin{array}{c}6 \\
(3.5)\end{array}$ & $\begin{array}{c}4 \\
(7)\end{array}$ & $\begin{array}{c}5 \\
(5)\end{array}$ & $\begin{array}{c}4 \\
(7)\end{array}$ \\
\hline $\begin{array}{l}\text { No. of places on GP elec- } \\
\text { tives } \\
\text { (Ranking) }\end{array}$ & $\begin{array}{l}27 \\
(7)\end{array}$ & $\begin{array}{l}42 \\
(2)\end{array}$ & $\begin{array}{c}30 \\
(5.5)\end{array}$ & $\begin{array}{c}40 \\
(3.5)\end{array}$ & $\begin{array}{l}60 \\
(1)\end{array}$ & $\begin{array}{c}40 \\
(3.5)\end{array}$ & $\begin{array}{c}30 \\
(5.5)\end{array}$ & $\begin{array}{l}11 \\
(8)\end{array}$ \\
\hline $\begin{array}{l}\text { No. of weeks for GP elec- } \\
\text { tives } \\
\text { (Ranking) }\end{array}$ & $\begin{array}{l}28 \\
(1)\end{array}$ & $\begin{array}{l}20 \\
(5)\end{array}$ & $\begin{array}{l}18 \\
(6)\end{array}$ & $\begin{array}{c}24 \\
(3.5)\end{array}$ & $\begin{array}{l}16 \\
(7)\end{array}$ & $\begin{array}{c}24 \\
(3.5)\end{array}$ & $\begin{array}{l}12 \\
(8)\end{array}$ & $\begin{array}{l}26 \\
(2)\end{array}$ \\
\hline $\begin{array}{l}\text { No. of days of GP contacts } \\
\text { during the first three years } \\
\text { (Ranking) }\end{array}$ & $\begin{array}{c}8 \\
(3)\end{array}$ & $\begin{array}{c}1 \\
(5)\end{array}$ & $\begin{array}{c}6 \\
(4)\end{array}$ & $\begin{array}{l}11 \\
(2)\end{array}$ & $\begin{array}{c}0 \\
(7.5)\end{array}$ & $\begin{array}{c}0 \\
(7.5)\end{array}$ & $\begin{array}{l}14 \\
(1)\end{array}$ & $\begin{array}{l}.5 \\
(6)\end{array}$ \\
\hline \multicolumn{9}{|l|}{ Subjective judgements } \\
\hline $\begin{array}{l}\text { GP input in the curriculum } \\
\text { (mean score from } 1=\text { low } \\
\text { through 5=high on several } \\
\text { items) } \\
\text { (Ranking) }\end{array}$ & $\begin{array}{c}4 \\
(3)\end{array}$ & $\begin{array}{l}4.6 \\
(1)\end{array}$ & $\begin{array}{c}4.25 \\
(2)\end{array}$ & $\begin{array}{l}2.6 \\
(6)\end{array}$ & $\begin{array}{l}3.6 \\
(4)\end{array}$ & $\begin{array}{l}3.4 \\
(5)\end{array}$ & $\begin{array}{l}2.2 \\
(7)\end{array}$ & $\begin{array}{c}2 \\
(8)\end{array}$ \\
\hline $\begin{array}{l}\text { Students' active/passive } \\
\text { participation in the GP } \\
\text { clerkship (l=passive; } 10= \\
\text { active) } \\
\text { (Ranking) }\end{array}$ & $\begin{array}{c}9 \\
(2)\end{array}$ & $\begin{array}{c}8 \\
(5)\end{array}$ & $\begin{array}{c}9 \\
(2)\end{array}$ & $\begin{array}{c}9 \\
(2)\end{array}$ & $\begin{array}{c}8 \\
(5)\end{array}$ & $\begin{array}{c}8 \\
(5)\end{array}$ & $\begin{array}{c}7 \\
(7.5)\end{array}$ & $\begin{array}{c}7 \\
(7.5)\end{array}$ \\
\hline Overall mean ranking & 2.57 & 3.14 & 3.71 & 4.5 & 4.57 & 5.28 & 5.64 & 6.57 \\
\hline
\end{tabular}

Table 2. Ranking of the faculties of medicine based on orientation towards general practice (GP orientation). Ranking from $1=$ strongest GP orientation through $8=$ weakest GP orientation. 


\section{Chapter 4}

Figure 1 shows that the percentages of students who graduated between 1989 and 1992 and between 1992 and 1995 and who entered general practice training were higher for the faculties with the strongest general practice orientation than for the faculties with the weakest general practice orientation ( $21 \%$ versus $19 \%$ and $27 \%$ versus $25 \%$ ), while the faculties with an intermediate general practice orientation had percentages in-between. From 1995 to 2001 the association was different with a systematic albeit not straightforward relationship between the percentages of students entering general practice training and degree of general practice orientation (Table 1). In the category of faculties with the strongest general practice orientation, Free University, Amsterdam showed lower percentages of students entering general practice training than the faculties of Nijmegen and Maastricht, while in the group with the lowest general practice orientation the faculty of Groningen consistently showed a relatively high number of students entering general practice training.

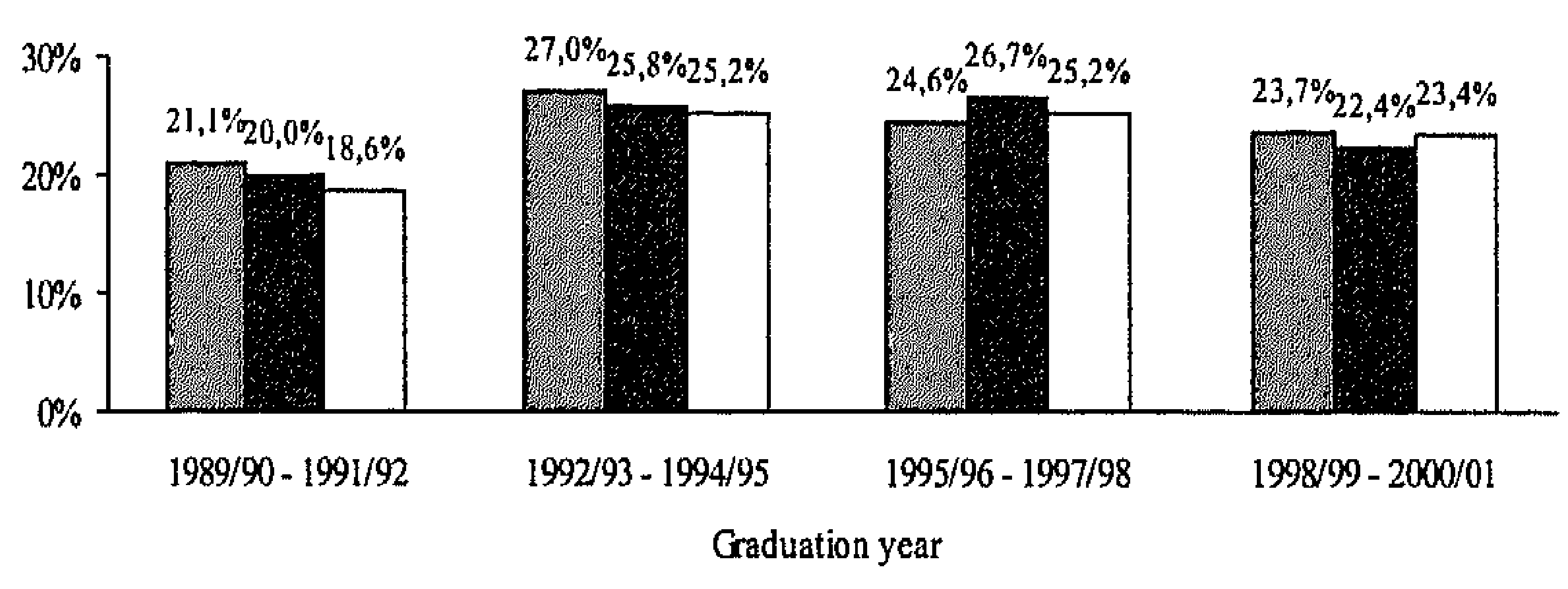

Strongest GP orientation $\mathbf{n}$ Intermediate GP orientation $\square$ Weakest GP orientation

Figure 1. Percentages of graduates entering general practice training, categorised according to GP orientation of the undergraduate medical curriculum of their university

The mean percentage of graduates completing general practice training was $96 \%$. Between 1991 and 1994 this percentage was highest for graduates from the faculties with the strongest general practice orientation $(99.4 \%$ versus $98.8 \%$ for the faculties with the weakest general practice orientation). Between 1994 and 2000, graduates from the faculties with the strongest general practice orientation showed a slightly lower percentage of successful completion of general practice training than graduates from the faculties with the weakest orientation towards general practice. 


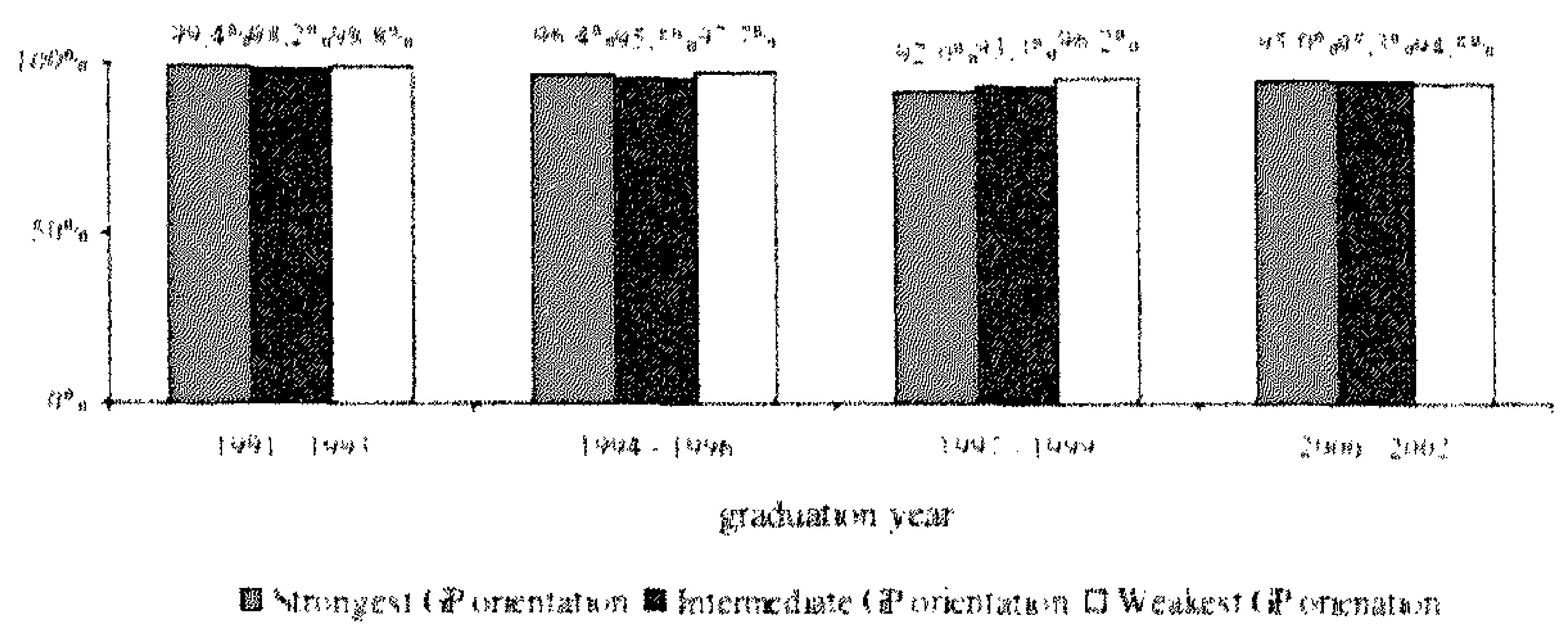

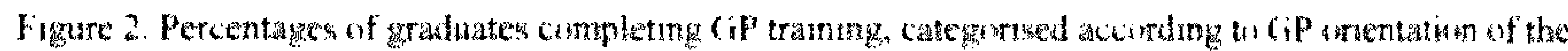
undergraduate medial curricalum of thes wnivernty.

\section{Discussion}

Longitudinal data on all medical students graduating between 1989 and 2001 were used to examine differences between the Dutch faculties of medicine in numbers of graduates entering and successfully completing general practice training. Although we did find differences, the maximum variation did not exceed $5 \%$. Variation was more pronounced within than between the faculties of medicine. In the early nineties there was a marked but unexplained increase in the percentage of students opting for general practice training.

The results show no clear association between the strength of the curriculum orientation towards general practice and number of entrants to general practice training, apart from a minor association during the early nineties when more graduates from the faculties with the strongest general practice orientation started general practice training compared to graduates from the faculties with the weakest general practice orientation. The faculties of medicine who historically had a stronger general practice orientation continued to include relatively more general practice content in their curricula.

This raises the question whether other factors than curriculum orientation may have impacted on graduates' career choices in favour of general practice. The duration of the general practice clerkship or other experiences in general practice for example may influence the likelihood of students choosing this specialty $[4,15,16]$. However, our results show no equal support for this effect. We found that the faculties of Maastricht and Nijmegen combined long general practice clerkships with a strong general practice orientation whereas the University of Amsterdam, with an equally strongly orientation towards general practice, did not offer a long clerkship. Moreover, the faculty of Groningen, which offered only a four-week clerkship, saw many of its graduates entering general practice training. 


\section{Chapter 4}

Our preliminary conclusion is that, while students' first experiences in general practice may awaken their interest in this specialty, the general practice content of the curriculum does not have a major impact on their eventual specialty choices.

The medical faculties that produced the highest percentages of general practice trainees shared a characteristic that sets them apart from the other faculties, namely their being situated in a relatively rural region. This seems in line with other studies which showed that students undertaking practical training in less urbanised areas appeared more likely to start a practice there [17]. However, we should also point to another common characteristic of these three faculties: an educational model that is more student centred and problem based than that of the other faculties of medicine. Earlier studies have shown that students from problem-based curricula tend to show more enthusiasm for primary care and general practice than students from traditional curricula [18] and that this may be reflected in a stronger preference for general practice [19]. However, it is entirely possible that the relationship between student-centred education and a career choice for general practice works the other way around [20]. Indeed, one might argue equally convincingly that students with a preference for general practice are more likely to enrol in a problem-based curriculum. Further research will have to shed more light on this.

The main limitation of this study is that we were unable to measure the general practice orientation of the curricula during the period for which we had data on graduation and general practice training. Our data on numbers of graduates and entry into general practice training related to students graduating between 1988/89 and 2001/01, whereas the general practice orientation of the curricula was measured only recently. It cannot be ruled out that earlier data would have yielded a different orientation ranking, especially in view of the fact that various faculties, notably those of Groningen and Utrecht, have introduced major curriculum renovations, while Maastricht recently introduced a 12week internship in general practice during the final year of the undergraduate curriculum. Similar developments are under way in other faculties.

Another limitation concerns the number of available training posts offered by the general practice training institutes. Most graduates do not enter specialist training until three years after graduation and their experiences during this period vary widely. However, it was technically impossible to calculate, for each cohort, the number of available training posts at the start of training.

The way general practice orientation was measured may be regarded as a third limitation. Today's curricula are much less discipline oriented than they used to be (with differences between faculties) and, as a result, the distinction between the disciplines is likely to be less obvious to students than to the teachers/experts who supplied the data for this study.

Despite these limitations we think the results provide an accurate longitudinal pattern of the numbers of students from the different faculties of medicine who decided to pursue a career in general practice. It should be pointed out that we studied the entire population of graduates during the study period and not a sample of that population, which means that statistical testing was not required. Despite the limitations, we believe the 
results support the conclusion that the influence of undergraduate curricula on students' preferences for general practice as a career is rather limited at best. Other factors are more likely to play a role, such as student-centred education, personal preferences and the situation on the labour market. Further research will have to elucidate this issue. 


\section{References}

1. Williams S, Saizow R, Ross L, Deci E. Motivation underlying career choice for internal medicine and surgery. Soc Sci \& Med. 1997;45 (11);1705-13.

2. Reed V, Jernstedt $G$, Reber $E$. Understanding and improving medical student specialty choice: a synthesis of the literature using decision theory as a referent. Teaching and Learning in Medicine. $2001 ; 13(2): 117-29$.

3. de Graaff E, Drop MJ, Post GJ, de Roos KP. Carrièrevoorkeuren en entree op de arbeidsmarkt van Maastrichtse basisartsen [Career preferences and the workforce market of the medical gradiuates from Maastricht]. Ned Tijdschr Geneeskd 1987;131:1677-8.

4. Bland C, Meurer L, Maldonado G. Determinants of primary care specialty choice: a non-statistical meta-analysis of the literature. Acad Med. 1995;70:620-41.

5. Dorsey E, Jarjoura D, Rutecki G. Influence of controllable lifestyle on recent trends in specialty choice by US medical students. JAMA. 2003;290(9):1173-8.

6. Lugtenberg $M$, Heiligers $P$, Hingstman L. Artsen en hun carrière wensen: een literatuurverkenning.[ Doctors and their career preferences: a literature review]: Utrecht: NIVEL; 2005.

7. Block S, Clark-Chiarelli N, Singer J. Mixed messages about primary care in the culture of U.S. medical schools. Acad Med. 1998;73(10):1087-94.

8. Maiorova T, Stevens F, Scherpbier A, van der Zee J. The impact of clerkships on students' specialty preferences: what do graduates learn for their profession? Medical Education 2008;42(6):554-62.

9. Morrison J, Murray T. Career preferences of medical students: influence of a new four-week attachment in general practice. British Journal of General Practice. 1996;46:721-5.

10. Howe A, Ives G. Does community-based experience alter career preference? New evidence from a prospective longitudinal cohort study of undergraduate medical students. Medical Education. 2001;35:391-7.

11. Saigal $P$, Takemura $Y$, Nishiue T, Fetters M. Factors considered by medical students when formulating their specialty preference in Japan: findings from a qualitative study. BMC Medical Education. 2007;7:31.

12. Schaapveld K, Roetman D. De beroepskeuze van in Leiden afgestudeerde artsen. [Career choice of doctors graduated in Leiden]. Ned Tijdschr Geneeskd. 2004;148:1544-6.

13. Cohen-Schotanus J, Reinders JJ, Agsteribbe J, Meyboom-de Jong B. Tien jaar arts: een longitudinaal onderzoek naar de loopbaan van artsen die hun studie begonnen in Groningen.[ Ten years being a doctor; a longitudinal study on the careers of the doctors who studied in Groningen]. Ned Tijdschr Geneeskd. 2002;146:2474-8.

14. Soethout MBM, van der Wal G, ten Cate $T$. Carrièrewensen en beroepskeuze van recent afgestudeerde artsen.[ Career preferences and career choices of the recently graduated doctors]. Ned Tijdschr Geneeskd. 2007;151:2118-23.

15. Stearns J, Glasser M, Miller B, Flach D, Cowen J. A longitudinal ambulatory care clerkship: graduates' reports on the effect on specialty choice and preparation for residency. Acad Med. 1993;68 (10 suppl):s37-9.

16. Meurer L. Influence of medical school curriculum on primary care specialty choice: analysis and synthesis of the literature. Acad Med. 1995;70 (5):388-97.

17. Moores D, Woodhead-Lyons S, Wilson D. Preparing for rural practice. Enhanced experience for medical students and residents. Canadian Family Physician. 1998;44:1045-50.

18. Matsui K, Ishihara S, Suganuma T, Sato Y, Tang A, Fukui Y, Yamaguchi N. Characteristics of medical school graduates who underwent problem-based learning. Annals of the Academy of Medicine, Singapore. 2007;36 (1):67-71. 
Medical faculties and graduates entering general practice

19. Albanese M, Mitchell S. Problem-based learning: a review of literature on its outcomes and implementation issues. Academic Medicine. 1993;68(1):52-81.

20. Fields S, Rattner S, Veloski J, Barzansky B. PBL and primary care career choice: a complex relationship. Acad Med. 1996;71:939-40. 


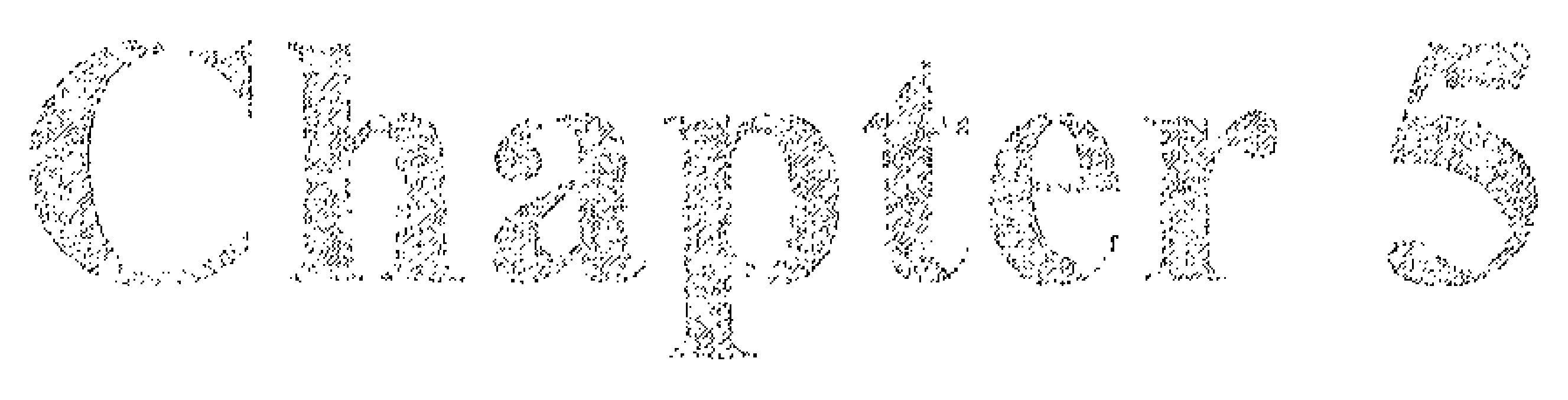

\section{The impact of clerkships on students' specialty preferences. What do} undergraduates learn for their profession?

\footnotetext{
Tanja Maiorova

Fred Stevens

Albert Scherpbier

Jouke van der Zee
}

Medical Education, 2008, 42 (6): 554 - 562 


\title{
Chapter 5
}

\begin{abstract}
Objective

Clinical experiences and gender have been shown to influence medical students' specialty choices. It remains unclear, however, which aspects of experiences make students favour some specialties and reject others. This study aimed to clarify the effects of clerkships on specialty choice and to identify explanatory factors.
\end{abstract}

Methods

We carried out a longitudinal cohort study to collect data on career preferences and attitudes towards future careers among 3 cohorts of students before and after clerkships in surgery $(n=200)$, internal medicine $(n=277)$ and general practice $(n=184)$. Regression analyses were performed to identify the determinants of career choice and the role of gender.

Results

Exposure to clinical settings encourages students to opt for a career in the corresponding specialty. Men were more stimulated than women by the general practice clerkship. Gender had no clear role as a predictor of career preference. The major predictor of career choice in all 3 specialties was positive evaluation of work-intrinsic factors. A preference for working with acute patients and technology-oriented work, prestige orientation and insignificance of a controllable lifestyle were determinants of a preference for surgery. Students with a preference for general practice had almost opposite preferences. Those who chose internal medicine favoured a controllable lifestyle.

\section{Discussion}

Factors other than gender appear to drive specialty decisions. Work content, type of patients and lifestyle options play major roles. Consequently, along with teaching about the practice of medicine, the matching of specialty preferences with reality is an essential outcome of clerkships. 
Impact of clerkships on specialty preferences

\section{Introduction}

Declining popularity of general practice as a career together with the gradually increasing number of women in medicine are recent developments in the physicians world[13].Since this can lead to potential misdistribution of the physician workforce in health care services, the classic research question as to which factors affect the career choices of medical graduates is revitalised. The level of factors influencing career preferences of medical students ranges from demographic to institutional (medical school) and from micro (personality) to macro (societal) level [4, 5]. Previous research highlighted work content and willingness to work with chronically ill patients as important determinants of choosing a career in general practice. By contrast, students seeking surgical training attached greater importance to prestige and career opportunities [6]. There is also evidence that increased awareness of a specialty and clinical experiences during clerkships are associated with shifts in preferences and eventual specialty choice [7-9]. Previous studies supported the assumption that general practice clerkships encourage students to pursue further training in this specialty $[10,11]$. It is not clear, however, whether such a positive clerkship effect is equally observable for other specialties too.

It is also unknown whether clerkship effects are different for men and women. Gender has always been an important determinant of career choice, with women being more likely to prefer part-time work and opportunities to combine work and personal life [12, 13]. Men are typically more attracted by technical challenges, prestige and learning potential[14]. In line with this, women tend to opt for careers in community-based areas and social medicine, whereas men are more inclined to prefer hospital-based specialties $[14,15]$. A number of recent studies have suggested, however, that the impact of gender is declining and male and female students' attitudes and overall perceptions of specialties are becoming more alike $[16,17]$. One reason for this may be that for men the quality of personal life has shown a substantial increase in importance [18]. It looks now as if a controllable lifestyle with time for leisure and a fixed number of weekly hours has a stronger appeal for men than the traditional male physician career motivators, such as prestige, remuneration and length of training [19]. Lifestyle and family factors are becoming more important in career decisions $[12,20,21]$.

In the present study we performed a comparative analysis of clerkships in general practice, internal medicine and surgery to examine

1. specific versus generic impact of clerkships,

2. whether clerkship impact is different for male and female students and

3. whether a clerkship affects students' specialty preferences. 


\section{Chapter 5}

\section{Methods}

\section{Participants}

We surveyed medical students of the University of Maastricht, The Netherlands. Students were asked to complete a questionnaire before and after 10-week clerkships in surgery and internal medicine, and a 12-week clerkship in general practice. We asked the students to complete the questionnaire during group meetings at the start and at the end of the clerkships. The physicians responsible for the organization of the clerkships asked consent. Than, the questionnaires were distributed before the meeting and collected afterwards.

New clerkship groups start every two (four in general practice) weeks the whole year through. The surgery and internal medicine cohorts were surveyed between September 2004 and September/ October 2005 respectively; the general practice cohort was surveyed earlier between September 2002 and July 2004. The numbers of participants are shown in Table 1.

Although the sequence of the clerkships is different for every student, the general practice clerkship always takes place in the second year of the clerkships period. Students who participated in internal medicine and surgery clerkships were involved in their first and second year of clerkships.

The cohorts of students involved in internal medicine and surgery clerkships overlapped to a certain degree: $47 \%$ of the surgery cohort has also participated in the internal medicine clerkship, $34 \%$ of the medical cohort participated in the surgery clerkship.

Due to not fully completed questionnaires, students' numbers in the analysis and tables can vary slightly. Analysing the data including only the students, who have fully completed the questionnaires, did not modify the results presented in this article.

\begin{tabular}{|c|c|c|c|c|c|}
\hline & \multirow[b]{2}{*}{$\begin{array}{l}\text { No of clerkship } \\
\text { students }\end{array}$} & \multirow[b]{2}{*}{$\begin{array}{l}\text { Neutral } \\
\text { losses }\end{array}$} & \multicolumn{2}{|c|}{ Obtained questionnaires } & \multirow{2}{*}{$\begin{array}{l}\text { Completed ques- } \\
\text { tionnaires before } \\
\text { and after clerk- } \\
\text { ships }\end{array}$} \\
\hline & & & $\begin{array}{l}\text { before } \\
\text { the clerkship }\end{array}$ & $\begin{array}{l}\text { after } \\
\text { the clerkship }\end{array}$ & \\
\hline Surgery & 370 (68\% women) & 45 & 325 ( $66 \%$ women $)$ & 200 (67\% women) & 178 \\
\hline Internal Medicine & 347 (68\% women) & 23 & $324(72 \%$ women $)$ & 277 (74\% women) & 247 \\
\hline General Practice & 206 ( $55 \%$ women $)$ & 3 & 203 ( $55 \%$ women) & 184 (56\% women) & 168 \\
\hline Total & 923 & 71 & 852 & 661 & 593 \\
\hline
\end{tabular}

Table 1. Numbers of students who participated in the research before and after clerkships in surgery, internal medicine and general practice 
Impact of clerkships on specialty preferences

\section{Instrument}

The questionnaire, primarily based on previous studies mentioned in the introduction $[14,22]$, contained the following questions before and after the clerkships: a) personal characteristics (age, gender); b) type of patients ("to what degree do you prefer to take care of chronically ill, geriatric, acute patients etc?" $1=$ not at all, $5=$ very much); c) type of care ("to what degree do you prefer palliative care, emergency care, technique apply, scientific work, management etc?" $1=$ not at all, $5=$ =very much); d) future job ("to what degree do you consider important for you future job: part-time work, income level, status, working hours, status, colleague's etc?" $1=$ not at all, $5=$ very much); e) evaluation of work of a surgeon/ internist/GP ("do you like the following aspects of being a surgeon/internist/general practitioner: type of patients, variety of work, status, income etc?" $1=$ not at all, $5=$ very much); f) preferred specialty ("what specialty do you prefer?"); d) likelihood of becoming a specialist, according to a corresponding specialty ("how likely are you to become a surgeon/ internist/ GP?" $1=$ not likely at all, $5=$ very much likely).

Factor analysis (varimax rotation) and scaling techniques were used to construct attitude variables from the questions about students' attitudes towards three main categories: (a) preferred patient categories; (b) preference for type of work in the future, and (c) evaluation of general practice, surgery and internal medicine as a profession. The items (5-point Likert scales), attitude variables (composed of sum scores), and reliabilities (Cronbach's alpha) are presented in appendix 1.

The questionnaires at the start and at the end of the clerkship were basically identical. After the clerkships the students were additionally asked to appraise the influence of clerkship preceptors as role models ("evaluate the skills of you preceptor: clinical, management, didactic, and communication skills" $1=$ insufficient, $5=$ good).

The construct validity of the questionnaire was checked by means of factor analysis (see appendix 1) [23].

\section{Statistical analysis}

We analysed data from students who completed both the first and the second questionnaire for a rotation in surgery, internal medicine or general practice. SPSS was used to analyse the data.

ANCOVA was performed to test the influence of the two possible confounding variables: the year of rotations (first or second) and overlap of cohorts. These variables had no significant influence on the results of analysis.

We calculated McNemar's chi-square to examine differences in specialty preferences before and after clerkships for male and female students [24]. When the frequencies were low, binominal tests were done. Male and female students' preferences were examined by calculating relative risk ratios ( $R R$ women/men). 


\section{Chapter 5}

McNemar- Bowker test of symmetry (chi-square) was used to test the differences in perceived likelihood to become a specialist before and after the clerkships.

Finally, logistic regression analysis was performed with students' perceived likelihood of becoming a general practitioner, a surgeon or an internist before and after the rotations as dependent variables and gender and students' attitudes as independent variables.

\section{Results}

\section{Specialty preferences}

Figure 1 shows the distribution of specialty preferences before and after rotations. After all three rotations there was an overall increase in preference for the specialty of the completed rotation $(p<.01)$. For surgery the increase was from $30 \%$ to $44 \%(p<.05)$ for male students and from $9 \%$ to $22 \%(\mathrm{p}<.01)$ for female students. After the rotations women were less likely than men $(R R=.059)$ to prefer surgery, and more likely $(R R=$ 1.53) than men to prefer general practice. Preference for internal medicine was almost equal in men and in women $(R R=1.07)$. 

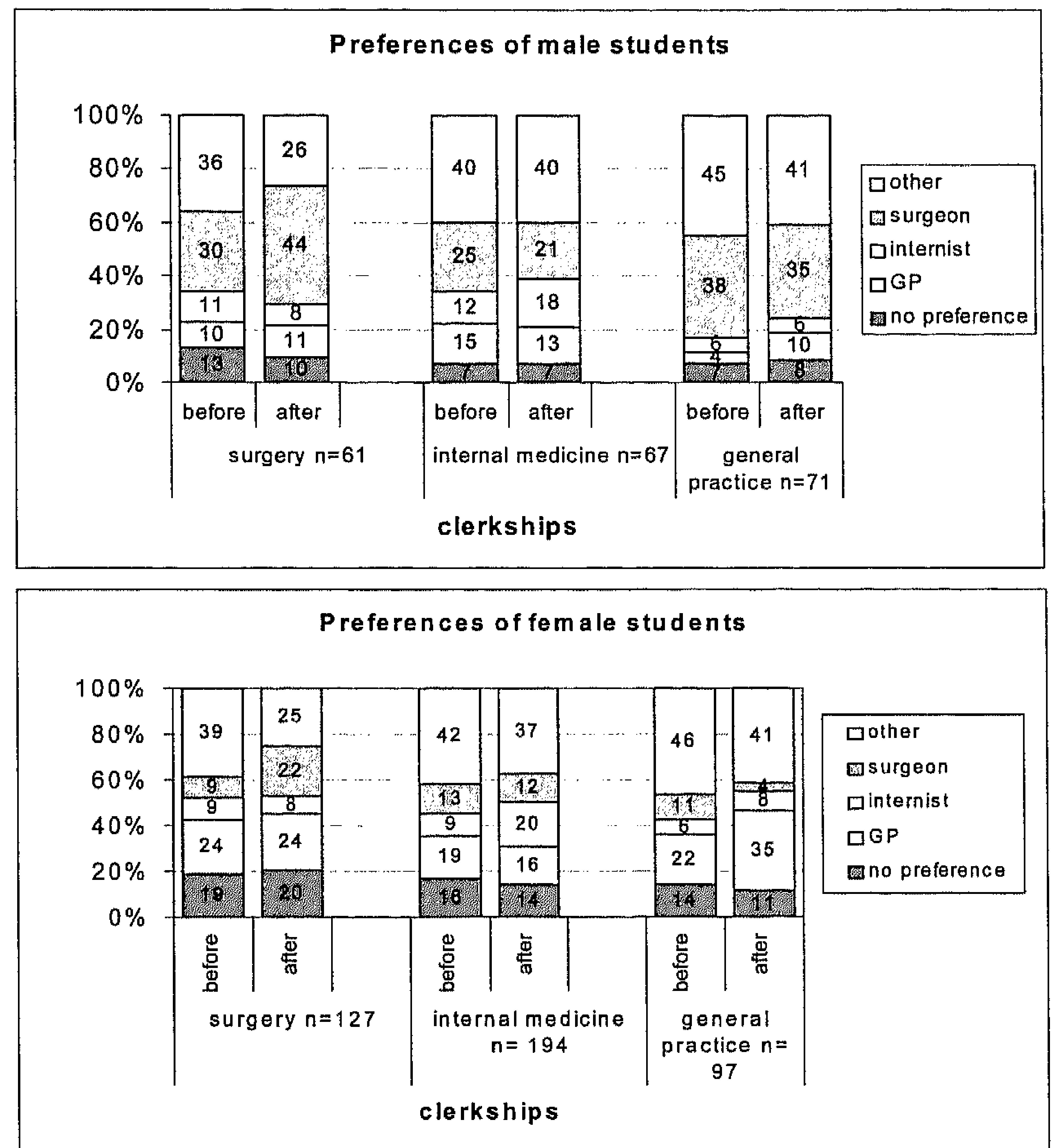

Figure 1. Specialty preferences before and after clerkships in general practice, internal medicine and surgery.

\section{Perceived likelihood of becoming a GP, surgeon or internist}

In addition to specialty preferences we asked the students before and after clerkships to indicate the perceived likelihood of becoming a surgeon, internist and general practitioner.

The changes of perceived likelihood before and after the clerkships (see table 2) were significant for all three specialties: surgery $(p<.01)$, internal medicine $(p=.045)$ and general practice $(\mathrm{p}<.01)$.

After the surgical clerkship the likelihood had increased in $31 \%$ of students and remained unchanged in $59 \%$ of students $(54 \%$ of these students reported a positive likelihood before as well as after the rotation). The increase in likelihood to become a surgeon was significant only for women $(\mathrm{p}<.01)$, although more men than women were planning a career in surgery. 


\section{Chapter 5}

After the internal medicine clerkship the perceived likelihood of choosing internal medicine was unchanged in $49 \%$ of students, with $62 \%$ of these students being positive about becoming an internist. There was no significant increase in likelihood for both genders tested separately.

The perceived likelihood of choosing a career in general practice showed a higher significant increase among male $(38 \%, \mathrm{p}<0.1)$ than among female students $(22 \%, \mathrm{p}<$ $.05)$. However, the majority of the students expressing a preference for general practice were female. Sixty-three per cent of the students reported an unchanged likelihood of a career in general practice, with nearly half of them willing to become a GP.

\begin{tabular}{llll}
\hline & Surgery & Internal medicine & General practice \\
\hline & Total $($ Men/women) $\%$ & Total (Men / women $) \%$ & Total ( Men /women $) \%$ \\
\hline Less likely & $10(11 / 9)$ & $21(21 / 21)$ & $8(5 / 10)$ \\
Unchanged & $59(65 / 56)$ & $49(55 / 47)$ & $63(57 / 68)$ \\
More likely & $31(24 / 35)$ & $30(24 / 32)$ & $29(38 / 22)$ \\
\hline Total N $(100 \%)$ & $\mathrm{N}=200(66 / 134)$ & $\mathrm{N}=277(70 / 207)$ & $\mathrm{N}=184(79 / 105)$ \\
\hline
\end{tabular}

Table 2. Changes (in percentages) in perceived likelihood of becoming a general practitioner/internist/surgeon after clerkship in these specialties

\section{Predictors of specialty preference}

Table 3 shows factors predicting students' perceived likelihood of becoming a surgeon, internist or GP before and after the respective clerkships.

In all three clerkships positive evaluation of intrinsic work factors (variety of work and patients, treatments) for the specialty was a strong positive predictor.

Motivating influence of the extrinsic work factors (i.e. status, income, and career prospects), was only positively related to the perceived likelihood of becoming a GP before the clerkship. After the rotation this effect had disappeared in favour of intrinsic factors motivation, which suggests that students changed their initial view of general practice as a profession. A similar effect was observed for the surgery rotation. 
Impact of clerkships on specialty preferences

\begin{tabular}{|c|c|c|c|c|c|c|}
\hline \multirow[b]{2}{*}{ Independent variables } & \multicolumn{2}{|c|}{$\mathrm{GP}, \mathrm{n}=175$} & \multicolumn{2}{|c|}{$\begin{array}{l}\text { Internal Medicine, } \\
\mathrm{n}=248\end{array}$} & \multicolumn{2}{|c|}{ Surgery, $\mathrm{n}=178$} \\
\hline & before & after & before & After & before & after \\
\hline Gender & .127 & -.046 & -.101 & -.062 & $-.168^{*}$ & -.082 \\
\hline \multicolumn{7}{|l|}{ Type of work and patients } \\
\hline $\begin{array}{l}\text { Chronically ill patients and } \\
\text { palliative care }\end{array}$ & .121 & $.170^{* *}$ & $.129^{*}$ & .029 & $-.194 * *$ & $-.210 * *$ \\
\hline $\begin{array}{l}\text { Acute patients and technology } \\
\text { - orientated work }\end{array}$ & $-.220 * *$ & $-.267 * *$ & -.002 & -.006 & $.319 * *$ & $.255^{* *}$ \\
\hline
\end{tabular}

Preferred work conditions

\begin{tabular}{lllllll}
\hline Prestige oriented & -.089 & $-.146^{*}$ & $.227^{*}$ & .020 & .022 & $.161^{*}$ \\
Controllable lifestyle oriented & .116 & .081 & -.065 & $.134^{*}$ & $-.183^{*}$ & $-.243^{* *}$ \\
\hline Evaluation of becoming a GP/ generalist / surgeon & & & & \\
\hline Work intrinsic & .115 & $.332^{* *}$ & $.324^{* *}$ & $.345^{* *}$ & $.165^{*}$ & $.209^{* *}$ \\
Work extrinsic & $.220^{* *}$ & .125 & -.099 & .000 & $.147^{*}$ & -.033 \\
\hline
\end{tabular}

Role model

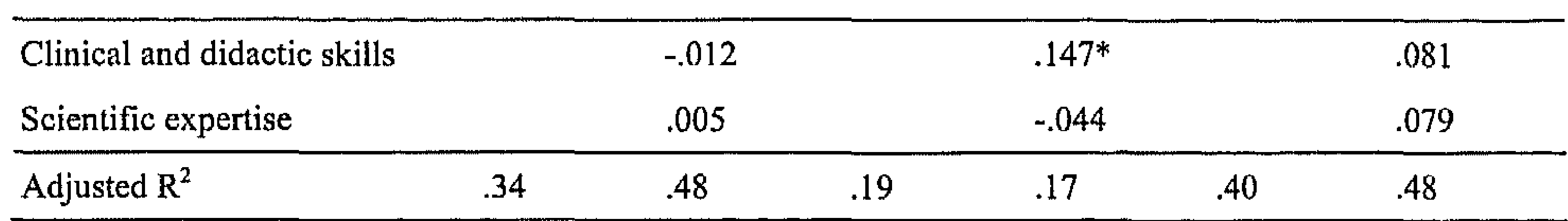

Table 3. Multiple Regression Analysis. The dependent variables are perceived likelihohod of becoming a general practitioner, internist or surgeon before and after the clerkships.

Table 3 also shows that a preference for working with acute patients and a favourable orientation towards technology are positively related to the perceived likelihood of becoming a surgeon, both before and after the clerkship. In contrast, a preference for working with chronic patients and palliative care was a negative determinant of the perceived likelihood of becoming a surgeon. For general practice these relationships were the other way around.

With respect to work conditions, preference for a controllable lifestyle was negatively related to the perceived likelihood of becoming a surgeon both before and after the surgical rotation, whereas a prestige orientation was found to have a positive effect on the perceived likelihood of becoming a surgeon after the rotation. After the GP rotation a prestige orientation was negatively related to the perceived likelihood of becoming a GP, while a positive effect before the internal medicine rotation had disappeared after the clerkship. Preference for a controllable lifestyle changed from a negative relationship with perceived likelihood of becoming an internist before the rotation to a positive one after clerkship. Preference for part-time work and regular working hours was not related to the perceived likelihood of becoming a GP. 
Neither gender nor role model of clerkship preceptors showed a substantial relationship with perceived likelihood of a career in any of the specialties. Role model only affected perceived likelihood of becoming an internist, while gender (male) predicted the likelihood of becoming a surgeon.

Finally, adjusted $R^{2}$ indicated that the independent variables were stronger predictors of the perceived likelihood of becoming a GP or surgeon both before and after the clerkships than of the perceived likelihood of choosing a career in internal medicine.

\section{Discussion}

This study underscores the importance of clinical experiences for career considerations [7. Our study showed similar patterns of change in specialty preference for general practice, surgery and internal medicine: students were encouraged by the clerkship to consider a future career in the specialty of the rotation. Although the perceived likelihood of opting for a career in general practice, surgery and internal medicine increased after the respective clerkships, the views of the majority of the students remained largely unchanged. It is likely that many students saw their ideas regarding a specialty, whether positive or negative, reinforced during the clerkship and as a result, did not alter their preferences.

Clerkship effects were different for male and female students. Relatively more male than female students prefer a career in surgery, and more female than male students prefer a career in general practice. Less expected, a higher percentage of female students reported an increased likelihood to become a surgeon and a higher percentage of male students indicated an increased likelihood of going into general practice after the rotations. In fact, we observed that preferences are spread according to a classic gender pattern: men opt more for surgery and women for general practice. However, there are relatively more female than male students who discover new attractive aspects of surgery and relatively more male than female students who report higher likelihood to become a general practitioner. This underscores the enlightening role of clerkships in career choices.

Our findings could not substantiate that gender was associated with the perceived likelihood of entering a specific specialty. However, specialty preferences reflected a certain gender-related pattern with men favouring surgery, women favouring general practice and preferences for internal medicine being equally divided between men and women. Apparently, factors other than gender are more essential in the decision-making process. In all three clerkships a positive view of factors that are intrinsic to the work was a positive predictor of the likelihood of opting for a specialty. In general practice this effect was only observed after the rotation, which may indicate that before the clerkship students did not have a clear idea of what general practice might entail. From our experiences, we believe that too often the prevailing view among students is that a GP is a 'dull' generalist who refers the 'interesting' patients to hospital-based specialties. Ap- 
parently, experiences in primary care settings promote an interest in general practice and show advantages that were not considered or known before $[15,22,25,26]$.

Students indicating a high likelihood of becoming a surgeon were consistently negative about working with chronic patients and positive with regard to emergency care and technology-oriented work. This is in contrast to students attracted to general practice. After the GP clerkship, willingness to deal with chronic problems, long-term contacts with patients and providing continuity of care were associated with a high perceived likelihood of becoming a GP. Apparently, the GP clerkship strengthens an interest in primary care patients.

After the internal medicine rotation, students with a high perceived likelihood of choosing internal medicine showed a preference for a controllable lifestyle. After the surgery rotation, there was a more positive relationship between perceived likelihood of becoming a surgeon and a preference for prestige and income than before the clerkship. Surgery has an image of requiring much time, effort and devotion, which does not allow for a controllable lifestyle [27]. Students saw their ideas about surgery confirmed, whereas during the internal medicine clerkship students may have appreciated the more favourable opportunities for part-time work and leisure time.

Gender differences regarding career choice appear to be not only based on typical male and female choices but seem to be a combination of attitudinal factors such as type of preferred patients and work (technology-oriented work and emergency situations versus chronic patients and palliative care) and lifestyle preferences (part-time work or career and income orientation). These findings substantiate that the function of clerkship is not only to give students experience in the practice of medicine but also to make students more aware of, and help them decide on their preferences for different types of medical work, patients and settings. In addition to medical skills, students also acquire a sense of professional identity and look for the specialty they fit [28]. Among the professions medicine is unique in providing such a broad comparative opportunity. As the results of this study bring to light, students get an idea of what kind of patients they prefer, what kind of work they like and dislike, and of the opportunities to combine work and leisure being a specialist. Not surprisingly, students choose a specialty on the basis of work content as experienced during a clerkship. The results also show that the importance of extrinsic aspects of a specialty (status, career, remuneration) diminishes after clerkship. It is the content of work that matters.

In this study, attitude-related factors seem to offer a better explanation of perceived likelihood of becoming a surgeon or a GP than of the likelihood of becoming an internist. Perhaps students who opt for general practice or surgery have a clearer picture of the values and expectations related to their chosen specialty. By contrast, undergraduates who report a high likelihood of becoming an internist may be attracted by a combination of the advantages of general practice and hospital work. It is not uncommon for graduates to gain some clinical experience in internal medicine before deciding on their final specialty choice. This may explain the discrepancy in this study between students' attitudes and perceived likelihood of becoming an internist. Besides learning from experi- 
Chapter 5

ences in medical practice, matching students' expectations with clinical practice should be an important objective and outcome of clinical clerkships.

Our study has several limitations. First, we used different cohorts, and two of them partly overlapped. Secondly, we were unable to measure the impact the clerkships sequence on the students' preferences. Every student has a unique clerkships planning and on this reason, it is not possible to analyze accurately the influence of each clerkship at the moment of our survey. However, as already indicated, neither the overlap, nor the year of rotations did have a significant influence on the results. A third limitation is that we have only surveyed cohorts from one university. Notwithstanding this, our findings build upon existing literature. More research is needed to substantiate our results. 
Impact of clerkships on specialty preferences

Appendix 1: Scales, items and reliabilities (alpha) concerning students' attitudes

\begin{tabular}{|c|c|c|c|c|}
\hline Scale & Items & Alpha GP & $\begin{array}{l}\text { Alpha } \\
\text { Internal } \\
\text { Medicine }\end{array}$ & $\begin{array}{l}\text { Alpha } \\
\text { Surgery }\end{array}$ \\
\hline \multicolumn{5}{|c|}{ Preferred patient category and type of work: } \\
\hline $\begin{array}{l}\text { - Chronically ill patients and } \\
\text { palliative care }\end{array}$ & $\begin{array}{l}\text { Chronically ill patients } \\
\text { Geriatric patients } \\
\text { Palliative care } \\
\text { Long-term contacts with patients }\end{array}$ & .72 & .65 & .68 \\
\hline $\begin{array}{l}\text { - Acute patients and } \\
\text { technology-orientated work }\end{array}$ & $\begin{array}{l}\text { Technical activities } \\
\text { Highly specialised work } \\
\text { Availability of personnel and } \\
\text { equipment } \\
\text { Emergency care } \\
\text { Acute patients }\end{array}$ & .75 & .73 & .69 \\
\hline
\end{tabular}

Preferred work conditions in the future

\begin{tabular}{|c|c|c|c|c|}
\hline - Prestige orientation & $\begin{array}{l}\text { Income } \\
\text { Career opportunities } \\
\text { High status }\end{array}$ & .70 & .65 & .61 \\
\hline - Controllable lifestyle orientation & $\begin{array}{l}\text { Part-time work } \\
\text { Regular working hours } \\
\text { Leisure time }\end{array}$ & .76 & .66 & .66 \\
\hline \multicolumn{5}{|c|}{ Evaluation of becoming general practitioner/internist/surgeon } \\
\hline - Work intrinsic factors & $\begin{array}{l}\text { Variety of patients and disorders } \\
\text { Contacts with family of patients } \\
\text { Individual treatments } \\
\text { Variety of work } \\
\text { Collaboration and communica- } \\
\text { tion with colleagues }\end{array}$ & .68 & .73 & .76 \\
\hline - Work extrinsic factors & $\begin{array}{l}\text { High status } \\
\text { Income } \\
\text { Career opportunities }\end{array}$ & .63 & .67 & .70 \\
\hline
\end{tabular}




\section{Chapter 5}

\section{References}

1. Van Offenbeek M, Kiewiet D, Oosterhuis M. The compatibility of future doctors' career intentions with changing health care demands. Med Educ 2006;40:530-538.

2. Sobral D. Influences on choice of surgery as a career: a study of consecutive cohorts in a medical school. Med Educ 2006;40:522-529.

3. Lambert TW, Davidson JM, Evans J, Goldacre MJ. Doctors' reasons for rejecting initial choices of specialties as long-term careers. Med Educ 2003;37:312-318.

4. Bland C, Meurer L, Maldonado G. Determinants of primary care specialty choice: a non-statistical meta-analysis of the literature. Acad Med 1995;70:620-41.

5. Henderson M, Hunt D, Williams J. General internists influence students to choose primary care careers: the power of role modeling. Am J Med Sci 1996;101:648-53.

6. Azizzadeh A, McCollum C, Miller C, Holliday K, Shilstone H, Lucci A. Factors influencing career choice among medical students interested in surgery. Curr Surg 2003;60(2):210-213.

7. Williams S, Saizow R, Ross L, Deci E. Motivation underlying career choice for internal medicine and surgery. Soc Sci Med 1997;45(11):1705-13.

8. Schwartz M, Linzer M, Babbott D, Divine G, Broadhead W. The impact of an ambulatory rotation on medical student interest in internal medicine. The Society of General Internal Medicine Task Force on Career Choice in Internal Medicine. J Gen Intern Med 1995;10:542-9.

9. Mihalynuk T, Leung G, Franser J, Bates J, Snadden D. Free choice and career choice: clerkship electives in medical education. Med Educ 2006;40:1065-71.

10. Kassebaum D, Szenas P, Schuchert M. Determinants of the generalist care intentions of 1995 graduating medical students. Academic Medicine 1996;71:198-209.

11. Ellsbury K, Carline J, Irby D, Stritter F. Influence of third-year clerkships on medical student specialty preferences. Adv Health Sci Educ 1998;3:177-186.

12. Ek E, Ek E, Mackay S. Undergraduate experience of surgical teaching and its influence on career choice. ANZ j surg 2005;75(8):713-718.

13. Gorenflo D, Ruffin M, Sheets $K$. A multivariate model for specialty preference by medical students. J Fam Pract 1994;39:570-6.

14. Baxter N, Cohen R, McLeod R. The impact of gender on the choice of surgery as a career. Am J Surg 1996;172:373-6.

15. Howe A, Ives G. Does community-based experience alter career preference? New evidence from a prospective longitudinal cohort study of undergraduate medical students. Medical Education 2001;35:391-7.

16. Ehrlich $P$, Seideman P. Deconstructing surgical education-teacher quality really matters: implications for attracting medical students to surgical careers. Am Surg 2006;72(5):430-434.

17. Davis B, Nelson D, Sahler O, Goldberg R, Greenberg L. Do clerkship experiences affect medical students' attitudes toward chronically ill patients? Acad Med 2001;76(8):815-820.

18. Brown A, Swinyard W, Ogle J. Women in academic medicine: a report of focus groups and questionnaires, with conjoint analysis. J Womens Health 2003;12(10):999-1008.

19. Dorsey E, Jarjoura D, Rutecki G. Influence of controllable lifestyle on recent trends in specialty choice by US medical students. JAMA 2003;290(9):1173-1178.

20. Brundage S, Lucci A, Miller C, Azizzadeh A, Spain D, Kozar R. Potential targets to encourage a surgical career. J Am Coll Surg 2005;200(6):946-53.

21. Wendel T, Godellas C, Prinz R. Are there gender differences in choosing a surgical career? Surgery 2003;134(4):591-6.

22. Morrison J, Murray T. Career preferences of medical students: influence of a new four-week attachment in general practice. Br J Gen Prac 1996;46:721-5.

23. Rummel R. Applied Factor Analysis. 1970;Sect. 19-21. 
24. Siegel S, Castellan N. Nonparametric statistics for the behavioral sciences. Second ed. New York: McGraw Hill; 1988.

25. Xu G, Hojat $M$, Brigham T, Veloski J. Factors associated with changing levels of interest in primary care during medical school. Academic Medicine 1999;74:1011-5.

26. Campos-Outcalt D, Senf J, Watkins A, Bastacky S. The effects of medical school curricula, faculty role models, and biomedical research support on choice of generalist physician careers: a review and quality assessment of the literature. Academic Medicine 1995;70:611-619.

27. Klass P. A not entirely benign procedure. Four years as a medical student. New York: Plume; 2000.

28. Dornan T, Boshuizen H, King N, Scherpbier A. Experience-based learning: a model linking the processes and outcomes of medical students' workplace learning. Med Educ 2007;41(1):84-91 


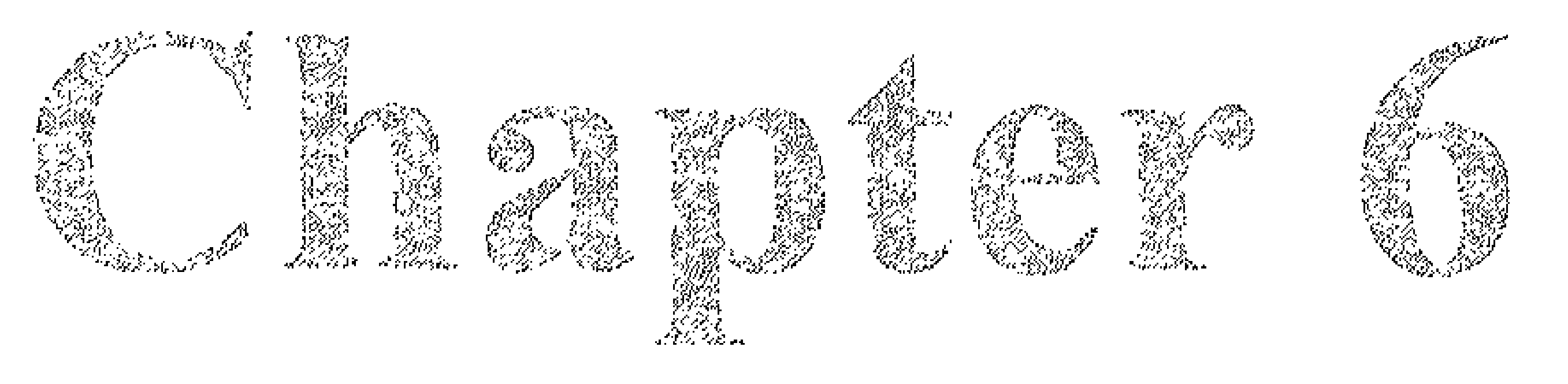

Shortage in general practice despite the
feminisation of the medical workforce:

a seeming paradox?

A cohort study

Tanja Maiorova

Fred Stevens

Jouke van der Zee

Beppie Boode

Albert Scherpbier

BMC Health Services Research, 2008, 17 (8):262 


\title{
Chapter 6
}

\begin{abstract}
Background

Female medical students often prefer primary care specialties, while male students appear to be attracted to hospital specialties. Notwithstanding the steady feminisation of medicine, in many countries there are still difficulties in recruiting trainees for general practice. This seeming paradox raises the question on what specific role gender plays in a specialty choice. The authors looked at the (a) the role of gender in general practice specialty choice of Dutch medical students, (b) the decisive factors in career choice and relation of gender to these, and (c) differences in how male and female students are influenced by the GP clerkship.
\end{abstract}

\section{Methods}

A cohort of 206 final year medical students at the Maastricht University, the Netherlands were asked to complete a questionnaire focusing on career preferences before and after a 12-week general practice clerkship and at graduation, a couple of months later.

\section{Results}

Gender was significantly related to willingness to become a GP in bivariate analysis. Adding variables in multivariate analysis made this effect disappear. While females expressed overall higher preference for general practice than males, after the GP clerkship likelihood of choosing general practice increased with $38 \%$ among male and $22 \%$ among female students. After graduation, interest in general practice had dropped, mainly among females. Attitudes predicting a GP career choice were: extrinsic career motivation before the clerkship, and the content of GP work (patient contacts, treatments) and motivation to work with chronic and palliative patients after the clerkship.

\section{Conclusions}

Gender 'as such' appeared not to be a distinctive predictor of specialty choice. It is students' attitudes towards GP work and preferred patient category that determine the career choice in general practice. However, more male students were positively influenced by the GP clerkship than female students. The motivating effect of the clerkship is not long lasting. Especially female graduates change their interest in favour of other specialties, which may explain why eventually few students choose general practice. It might be worthwhile to reinforce an initial preference for general practice by motivational guidance throughout the whole period of clerkships. 
Shortage despite the feminisation: a paradox?

\section{Background}

All over the world a steady feminisation of medicine is taking place [1-7]. Formerly male-dominated specialties are nowadays overrepresented by women [8]. In the Netherlands in $200865 \%$ of medical students were female [9]. Since 1970 the percentage of women doctors in the UK has risen by over $40 \%$ [5]. In the US in $200749 \%$ of medical students are female, compared to only $13 \%$ female medical students in $1970[10,11]$. This will have consequences for the future supply of physicians in different medical specialties, as gender is found to be one of the strongest demographic determinants of specialty choice [12]. According to a number of studies done in the UK, USA, Australia, Norway and the Netherlands, women show a strong preference for communitybased careers, whereas men tend to prefer hospital-based ones [13-17].

Gender differences in medical specialty preferences have been explained from structural as well as from individual theories [18,19]. Seen from a structural perspective, a choice for a certain medical specialty depends for an important part on the acceptance of the work environment and conditions in which the career will take place. For example, a medical student who wants to specialize in a surgical specialty and to work in a hospital must be willing to accept hierarchy and long and irregular working hours. By contrast, doctors who wish to work more autonomously and to combine a career with time for their family will not be likely to invest in specialist training which involves much absence from home and family, frequent duties and long work days. In this regard, community-based specialties provide more stable structural opportunities to work part-time without shifts.

Individual-oriented explanations of specialty choice have as their starting point that interests in and attitudes towards specialties are in themselves strongly gender-based. For example, women value patient contacts more, while men usually score higher in biomedical orientation, academic interest, prestige en (high) income expectations.

There is also evidence that men are more likely to choose technical challenge, earning potential, prestige, while women consider work conditions, part-time work and parental leave ability more important [13]. In this light, high scores on biosocial orientation and avoidance of role strain correlates positively with interest in primary care and are typical for women [20].

Steady feminisation of medicine in combination with higher preference for part-time work will influence the workforce outcome, in particular in general practice, i.e. one would expect increasing numbers of medical students entering general practice. However, a peculiar paradox is that there are still difficulties in recruiting trainees for general practice [21]. While several factors may contribute to the current and predicted physician workforce problems in primary care, it remains worldwide a fact that few graduates intend to become a general practitioner [8, 12, 22-24]. This contradiction of feminisation on the one side and few graduates choosing for general practice on the other, raises the question on how gender is related to specialty choice and what other factors contribute to a certain specialty choice. 


\section{Chapter 6}

Past research identified several factors which influence the specialty choice in general practice. For example, early interest and experience in primary care significantly influences students' intentions of pursuing general practice as a future profession $[14,25$ 28]. Medical students plan to enter general practice more frequently after having been exposed to primary care and after having done a clerkship in a general practice setting $[25,29]$. Clerkships are an important stage for students to put up their specialty preferences. In this paper we focus on the decision making process by analysing specialty preferences before and after the clerkship in general practice and investigate the role of gender in the motivation to become a general practitioner.

We sought to answer the following specific research questions:

1. What is the role of gender in GP specialty preference?

2. What are decisive factors in specialty preference and are these different for male and female students?

3. Is there a gender difference in how medical students are influenced by the GP clerkship?

\section{Method}

\section{Participants}

In 2002-2003, we surveyed students in the final year of the 6-year undergraduate medical curriculum of the University of Maastricht, the Netherlands. The clerkship in general practice (similar to family medicine in the U.S.) is compulsory and takes 12-weeks. Though the sequence of the clerkships is different for every student, the general practice clerkship always takes places in the final year.

Of the 206 registered students ( $55 \%$ women) participating in general practice clerkship, 184 students (56\% women) completed questionnaire before and after the general practice clerkship. We asked the students to complete the questionnaire during group meetings at the start and at the end of the clerkship. In total 119 students (60\% women) returned the postal questionnaire sent after graduation. Because some questionnaires were not fully completed, student's numbers in the analysis vary slightly.

\section{Instrument}

New clerkship groups start every four weeks, the whole year through, between September and June. We asked the students to complete a questionnaire during group meetings at the start and at the end of the clerkship. Researchers distributed the questionnaires before the meeting and collected them afterwards. Students' consent was asked by the physicians responsible for the organization of the clerkships. At the end of the academic 
year, the students were sent a short postal questionnaire. The questionnaire, which was primarily based on previous studies mentioned above, contained questions about personal characteristics (age, gender, parents' occupation, previous study, and work experiences), general attitude towards a future physician career, general practice in particular, and likelihood to become a general practitioner. Factor analysis (varimax rotation) and scaling techniques were used to construct attitude variables from the questions about students' attitudes towards three main categories: (a) preferred patient category and type of work, (b) preferred work conditions in the future and (c) assessment of general practice as a profession. The items (5-point Likert scales), attitude variables (composed of sum scores), and reliabilities (Cronbach's alpha) are presented in table 1.

The questionnaires at the start and at the end of the clerkship were identical. The postal questionnaire, sent after the students had qualified, contained a question on their ultimate specialty choice.

\section{Data analysis}

We performed ANOVA (using SPSS) for gender, background characteristics, students' attitudes towards, and the likelihood of becoming a general practitioner (GP) before and after the general practice clerkship. Subsequently, we used multiple regression analyses to examine which factors predicted the perceived likelihood of becoming a GP before and after the clerkship. The likelihood of becoming a GP was the dependent continuous variable; background characteristics, preferred patient categories and type of work, preferences for future work conditions, and evaluation of becoming a GP were the independent variables. To compare the longitudinal changes in likelihood of becoming a GP between the three time points, we used one-way repeated-measures ANOVA. Because of variance or low frequencies, age (23-27 years old), marital status ( $2 \%$ married), and having children $(1 \%)$ were left out of the analysis. 


\section{Chapter 6}

\begin{tabular}{|c|c|c|}
\hline Scale & Items & Alpha \\
\hline \multicolumn{3}{|l|}{ Preferred patient category and type of work: } \\
\hline - Chronically ill patients and palliative care & $\begin{array}{l}\text { Chronically ill patients } \\
\text { Geriatric patients } \\
\text { Palliative care } \\
\text { Long-term contacts with patients }\end{array}$ & .72 \\
\hline - Acute patients and technology-orientated work & $\begin{array}{l}\text { Technical activities } \\
\text { Highly specialised work } \\
\text { Availability of personnel and equipment } \\
\text { Emergency care } \\
\text { Acute patients }\end{array}$ & .75 \\
\hline \multicolumn{3}{|l|}{ Preferred work conditions } \\
\hline - Prestige orientation & $\begin{array}{l}\text { Income } \\
\text { Career opportunities } \\
\text { High status }\end{array}$ & .70 \\
\hline - Controllable lifestyle & $\begin{array}{l}\text { Part-time work } \\
\text { Regular working hours } \\
\text { Leisure time }\end{array}$ & .76 \\
\hline \multicolumn{3}{|l|}{ Assessment of work in general practice } \\
\hline - Work intrinsic factors & $\begin{array}{l}\text { Variety of patients and disorders } \\
\text { Contacts with family of patients } \\
\text { Individual treatments } \\
\text { Variety of work } \\
\text { Collaboration and communication with col- } \\
\text { leagues }\end{array}$ & .68 \\
\hline - Work extrinsic factors & $\begin{array}{l}\text { High status } \\
\text { Income }\end{array}$ & .63 \\
\hline & Career opportunities & \\
\hline - Work conditions & $\begin{array}{l}\text { Working hours } \\
\text { Work load }\end{array}$ & .81 \\
\hline
\end{tabular}

Table 1. Scales, items and reliabilities (alpha) concerning attitudes towards medicine and general practice in particular from medical students of the Maastricht University in 2002/03. N=175. 


\section{Results}

\section{Gender and determinants of career choice}

Attitude variables related to career choice are differently related to gender (table 2). Female students were more likely to have considered an allied profession and to have work experience in patient care before studying medicine. Having participated in another health professions educational program did not differ for male and female students. Females were more attracted to work with chronic patients, palliative care and controllable lifestyle. Male students were more inclined to technology-oriented work, acute patients and prestige. Intrinsic aspects of a GP job were valued higher by women before the clerkship and were valued the same by men and women after the clerkship.

\begin{tabular}{llllllll}
\hline & \multicolumn{2}{l}{ Before the clerkship } & \multicolumn{4}{c}{ After the clerkship } \\
\cline { 2 - 7 } & \multicolumn{2}{c}{ Mean (SD) } & P value & \multicolumn{2}{c}{ Mean (SD) } & P value \\
& Male & Female & & Male & Female & \\
\hline $\begin{array}{l}\text { Likelihood to become a GP } \\
(1=\text { not likely, 5= highly likely) }\end{array}$ & $2.4(.7)$ & $2.9(.9)$ & .00 & $2.7(.9)$ & $3.1(1.1)$ & .003 \\
\hline
\end{tabular}

Background characteristics $(0=$ no, $1=$ yes $)$

\begin{tabular}{lccc}
\hline Work experience in patient care & $.3(.4)$ & $.6(.4)$ & .00 \\
Other health care education & $.3(.4)$ & $.4(.4)$ & .084 \\
Having considered allied profession & $.1(.3)$ & $.3(.4)$ & .001 \\
\hline
\end{tabular}

Preferred patients category and type of work ( $1=$ not interested, $5=$ interested $)$

\begin{tabular}{lllllll}
\hline Chronic patients and palliative care & $3(.7)$ & $3.5(.6)$ & .003 & $3(.7)$ & $3.5(.6)$ & .00 \\
$\begin{array}{l}\text { Acute patient care and technology- } \\
\text { oriented work }\end{array}$ & $4(.6)$ & $3.6(.6)$ & .001 & $4.2(.6)$ & $3.8(.6)$ & .002 \\
\hline
\end{tabular}

Preferred work conditions ( $1=$ not important, $5=$ important $)$

\begin{tabular}{lcccccc}
\hline Prestige orientation & $2.65(.8)$ & $2.15(.8)$ & .00 & $2.9(.7)$ & $2.45(.8)$ & .00 \\
Controllable lifestyle orientation & $2.95(.9)$ & $3.4(.8)$ & .001 & $2.85(.9)$ & $3.5(.8)$ & .00 \\
\hline Assessment of becoming a general practitioner (I= not attractive, $5=$ attractive) & & & \\
\hline Work intrinsic & $3.8(.6)$ & $4(.5)$ & .00 & $3.8(.6)$ & $3.8(.6)$ & .125 \\
Work extrinsic & $2.6(.6)$ & $2.6(.5)$ & .399 & $3(.6)$ & $3(.6)$ & .453 \\
Work conditions & $3.2(.8)$ & $3.3(.8)$ & .618 & $3.5(.9)$ & $3.5(.8)$ & .586 \\
\hline
\end{tabular}

Table 2. Bivariate relationships between background characteristics, attitudes towards future work and general practice (mean score) and gender of medical students of the Maastricht University in 2002/03. ANOVA was performed. $\mathrm{P}$ - values are two-sided. $\mathrm{N}=175$. 


\section{Chapter 6}

\section{Determinants of preference for general practice}

Before and after the clerkship female gender was positively associated with a preference for general practice as a career (Table 3 ). This effect disappeared, however, when other independent variables were added to the regression analysis.

Before the clerkship, having considered an allied profession and having studied for another healthcare occupation were both positively related to a preference for general practice, as were positive attitudes towards the extrinsic job characteristics of general practice, such as status, income, and career opportunities. The preference of becoming a GP was lower among the students who had interest in acute patients and who were drawn to the technological aspects of medicine.

\begin{tabular}{lllll}
\hline & Before clerkship & \multicolumn{2}{l}{ After clerkship } \\
\hline Independent variables & Model 1 & Model 2 & Model 1 & Model 2 \\
\hline Gender & $.314^{* *}$ & .069 & $.222^{* *}$ & -.060 \\
\hline Background characteristics & & & \\
\hline $\begin{array}{l}\text { Having considered allied profes- } \\
\text { sion }\end{array}$ & $.189^{* *}$ & & .066 \\
Physician parent & & & .074 \\
Work experience in patient care & -.063 & & -.007 \\
Other health care education & .033 & & .074 \\
\hline
\end{tabular}

\section{Preferred patients category and type of work}

\begin{tabular}{lll}
\hline $\begin{array}{l}\text { Chronically ill patients and pal- } \\
\text { liative care }\end{array}$ & .025 & $.148^{*}$ \\
$\begin{array}{l}\text { Acute patients and technology- } \\
\text { oriented work }\end{array}$ & $-.184^{*}$ & $-.260^{* *}$ \\
\hline Preferred work conditions & & \\
\hline Prestige orientation & -.114 & $-.155^{*}$ \\
Controllable lifestyle orientation & .087 & .100 \\
\hline & & \\
Assessment of becoming a general practitioner & & $.310^{* *}$ \\
\hline Work intrinsic & .121 & .077 \\
Work extrinsic & $.201^{* *}$ & .115 \\
Work conditions & .018 & .458 \\
\hline Adjusted $\mathrm{R}^{2}$ & .405 & .043 \\
\hline
\end{tabular}

Table 3. Multiple Regression Analysis. The dependent variable is the likelihood of becoming a general practitioner before and after the general practice clerkship among medical students of the Maastricht University in 2002/03. Independent variable values are standardized Beta. $N=175$, $^{* *} \mathrm{p}<0.01 ;{ }^{*} \mathrm{p}<.05$. 
Comparing the predictors of general practice preference before and after the clerkships shows that a positive assessment of the extrinsic aspects of general practice was not related to a higher likelihood to become a GP afterwards. After the clerkship, motivation to work with chronically ill and palliative patients and positive assessment of the intrinsic aspects of general practice (treatments, contact with patients, and variety of work) became significant predictors of a higher likelihood of becoming a GP.

\section{Preference for general practice}

The likelihood of pursuing a career in general practice before and after the clerkship and at graduation is represented on figure 1. After the clerkship, the overall preference for specialisation in general practice had risen among male and female students. The likelihood to become a GP increased among a higher percentage of male than female students ( $38 \%$ versus $22 \%$; chi-square $=6.5, \mathrm{p}<0.05$ ) although female students expressed a higher preference for general practice. By the time of graduation this preference had decreased again in both male and female students. One-way repeated-measures ANOVA was used to compare the mean scores before and after the GP clerkship and after the graduation separately for male and female students. Males $F=1.18, p=0.92$; females $F=9.42, p<$ 0.01 . Remarkably, the overall likelihood of female graduates to become a GP became even lower than that of male graduates.

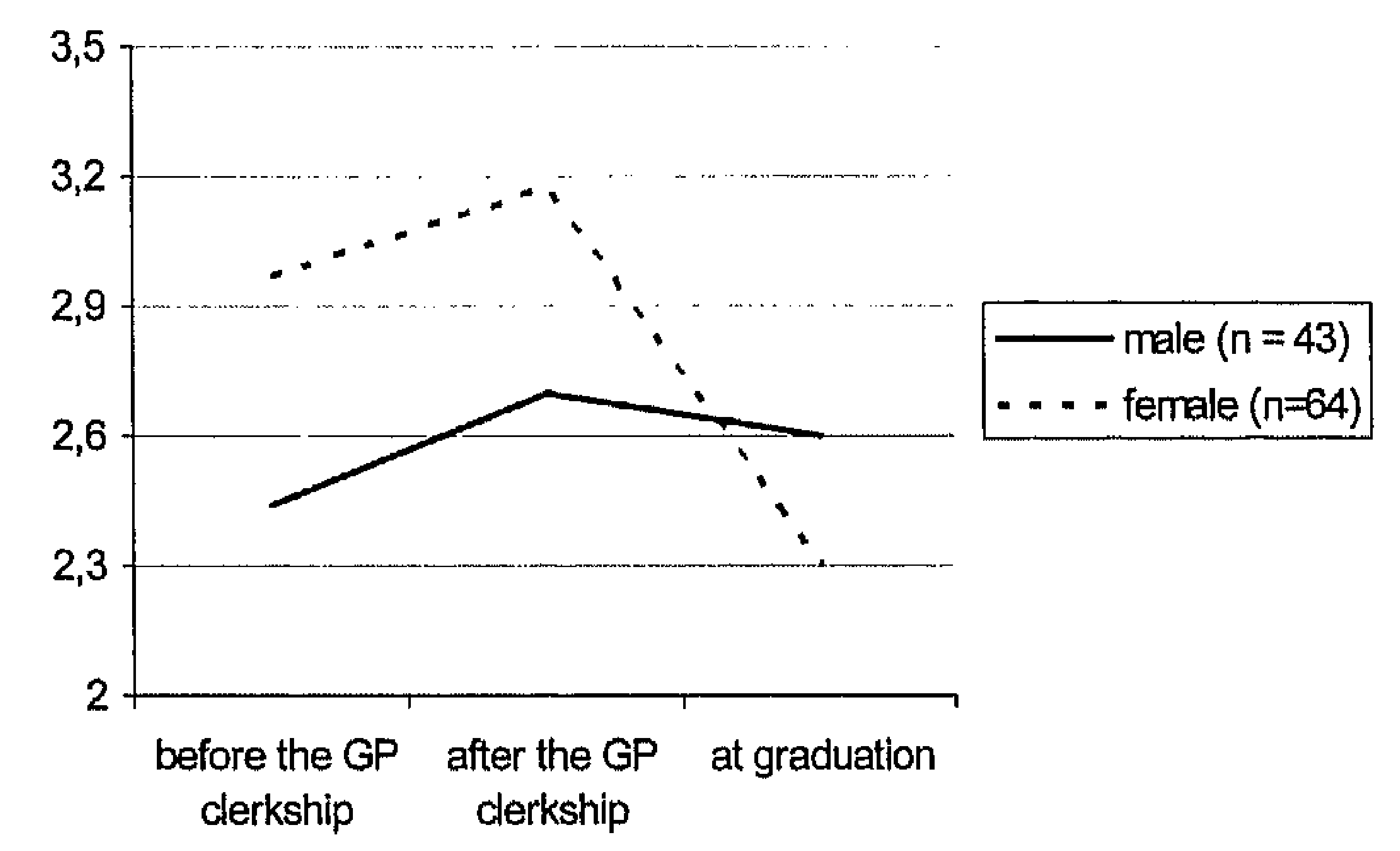

Figure 1. Mean score of the likelihood of becoming a GP before and after a GP clerkship and after the graduation of medical students of The Maastricht University in 2002/03. The mean score scale from $1=$ unlikely to $5=$ highly likely, $\mathrm{N}=107$. 


\section{Chapter 6}

\section{Discussion}

We investigated the effects of gender and a number of other factors on the perceived likelihood of planning a GP career before and after the clerkship in general practice. Previous studies have shown that gender is an important determinant of a specialty choice in general practice. In our multivariate analyses, however, we found that the relationship between gender and students' preferences did not hold after we included attitudinal variables. This raises the intriguing question of what the gender effect stands for. On the basis of the findings, we suggest that gender differences in selecting general practice as a specialty is not a clear-cut male-female distinction but instead reflects a combination of a number of factors, such as having a broader view of medicine, preferred type of work and patients and content of work. Regarding gender differences in medical specialty choices, two explanations were offered in the literature: individual and structural theory [7]. The question is how our findings fit into these theories.

The individual-oriented approach describes gender differences in terms of individual, gender-related interests and specialty preferences. In this study, interest in the content of work in general practice, measured by work-intrinsic factors such as kind of treatments, long term patient contacts, and variety of work, is the crucial factor when considering a career in this field. The finding that stimulation of students' interest in the type of problems faced in a certain specialty is the strongest motivational factor of the specialty choice, concurs with previous research [30]. It is important to note, however, that in our study the initial difference between male and female students in the assessment of work content in general practice has disappeared after the clerkship.

Our results further suggested that men were more interested in the technological and aspects of medicine and acute patients, whereas women were more interested in palliative care and chronically ill patients.

Although men and women had diverse primary interests in type of work and patients, this difference did not play an important role in the GP specialty preference. Similar conclusions were drawn from another study, where male and female residents were attracted to a particular specialty for similar reasons [24]. For both men and women an interest in the technological aspects of medicine and in acute patients was a particular negative predictor of a GP career preference. After the clerkship, an interest in working with chronically ill and palliative patients was a significant positive predictor of a becoming a GP. These findings are in line with previous research showing that generalists point out patient relationships as an important reason for selecting their specialty [31] [24]. We conclude from this that the inner interest in the GP specialty does not discriminate between male and female students, and hence, the individualistic theory can only to some extent give an explanation of the backgrounds of the specialty choice in general practice.

The structural approach attempts to explain the gender difference in the light of work conditions and societal context. The disappearance of the impact of extrinsic factors 
(status, income, and career opportunities) after the clerkship in favour of work-intrinsic factors underscores the importance of inner interest in the GP specialty. Assessment of work conditions (work load and hours) in general practice did not predict the likelihood to become a GP either. Additionally, despite our expectations based on previous studies, controllable lifestyle options did not relate to a GP specialty preference.

The fact that individualistic theory only partially explains the difference between male and female students in our study, and that structural approach did not substantiate the results, asks for additional explanations [18,32]. First, these theories were applied some time ago and the interests of a new generation of male and female students may have become more alike. Students seem to identify more with the values of the preferred specialties rather than with values of the same gender [33]. In recent years women became more interested in traditionally "male' specialties, such as surgery $[18,34,35]$. Furthermore, our results show that although women are more inclined to enter general practice, a higher percentage of male than female students was motivated by the clerkship to become a GP. In other words, the preferences of men and women are likely to converge. Another finding is that medical students ground their initial choices on the content of a subject matter. At the undergraduate stage work conditions seem less important to them. Probably, the question of a balance between work and private life is a question of later concern. There is evidence from earlier research that women were initially as likely as men to start a career in surgery and internal medicine [18]. However, later on, a high proportion of women did not complete their training because of difficulties of combining work and child care. They switched to other specialties. Our conclusion is that lifestyle options become more important on the later stage. This finding is not inconsistent with results of previous research where medical graduates have increasing preference for specialties with controllable lifestyle [35]. This could be due to the differences in the medical undergraduate education in U.S. and The Netherlands.

With regard to other factors affecting the choice for general practice, we found that having studied another, medicine related discipline had a positive predictive value. We surmise that these students have been able to develop a broader view on medicine and, therefore, are more likely to opt for a GP career. Students with "broad-based" undergraduate preparation frequently chose specialties with many doctor-patient interactions [36]. Thus, a broader view of medicine and health care, whether gained from earlier work experience or from studies other than medicine, increases the likelihood that a student will follow a career in general practice.

In this study, the factors we have explored seem to offer only a partial explanation for the perceived likelihood of becoming a general practitioner. Possible other determinants such as personality characteristics and social background may be included in future research.

We started this article with describing the paradox of the increasing influx of women and new generations of physicians in medicine on one hand, and the difficulties to re- 


\section{Chapter 6}

cruit sufficient trainees for general practice on the other. Our study showed that men and women do not differ substantially in their interest in general practice. Flexible work conditions, which are mainly the preference of women, are not important at the undergraduate stage when initial specialty preferences are shaped. Hence, an increasing share of female students would not directly lead to the increase in the popularity of general practice.

The question, however, is what happens to all the potential trainees for general practice at graduation? Our results show that the positive effect of the clerkship was not long lasting, and relatively few students persisted in their initial plan to become a general practitioner after they had graduated. At graduation the interest in general practice had dramatically fallen amongst female students and became even lower than among male students. This drop may partly explain the inconsistency between the expectations of increasing interest in general practice care and low popularity of this specialty. Zinn and colleagues, in their study of students' primary care orientation, noted a decline in primary care interest among medical students between the fourth year and the residency [37]. Residents placed more value on technical aspects and had less interest in psychosocial issues. It might be that the positive experience during the clerkship in general practice is overshadowed by experiences from other clerkships in the final year. However, this explanation should be used cautiously, as the study did not show any relation between clerkships sequence and preference for general practice. While male graduates hold almost the same likelihood to become a GP, women seemed to favour other alternative specialties. In other words, it looks as if men are more firm in their GP decision than women, who might first want to try a hospital career.

Based on our findings, we suggest some implications for the practice. In order to stimulate students to choose general practice as a specialty, emphasis should be placed on the attractiveness of the content of work and type of patients in general practice. Other factors like working conditions and lifestyle considerations are less salient in shaping specialty preferences of undergraduate students.

Furthermore, seeing that the increased interest of students in general practice after the clerkship rotation was found to have diminished at graduation particularly among women, it seems advisable to take measures to sustain students' interest in general practice also after the clerkship, for instance by offering them experiences in general practice throughout the clinical phase of the curriculum until graduation. To support our findings, a similar survey could be replicated across more than one cohort of students. 


\section{Conclusion}

Predominantly individual interest in the content of GP work and preferred type of patients to work with determine the specialty choice in general practice, regardless of gender. Gender 'as such' appeared not to be a predictor of career choice. Male and female interests in medical specialty choice tend to converge. Work conditions do not play a role in the specialty preference at the undergraduate stage. Even though more females prefer to become a GP, males are influenced more by the clerkship than female students. However, the motivating effect of the clerkship is not long lasting. Mainly female graduates change their interest in favour of other specialties. This might explain why in spite of the rising number of female medical students general practice is still not a popular career choice among students. It might be worthwhile to reinforce an initial preference for general practice by motivational guidance throughout the whole period of clerkships. There is more longitudinal research needed to explore why students abandon the option to become a GP and what are the factors which play role in the definitive specialty choice of medical graduates. 


\section{Chapter 6}

\section{References}

1. Denekens J: The impact of feminisation on general practice. Acta Clinica Belgica 2002, 57(1):510.

2. Lawrence J, Poole P, Diener S: Critical factors in career decision making for women medical graduates. Medical Education 2003, 37(4):319-327.

3. Levinson W, Lurie N: When most doctors are women: what lies ahead? Annals of internal medicine 2004, 141(6):471-474.

4. McKinstry B, Colthart I, Eliott K, Hunter C: The feminization of the medical work force, implications for Scottish primary care: a survey of Scottish general practitioners. BMC Health Services Research 2006, 6:56.

5. Fysh T, Thomas G, Ellis H: Who wants to be a surgeon? A study of 300 first year medical students. BMC Medical Education 2007, 7:2.

6. Riska E: Towards gender balance: but will women physicians have an impact on medicine? Social Science and Medicine 2000, 52(2):179-187.

7. Gjerberg E: Medical women - towards full integration? An analysis of the specialty choices made by two cohorts of Norwegian doctors. Social Science and Medicine 2001, 52:331-343.

8. Lambert T, Michael J, Turner G: Career choices of United Kingdom medical graduates of 2002: questionnaire survey. Medical Education 2006, 40:514-521.

9. Cenraal Bureau voor de Statistiek: Hoger onderwijs, ingeschrevenen naar studierichting en leeftijd. www.cbs.nl 2008.

10. Barzansky B, Etzel SI: Medical schools in the United States, 2006-2007. JAMA 2007, 298(9):1071-1077.

11. American Medical Association. Women in Medicine in America: In the Mainstream. In Volume 12. Chicago, Ill: American Medical Association; 1995.

12. Buddeberg-Fischer B, Klaghofer R, Abel T, Buddeberg C: Swiss residents' specialty choices impact of gender, personality traits, career motivation and life goals. BMC Health Services Research 2006, 6:137.

13. Baxter N, Cohen R, McLeod R: The impact of gender on the choice of surgery as a career. American Journal of Surgery 1996, 172:373-376.

14. Howe A, Ives G: Does community-based experience alter career preference? New evidence from a prospective longitudinal cohort study of undergraduate medical students. Medical Education 2001, 35:391-397.

15. Du Moulin M, Heymans R, Noordenbos G: Gender factors in the selection of training for a medical specialty. Nederlands Tijdschrift voor Geneeskunde 2000, 144:129-133.

16. Alison M, Kamien M, Lopez D: Medical career choice and practice location: early factors predicting course completion, career choice and practice location. Medical Education 2004, 38:239-248.

17. Linzer M, Slavin T, Mutha S, Takayama J, Branda L, VanEyck S, McMurray J, HK R: Admission, recruitment, and retention: finding and keeping the generalist-oriented student. SGIM Task Force on Career Choice in Primary Care and Internal Medicine. Joumal of General Internal Medicine 1994, 9:14-23.

18. Gjerberg E: Gender similarities in doctors' preferences--and gender differences in final specialisation. Social Science and Medicine 2002, 54(4):591-605.

19. Bland C, Meurer L, Maldonado G: Deteminants of primary care specialty choice: a non-statistical meta-analysis of the literature. Academic Medicine 1995, 70:620-641.

20. Murdoch M, Kressin N, Fortier L, Giuffre P, Oswald L: Evaluating the psychometric properties of a scale to measure medical students' career-related values. Academic Medicine 2001, 76: 157-165.

21. Schroeder S: Training an appropriate mix of physicians to meet the nation's needs. Academic Medicine 1993, 68(2):118-122. 
22. Schafer S, Shore W, French L, Tovar J, Hughes S, Hearst N: Rejecting family practice: why medical students switch to other specialties. Family Medicine 2000, 32(5):320-325.

23. Hays R: Choosing a career in general practice: the influence of medical schools. Medical Education 1993, 27:254-259.

24. Garibaldi R, Popkave C, Bylsma W: Career plans for trainees in internal medicine residency programs. Academic Medicine 2005, 80(5):507-512.

25. Kassebaum D, Szenas P, Schuchert M: Determinants of the generalist care intentions of 1995 graduating medical students. Academic Medicine 1996, 71:198-209.

26. Campos-Outcalt D, Senf J, Watkins A, Bastacky S: The effects of medical school curricula, faculty role models, and biomedical research support on choice of generalist physician careers: a review and quality assessment of the literature. Academic Medicine 1995, 70:611-619.

27. Xu G, Hojat $M$, Brigham T, Veloski J: Factors associated with changing levels of interest in primary care during medical school. Academic Medicine 1999, 74:1011-1015.

28. Schwartz M, Linzer M, Babbott D, Divine G, Broadhead E: Medical student interest in internal medicine. Initial report of the Society of General Intemal Medicine Interest Group Survey on Factors Influencing Career Choice in Internal Medicine. Annals of Internal Medicine 1991, 114:6-15.

29. Saigal $P$, Takemura $Y$, Nishiue $T$, Fetters $M$ : Factors considered by medical students when formulating their specialty preference in Japan: findings from a qualitative study. BMC Medical Education 2007, 7:31.

30. Williams S, Saizow R, Ross L, Deci E: Motivation underlying career choice for internal medicine and surgery. Social Science and Medicine 1997, 45(11):1705-1713.

31. Senf J, Kutob R, Campus-Oscalt D: Which primary care specialty? Factors that relate to a choice of family medicine, internal medicine, combined internal medicine-pediatrics. Family Medicine 2004, 36:123-130.

32. Stilwell N, Wallick M, Thal S, Burleson J: Myers-Briggs type and medical specialty choice: a new look at an old question. Teaching and Learning in Medicine 2000, 12(1):14-20.

33. Ellsbury $\mathrm{K}$, Carline J, Irby D, Stritter F: Influence of third-year clerkships on medical student specialty preferences. Advances in health science education 1998, 3:177-186.

34. Maiorova T, Stevens F, Scherpbier A, van der Zee J: The impact of clerkships on students' specialty preferences: what do graduates learn for their profession? Medical Education 2008, 42(6):554-562.

35. Lambert $\mathrm{E}$, Holmboe $\mathrm{E}$ : The relationship between specialty choice and gender of U.S. medical students, 1990-2003. Academic Medicine 2005, 80(9):797-802.

36. Koenig J: Comparison of medical school performances and career plans of students with broad and with science-focused premedical preparation. Academic Medicine 1992, 67:191-196.

37. Zinn W, Sullivan A, Zotov N, Peters A, Connelly M, Singer J, Block S: The effect of medical education on primary care orientation: results of two national surveys of students' and residents' perspectives. Academic Medicine 2001, 76:355-365. 


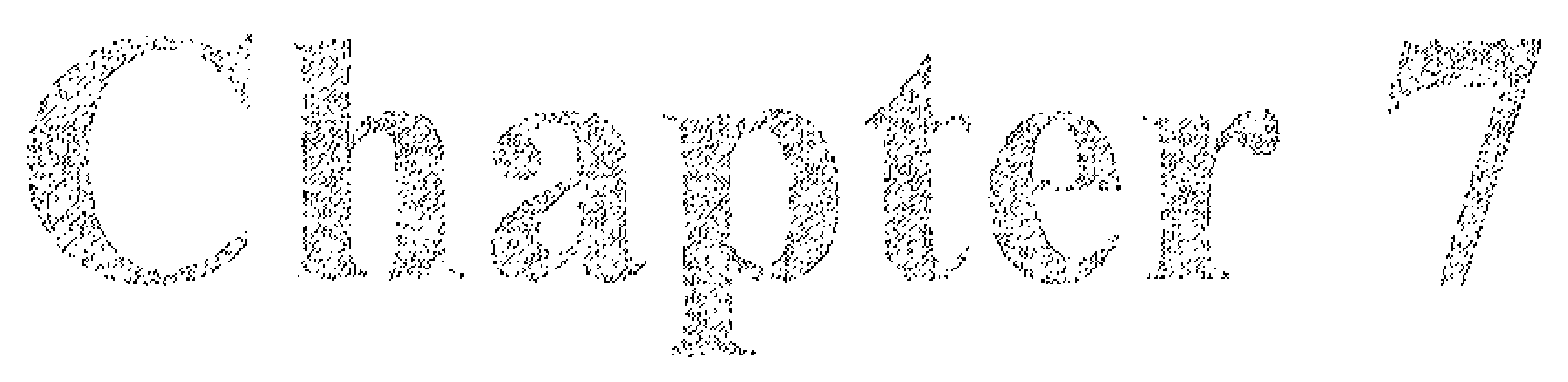

Main findings and discussion 
Chapter 7

In this thesis we have pictured practice preferences of newly graduated GPs and the potential speciality preferences of medical students. Insight into these issues is helpful in ensuring a balanced workforce in general practice. Feminisation of the medical profession, societal changes (such as the ageing of the population and the more egalitarian doctor-patient relationships) and the changing image of general practice as a profession may influence the preferences of newly graduated GPs and the attractiveness of general practice as a career for medical students. The effects of gender on the culture, practice and organisation of medicine are considered important issues [1]. In this chapter we describe the main findings of this thesis and discuss the implications for policies regarding general practice, the medical curriculum, and further research.

The three main research questions were:

1. What kinds of work arrangements do newly graduated GPs prefer and were they able to realise their preferences in the past 25 years? How do these preferences differ for men and women?

2. Does the undergraduate medical curriculum relate students' decisions to pursue a career in general practice?

3. What are the decisive factors in medical students' career choices, and what is the role of gender in decision-making regarding future specialisation?

To answer these questions two studies were conducted. They will be described briefly in the following sections. Gender has been the main subject throughout our study, and therefore we compared male and female career preferences and career paths. We started with a study on preferred work arrangements of GPs, using longitudinal data of all GPs in the Netherlands, graduated after 1980 . Next, we investigated how the decision to enter postgraduate training in general practice was related to the undergraduate medical curriculum and whether there were differences in this regard between the eight Dutch faculties of medicine. Finally, we studied the career preferences of medical students at Maastricht University during the clerkship period.

Research question 1: What kinds of work arrangements do newly graduated GPs prefer and were they able to realise their preferences in the past 25 years? How do these preferences differ for men and women?

We conducted two studies to examine the work preferences of young GPs and whether they succeeded in realising them. In Chapter 3 the development of different preferences in male and female GPs is described. In Chapter 4 we addressed the question to what extent male and female GPs were able to realise their preferences in the past 25 years. 
Main findings and discussion

\section{Preferences of recently graduated GPs looking for a practice}

- The differences between male and female preferences regarding future practice settings have diminished over the years. Although male practitioners still have a stronger preference for solo practice compared to female practitioners, both male and female GPs now prefer partnerships [2] [3]. Preference for solo practice has almost disappeared.

- Principal positions in a group practice are equally favoured by male and female GPs. Women show a stronger preference for non-principal positions compared to men and the proportion of both male and female GPs in such positions has increased.

- Gender differences regarding preferred practice size did not change in the past 20 years. Women prefer smaller practices than do men. Preferences for practice size was not related to type of practice (solo or group practice). As more women become GPs the demand for small group practices is likely to grow.

- Female GPs show a stronger preference to associate with another GP than for taking over an established practice. This suggests that women favour sharing responsibilities in organizing and managing a practice rather than being in charge. In recent years this trend is also observed among male GPs.

Since the number of female GPs is increasing and preferences of male GPs are changing, we can expect a stronger preference for partnerships, for non-principal positions, for smaller practices and an increased share of associations of general practitioners within a practice in the coming years. There are several possible explanations for there developments. First, the increasing proportion of female GPs highlights different attitudes to work. Women are, more than men, motivated to work together and to share responsibilities. Searle noted: "women want to share power, to break down some of the individualism and move to collectivism" [4].

Another explanation is the increasing preference for working part time and flexible work hours. A part-time job and flexibility are easier to realise when sharing responsibility with colleagues. As still more women are entering general practice, there will also be more demand for flexible working hours to be able to combine work and private life. However, not only women are responsible for this development $[5,6]$. While the majority of female medical specialists wish to work part time (79\%), more than $40 \%$ of men has the same preference [7] [8]. In general practice, the proportion of men working part time increased from $20 \%$ in 1997 to $43 \%$ in $2007[9,10]$. Because of female participation in the labour market, the positions of men and women have become more egalitarian, at least in Western European countries and the US. As Gray notes: "Women today are so tired and stressed, they too want a happy wife to greet them at home" [11]. Household responsibilities are no longer the exclusive domain of women and the division of child care tasks between men and women is changing in the Netherlands [8]. Men are also becoming involved in family care and want to work fewer hours [12]. 


\section{Chapter 7}

Household tasks take time and effort and are not easy to combine with long working hours. This could be a reason why men tended to increasingly fancy part-time work for themselves in recent years. In other words, the male career focus has become more susceptible to domestic factors [8]. As Vaughn said, "Women have always fitted their work into their lives, and an increasing number of men are attracted by this option" [13].

The change in male and female roles involves a gender identity question, which has become an issue in recent years. The stereotypes of typical male and female physicians' orientations towards job arrangements have changed. Even though men and women still have different values, the attitude gap has narrowed.

We expect that group practices will continue to be the most favoured practice setting and that male and female preference for this type of practice will continue to converge.

With the increasing preference for group practices and non-principal positions, the next question is whether young GPs manage to realise their preferences. To answer this question we examined how the initial preferences of young GPs at the start of their professional career were related to the type of practice in which they ended up eventually.

\section{Realisation of general practice preferences}

- Male GPs were more often successful in finding positions in solo practice, and female GPs were more successful in joining a group practice, regardless of their original practice preference. This was also the case for GPs without a specific preference for a practice type.

- Through the years those who were looking for a non-principal position were increasingly successful in finding a place that matched their preference.

- Over the years an increasing proportion of GPs, both male and female, was able to fulfil their preference for working in a group practice, and more men joined group practices, even if they initially preferred solo practice.

Thus, most GPs were able to realise their preferences. This was possible because apparently the number of vacancies in group practices increased together with the number of GPs seeking such a position. This is probably due to the fact that many former solo practices of retiring GPs were turned into partnerships to meet the current demand. In this light, a workforce crisis seems unlikely as changing preferences in favour of group practice were combined with greater availability of such practices.

\section{General practitioners who left the profession}

In spite of the fact that most GPs succeeded in finding a practice, there is a number of GPs who did not find a place and left the profession altogether. The proportion of GPs who did so was rather high in the 1980s but has decreased steadily over the years. This suggests that it has become easier for GPs to find a practice to match their preferences in the recent years. However, a rather small group of GPs without a specific practice 
preference continued to show the same drop-out rates over the years. This contradicts the assumption that GPs without specific preferences are more flexible in finding a position. On the contrary, this group appears to be more easily inclined to leave the profession.

The reason for leaving general practice most frequently reported by men and women was being unable to find a practice according to their preference. This indicates that a mismatch between preferences and available positions is at the root of the loss of qualified GPs. Financial reasons and accepting another interesting job were also important grounds for men to leave general practice. Women mentioned limitations due to family circumstances as an important second reason. This finding is consistent with results from previous research that out of hours commitments and difficulties of combining work and family were important factors for not practising as a principal in favour of locum work. Men are probably more strongly influenced by varying circumstances than are women, and women are more strongly influenced by family-related considerations. Surprisingly, a number of GPs, slightly more women than men, never seriously considered working as a GP. They probably started general practice vocational training because of a lack of better alternatives after graduating from medical school.

Research question 2: Does the undergraduate medical curriculum relate to students' decisions to pursue a career in general practice?

A link between the undergraduate curriculum and students' career choices was explored in previous studies. Educational centres in the USA are encouraged to produce more primary care physicians in order to lower the costs of health care [14]. The medical curriculum is believed to offer opportunities for manipulating the career choices of medical students [15].

We first explored to what degree the departments of general practice of the eight Dutch faculties of medicine contributed to the teaching of knowledge and skills in the undergraduate medical curriculum of their university. This was assessed by means of a questionnaire study among undergraduate education coordinators of the eight departments of general practice. Based on the results, we ranked the eight faculties of medicine in order of the degree of general practice orientation in their undergraduate curriculum. Next, we examined whether these results were related to (1) the percentages of graduates entering postgraduate training in general practice and (2) general practice trainees who successfully finished postgraduate training.

The departments of general practice of the universities of Maastricht and Nijmegen, and the University of Amsterdam showed the highest contribution to the undergraduate curriculum and were therefore ranked as the most general practice oriented curricula.

We found only a small positive relationship between the degree of the general practice involvement in the curriculum and the proportion of graduates entering general practice 


\section{Chapter 7}

training in the cohorts of the early 1990s. The highest ranking universities historically had a strong primary care mission. The curriculum may have had a stronger influence on career choices in the past. The way we ranked the universities in 2008 may reflect the previous primary care orientation.

We did not find a correlation between the degree of general practice orientation of the undergraduate curriculum and the percentage of students successfully completing postgraduate training in general practice. We assume that the postgraduate training programme and personal considerations are responsible for students dropping out of the training programme.

Similar to other studies, our study also showed that a high proportion of students entering general practice had graduated from universities situated in less urbanized areas. These faculties also organize their curriculum according to the principles of problembased learning (student-centred system). Possibly, this student-centred approach to education has a positive effect on a career choice in general practice [16]. There is evidence from previous research that students from these kinds of schools are more interested in community medicine, and often have a more holistic approach to patients than students from traditional curricula [17-19]. They also have better communication skills and stronger ability to work autonomously [20]. However, there is no straightforward relationship between student-centeredness and career choice. There may be an effect of self-selection, with students who are attracted to primary care also being earlier inclined to opt for a problem-based learning educational system [15].

In summary, we were unable to confirm the results of previous studies into the relationship between primary care oriented curricula and the percentage of students entering general practice. Obviously there are other decisive factors which play a major role in students' career choices, such as personal preferences, role models and other clinical experiences. Although curricula differ in the degree of general practice orientation, it could be merely a reflection of previous primary care mission. There is no evidence of a relationship with students' current career choices in general practice.

\section{Research question 3: What are the decisive factors in medical students' career choices, and what is the role of gender in decision-making regarding future speciali- sation?}

The decisive factors in students' career preferences and the role of gender in particular were investigated by surveying students before and after their clerkship rotations in surgery, internal medicine and general practice at Maastricht University. The cohort of students involved in the general practice clerkship was also asked about their final career choice at graduation. Two different questions were posed: one about their future speciality preference and one about the likelihood of their becoming a surgeon, internist or GP after they had completed the clerkship in that particular speciality. Attention was paid to any differences between men and women in career preferences. 
Clerkships are described in the literature as having a motivating effect on students' career choice in favour of the corresponding speciality. The overall outcome from our study that students become motivated by their clinical experiences during clerkships is in line with the international literature [21-23]. After the rotations in surgery, internal medicine and general practice there was an overall increase in preference for the speciality of that rotation. In all three clerkships about half of the students had not changed their initial preference after the clerkship. Thus, for half of the students clerkships confirm their ideas about a speciality.

For general practice the motivating effect did not last long, however. After several months around the graduation the likelihood of choosing general practice had decreased, mainly among the female students. Men appear to adhere to their decision more firmly than women, who are more likely to change their minds. In the introduction to this thesis, we referred to the paradox of the increasing proportion of female medical students one the one hand and the absence of increasing popularity of general practice on the other hand. This drop in interest in a general practice career mainly among female students may partly explain this paradox.

\section{Decisive factors in career choices}

We explored the decisive factors in choosing a certain speciality before and after the clerkship. These factors were divided into three main categories: preferred type of patients (chronically ill and palliative care, acute patients and technology-oriented work), preferred work conditions (prestige oriented, controllable lifestyle oriented) and appraisal of being a surgeon, internist or a general practitioner (intrinsic work-related factors, extrinsic factors not related to work and working conditions). For general practice the influence of personal characteristics was also explored.

The distribution of speciality preferences followed the traditional pattern. Male students were more inclined to prefer a surgical speciality and women favoured general practice. Internal medicine was equally preferred by male and female students. Nevertheless, gender in itself was not a significant predictor of the perceived likelihood of becoming a $\mathrm{GP}$, internist or a surgeon. In bivariate analyses gender was positively related to career choice before and after the clerkships. However, when other attitudinal factors (such a personal characteristics and attitudes towards future work) were added to the analyses, the direct effect of gender disappeared. As gender 'in itself' appeared not to play a role in career preferences, the question is which factors do play a role and to what extent are these gender related. In the literature two theories are proposed to explain gender differences in career choices [24]. The individual theory emphasises individual differences between men and women in the nature of their choices. The structural theory explains the difference in choices from the position of different work circumstances preferred by men and women. 


\section{Chapter 7}

In all three clerkships, a positive evaluation of the intrinsic aspects of a speciality (content of work, such as type of patients and disorders to deal with, treatments, variety of work et cetera) was a strong predictor of a career preference for the corresponding speciality. Male and female students were equally interested in the intrinsic aspects of general practice but this effect only occurred after the clerkship. This might indicate that students did not have a clear idea of what general practice might entail before the clerkship. During the clerkships, students discover new interesting aspects of this subject. It seems that during the undergraduate curriculum students focus mainly on diseases and see the GP as someone who refers the more interesting cases to a specialist in the hospital. Many students may not know that only $6 \%$ of patients are referred and that the other patients are treated by the GP.

Willingness to work with patients with chronic illnesses and those in need of palliative care was positively related to a career preference for general practice and negatively related to a surgical career. Those who like technical procedures and attach great importance to their prestige as a doctor were less likely to choose general practice and had a higher likelihood of becoming a surgeon. Apparently, students who prefer a surgical career have opposite preferences in patient care to those who prefer a career in general practice. This is in line with previous research showing that GPs mention relations with patients as the most important reason for having selected their speciality [25].

Attitudes towards medicine and general practice were different for men and women. Female students were more attracted to working with patients with chronic diseases, to palliative care and to controllable lifestyle options. Male students favoured more technology-oriented work, acute patients and prestige. However, these different interests were not decisive in career choices as both male and female students who manifested an interest in chronic diseases and continuous care had a high likelihood to become a GP. In the light of individual and structural theory the following can be observed. Taking into account that male and female students did not differ in their interest in intrinsic aspects of general practice, type of work and patients, individual theory cannot explain our results comprehensively. Students identify more with the values of the preferred speciality and less with their gender [26]. This might explain why gender 'in itself' does not predict career choice. There is evidence that in recent years women have become more interested in traditionally male specialities, such as surgery [27]. Similarly our results have shown that clerkship effects were different for female and male students. In the surgery clerkship, the increase in the perceived likelihood of becoming a surgeon was significant only for female students. And in general practice this increase in preference was stronger among male than among female students. We conclude that during the clerkship male students discovered attractive aspects of general practice and female students become interested in surgery. "...surgical subspecialties have become more appealing to women while attracting a relatively constant percentage of men" [28]. In other words, preferences of men and women are likely to converge. "There is minimal evidence for gender differences in medical students' motivations and attitudes' [1]. 
A controllable lifestyle (part-time work, leisure time) was seen as not important by those who reported a high likelihood of becoming a surgeon and was not related to general practice preference at all. Surgery requires a great degree of dedication which apparently is not consistent with a controllable lifestyle. After the internal medicine clerkship a positive appraisal of a controllable life style was related to a stronger preference for internal medicine. Although internal medicine is a hospital speciality, it still allows for more flexible working hours than students had probably expected before the clerkship. The positive evaluation of extrinsic work aspects (status and income) was only related to the choice of a career in general practice and surgery before the clerkship. After the rotation this effect had disappeared. This underscores the importance of intrinsic interest in the subject, which is acquired during clerkships. Furthermore, for general practice, the appraisal of work conditions did not play a role either. Lifestyle options, work conditions and extrinsic aspects of work can be seen as indicators of the structural determinants of gender differences in medical career choices. Thus, the structural theory approach could not explain career choices of male and female students. It seems that the balance between work and private life is a matter of concern in the later, postgraduate career stage. During the clerkship period, students are making their initial speciality choices based on the content of work and type of patients. A similar pathway of decision making was framed in previous research. Women were equally likely to pursue a career in hospital-based specialities as the men were. However, later on, women stopped their training because of family strains [24]. This demonstrates, again, that both men and women base their initial choices on the primary interest and adjust them later, depending on lifestyle perceptions.

\section{Methodology}

\section{Generalisability of findings}

In any research it is important to know whether the findings can be generalized to other settings. In our study, we obtained retrospective data from NIVEL" over a 25 -year period (1980-2005). This encompasses the complete population of Dutch GPs who were looking for a position in general practice. Therefore, our findings are population derived and, thus wholly generalizable.

In accordance with our findings, the changes in the field of primary care in the Netherlands during these years are found in other countries as well. For example, the proportion of female doctors is increasing everywhere in Western Europe [29] ( In Eastern Europe it has been a female dominated profession for a long time). The overall influx of women into medicine has highlighted issues concerning flexibility and the work-family

* Netherlands Institute of Health Services Research, Utrecht, The Netherlands 


\section{Chapter 7}

balance. In the UK from the 1970s onwards the share of solo practices has decreased in favour of group practices. Also the percentage of non-principal positions has risen [30]. Societal changes like the ageing of the population are a widespread phenomenon in other European countries too [31]. This will probably lead to more demand for longterm care and more frequent contacts with patients. Taking into account the overall feminization and the fact that health care demands will develop in a similar way in all European countries, we expect to observe in other European countries the same trends we found in preferences for general practice in the Netherlands.

\section{Limitations}

Our study has several limitations. Dutch GPs were asked to complete a written questionnaire concerning their work preferences (type and size of practice, type of settlement) when looking for a position. Although we disposed of the full NIVEL database of future GPs, complete information for a limited group was missing: those who found a practice more or less immediately after graduation. Their practice preferences could not be established. Nevertheless, we believe that the absence of these respondents did not affect the results, as numbers of missing respondents were rather small.

Another limitation is that in examining whether GPs were able to realize their initial practice preference, we did not take into account the fact that these preferences might have changed over the years. This bias implies that success in realization of a certain practice preference reflects not only the opportunity of finding a desirable practice but also changing preferences during the period when the GP was looking for a position.

The study on the relationship between the primary care orientation of a medical faculty and the percentage of students entering general practice training has limitations as well. First, the main limitation is that we measured the extent of primary care orientation of the medical faculties in 2008, and then related this to the data from students graduating from those faculties between 1990 and 2000 and entering postgraduate training in general practice up until now. This may have caused some discrepancy as the content of the curricula changed during those years. However, the percentages of undergraduate students going into general practice from the respective medical faculties did not change dramatically during this period. Secondly, the primary care orientation of medical faculties was based on a questionnaire completed by the eight coordinators of general practice in the undergraduate medical curriculum. This is rather a small number. It should be noted here, however, that consulting experts or key informants is considered one of the ways to gather reliable information [32]. Additionally, the way the medical faculties were ranked in regard to general practice orientation is in line with the expectations based on the assumptions beforehand (Maastricht University and The University of Amsterdam used to have a primary care mission in the past).

The survey of the student cohorts from Maastricht University also had some limitations. We investigated different cohorts during the clerkship period. Hence, we did not study 
the same group of students, although the cohorts of students who were involved in internal medicine and surgery rotations partly overlapped.

Another limitation is that we were unable to measure the impact of the clerkship sequence on students' preferences. At Maastricht, every student has a unique clerkship schedule. For this reason it was not possible to control for the influence of the sequence of clerkship rotations on students' career preferences. We tested the impact of overlap and the year of rotations. Both had no significant confounding effect on the results.

\section{Strength of the study}

Our unique data set provided by NIVEL ${ }^{*}$ consists of information of all GPs who qualified in the Netherlands during the past 25 years. Previous research into practice preferences and their realization among newly qualified GPs was often confined to samples or to an analysis of one or only a few year cohorts [33] [34] [35]. We extend upon this data using the whole population over a long period.

Next, we have depicted the percentage of undergraduate students from each medical faculty in the Netherlands who embarked upon postgraduate training in general practice during a period of ten years. We have also ranked and compared medical faculties according to the extent of general practice orientation of the undergraduate curriculum. In spite of the limitations we have mentioned, this study is the first effort in the Netherlands to try to find a link between the undergraduate curriculum and students' career choice in general practice. This is especially important, as we attempted to give a picture of the educational continuum of GPs. Based on the GPs' types of positions in general practice and the number leaving general practice, we made a comparison between the eight universities in general practice orientation and the proportion of students who become GPs, finally ending with students' career choices, general practice in particular, of students at Maastricht University. This justifies formulating expectations regarding future developments in general practice.

\section{Research implications}

In this thesis we explored several aspects of the educational continuum of GPs from medical student to working in general practice. We have provided insights into the decision making processes of medical students and GPs and the role of gender in these processes. Based on our findings we propose the following recommendations for future research.

\footnotetext{
${ }^{*}$ Netherlands Institute of Health Services Research, Utrecht, The Netherlands
} 


\section{Chapter 7}

Analyzing the preferences of young GPs for a certain type of practice and examining their success in matching their expectations with their actual position in general practice we observed a general trend among GPs from solo to group practice. This preference appears to have been met, especially in the previous decade. However, type of practice is not the only criterion GPs use in seeking a position. There are other important elements that determine the appeal of a practice, like location in a certain region. GP practices are not distributed evenly across the country and the mismatch between needed and available GPs can lead to health care undersupply, particularly in unpopular areas. Further research should look more carefully into other factors contributing to young GPs finding a practice in accordance with their wishes, such as location, type of work, and patient population. This will contribute to a more exact estimation of potential mismatches between demand and supply of GPs.

Another interesting question is the source of the growing preference for partnerships. We have mentioned working part-time and flexible working hours as important reasons for this, both for male and for female doctors. It is quite clear that these options are important to women because they continue to take most of the responsibility for domestic and family tasks. However, what could account for male GPs' preference for a reduced work load and participating in child care? There are two possibilities. The first one is the changing work culture together with a new generation of physicians. [13, 29] The second one is that a different type of man, more emancipated, is being attracted to medicine as it has become a less male dominated specialty. It seems that men are more frequently opting for more lucrative fields, such as business administration, economics, law and information technology [36]. The alternative specialties to which men are drawn could be an interesting topic for further research. It would also be interesting to investigate why the medical profession is becoming female dominated and how this relates to de-professionalization.

We surveyed students at Maastricht University concerning their specialty preferences before and after clerkships rotations in three disciplines. In order to obtain a more detailed and richer picture of how students' specialty preferences develop, we would recommend following cohorts of medical students, preferably from their first year until several years after graduation. Young doctors often do not make their final career choice until they have had some clinical work experience. A career choice for general practice in particular is only made after spending some time in the hospital. In our study we were unable to control for the effects of previous clerkship rotations or for postgraduate clinical experiences. That is why we propose further research in which more attention is devoted to the full clerkship path, the sequence of rotations and early clinical work experiences, because we believe that this will enhance our understanding of developing attitudes and yield more solid results.

We ranked the eight Dutch medical faculties according to the degree of general practice orientation and examined if there was a relationship with the proportion of students go- 
ing into general practice. The method we used to measure general practice orientation, a brief questionnaire, has several limitations. In order to justify our results further studies into curriculum characteristics are required. For example, other variables could be taken into account in designing a scale to measure the degree of general practice orientation. Also, more experts could be asked to provide information. We also recommend further studies into connections between curriculum characteristics and students career choices based on more recent data.

\section{Implications for public health policy and health services}

In addition to the implications of the findings presented in this thesis for further research, there are important implications for policies relating to manpower planning and medical education. The implications for manpower planning are concerned with working conditions and type of practices and the implications for medical education relate to the input of general practice in the undergraduate curriculum and its role in students' definitive career choices.

\section{Policies regarding general practice}

Considering the trends in general practice in recent years, we expect to see an increasing and continuing preference for group practices with smaller numbers of patients. This is partly due to the increasing presence of women in medicine and to changing preferences of male doctors. The same developments can be expected in other countries in Western Europe [37]. For policy makers it is important to notice that there is a number of GPs who despite completing vocational training are not active in general practice and thus not available for the labour market. The loss of newly trained GPs is expensive and depressing for both institutions and individuals. Considering the increasing need for primary care, GPs leaving general practice have a negative impact on health care supply. In order to minimise movement out of general practice, efforts should be made to retain GPs by catering to their preferences. A part of the solution to workforce shortages, like those in the UK, lies in better retention and management of existing resources [38]. More women entering general practice worldwide and male GPs showing a propensity to work part-time are phenomena that stress the urgency of providing more flexible arrangements for family leave and part-time jobs.

Because the group of GPs who did not state a specific preference for type of practice after postgraduate training turned out to be at risk of leaving general practice, this group should be given special attention by training institutes because their lack of preference may signify a weak interest in the specialty.

Admission policies could be made stricter in order to reduce the number of trainees who are not really planning to work as a GP or are at risk of leaving general practice eventually. For the same reason lifestyle friendly work schedules and opportunities to combine 


\section{Chapter 7}

work and family are of the essence to secure GPs' involvement in general practice. Female medical graduates from New Zealand stated that "training and employment must be flexible enough to allow for maximum participation of women in the workforce" [39].

\section{Medical education implications}

Another implication of this thesis is that students' decision making processes relating to their future careers should be given attention. Specialty choice is a matter of concern for workforce planning in health care. Given the increasing need for primary care and the growing preference for part-time work, more GPs will be needed. It is important to take into account that the increasing percentage of female medical students is no guarantee that more students will choose general practice over hospital specialties. In order to stimulate students to choose a certain specialty, emphasis should be placed on the intrinsic attractiveness of work in general practice. Particularly, since our results show that for undergraduate students working conditions and lifestyle considerations are less salient in shaping their preference. Our finding that male students' interest in general practice tended to have increased after the general practice rotation suggests that it might be worthwhile to target this group in emphasizing the content of general practice.

Seeing that the increased interest of students in general practice after the clerkship rotation was found to have diminished at graduation particularly among women [40], it seems advisable to take measures to sustain students' interest in general practice also after the clerkship, for instance by offering them experiences in general practice throughout the clinical phase of the curriculum.

Clerkships are an essential part of the educational programme. But what do students actually learn? And what is the function of clerkships for students' medical careers?

We can approach this question from the perspectives of the student and the university. Our study showed that students use clerkships not only to gain medical skills and knowledge, but also to discover which specialty best suits their inclinations. Students use clerkships to compare and test specialties before making their final career choice. Participating in patient care and observing specialists at work allows students not only to learn the theory of a specialty but also to get acquainted with the work climate and culture. Experiences during the clerkships "offer students opportunities to confirm or disconfirm their preferences for desired specialties" [26].

The faculty of medicine's main aim for the clerkships is to train students to be good doctors, scientists and experts. Specialists also try to promote their specialties to attract new recruits. In the case of general practice, it turned out that curriculum/ clerkship length did not affect the percentage of students entering general practice. Should this finding have consequences for the curriculum? It is important to say that it is the task of the department of general practice to show students the role of primary care and teach them the relevant clinical competences. It is important that students are made aware of 
what the work of a GP entails if only to make them better able to cooperate with GPs when working in a hospital specialty. Hospital and primary care specialists must share the responsibility for their patients. Looking at the quality of education, knowledge on the organisation of care and medical expertise could be improved by means of integrated clerkships where all specialties work together (similar to interdisciplinary blocks or units). This will make a medical domain less discipline specific, and more focused on health care.

\section{Conclusion}

This thesis addressed the practice preferences of young GPs and medical students' preferences for a career in general practice against the background of the steady feminization of the medical workforce. It appeared that women have introduced different preferences relating to work into medical practice and that men are also increasingly adopting these preferences. We have gained new insights into the decision-making processes of medical students with regard to a career in general practice and from that we have derived suggestions for strategies to motivate students to opt for a career in general practice. This thesis has attempted to contribute to the literature and to provide recommendations for policy-making and research regarding the general practice workforce. 


\section{References}

1. Kilminster, S., et al., Women in medicine--is there a problem? A literature review of the changing gender composition, structures and occupational cultures in medicine. Med Educ, 2007. 41: p. 3949.

2. Baker, M., J. Williams, and R. Petchey, GPs in principle but not in practice: a study of vocationally trained doctors not currently working as principals. BMJ, 1995. 310: p. 1301-04.

3. Johnson, N., et al., The career outcomes for doctors completing general practice vocational training 1990-1995. British Journal of General Practice, 1998. 48: p. 1755-1758.

4. Searle, J., Women and medicine - a new paradigm. Med Educ, 2001. 35(8): p. 718-9.

5. Muysken - du Saar, A.M., Vrouwelijke huisartsen onschuldig. Medisch Contact, 2000. 55(45). [Female doctors are not guilty].

6. Hingstman, L., J.M. Bensing, and J. Harmsen, Pas afgestudeerde huisartsen op zoek naar een praktijk. Wensen en voorkeuren. Medisch Contact, 1994. 49(15): p. 500-2. [Recently graduated general practitioners looking for a position. Wishes and preferences].

7. Lugtenberg, M., P. Heiligers, and L. Hingstman, Artsen en hun carriére wensen: een literatuurverkenning. 2005, Utrecht: NIVEL. [Doctors and their career preferences: literature review].

8. Heiligers, P. and L. Hingstman, Career preferences and the work-family balance in medicine: gender differences among medical specialists. Soc Sci and Med, 2000. 50(9): p. 1235-1246.

9. Hingstman, L., Cijfers uit de registratie van huisartsen: peiling 1997. 1997, NIVEL: Utrecht. [Numbers from the registration of general practitioners in 1997].

10. Hingstman, L. and R. Kenens, Cijfers uit de registratie van huisartsen: peiling 2007. 2007, NIVEL: Utrecht. p. 14. [Numbers from the registration of general practitioners in 2007].

11. Gray, J., Why Mars \& Venus collide. 2008, London: Harper Element.

12. Boerma, W.G.W. and A.v.d. Brink-Muinen, Gender-related differences in the organization and provision of services among general practitioners in Europe. Med Care, 2000. 38: p. 993-1002.

13. Vaughan, C., Career choices for generation X (Editorial). BMJ, 1995. 311: p. 525-526.

14. Politzer, R.M., et al., Primary care physician supply and the medically underserved. A status report and recommendations. JAMA, 1991. 266(1): p. 104-9.

15. Fields, S., et al., PBL and primary care career choice: a complex relationship. Acad Med, 1996. 71: p. $939-40$.

16. Albanese, $M$. and S. Mitchell, Problem-based leaming: a review of literature on its outcomes and implementation issues. Acad Med, 1993. 68(1): p. 52-81.

17. Matsui, K., et al., Characteristics of medical school graduates who underwent problem-based learning. Annals of the Academy of Medicine, Singapore, 2007. 36(1): p. 67-71.

18. Peters, A., et al., Long-term outcomes of the New Pathway Program at Harvard Medical School: a randomized controlled trial. Acad Med, 2000. 75(5): p. 470-9.

19. Peterson, R., M. Hakendorf, and T. Guscott, Improving aged care education for Australian rural nurses using problem-based learning. J Contin Educ Nurs, 1999. 30(3): p. 120-7.

20. Thammasitboon, K., et al., Problem-based learning at the Harvard School of Dental Medicine: self-assessment of performance in postdoctoral training. J Dent Educ, 2007. 71(8): p. 1080-9.

21. Williams, S., et al., Motivation underlying career choice for internal medicine and surgery. Social Science and Medicine, 1997. 45(11): p. 1705-13.

22. Schwartz, M., et al., The impact of an ambulatory rotation on medical student interest in internal medicine. The Society of General Internal Medicine Task Force on Career Choice in Internal Medicine. J Gen Intern Med, 1995. 10: p. 542-9.

23. Mihalynuk, T., et al., Free choice and career choice: clerkship electives in medical education. Med Educ, 2006. 40: p. 1065-71. 
24. Gjerberg, E., Gender similarities in doctors' preferences--and gender differences in final specialisation. Soci Sci and Med, 2002. 54(4): p. 591-605.

25. Senf, J., R. Kutob, and D. Campus-Oscalt, Which primary care specialty? Factors that relate to a choice of family medicine, internal medicine, combined internal medicine-pediatrics. Fam Med, 2004. 36: p. 123-30.

26. Ellsbury, K., et al., Influence of third-year clerkships on medical student specialty preferences. Advances in Health Science Education, 1998. 3: p. 177-186.

27. Maiorova, T., et al., The impact of clerkships on students' specialty preferences: what do graduates learn for their profession? Med Educ 2008. 42(6): p. 554-62.

28. Lambert, E. and E. Holmboe, The relationship between specialty choice and gender of U.S. medical students, 1990-2003. Acad Med, 2005. 80(9): p. 797-802.

29. Jovic, E., J. Wallace, and J. Lemaire, The generation and gender shifts in medicine: an exploratory survey of internal medicine physicians. BMC Health Services Research, 2006. 6(1): p. 55.

30. Government Statistical Service. Statistics for general medical practitioners in England: 1994 2004, in Statistical Bulletin. 2005, Department of Health Publications: London.

31. Aging: Europe's growing problem. 11 September, 2002, BBC News: United Kingdom.

32. Kroneman, M.W. and J. van der Zee, Health policy as a fuzzy concept: methodological problems encountered when evaluating health policy reforms in an international perspective. Health Policy, 1997. 40(2): p. 139-55.

33. Taylor, D.H.J. and B. Leese, Recruitment, retention, and time commitment change of general practitioners in England and Wales, 1990-4: a retrospective study. BMJ, 1997. 314: p. 1806.

34. Lambert, T.W., J. Evans, and M.J. Goldacre, Recruitment of UK-trained doctors into general practice: findings from national cohort studies. $\mathrm{Br} \mathrm{J}$ of Gen Prac, 2002. 52: p. 364-372.

35. Lambert, T.W. and M.J. Goldacre, Career destinations and views in 1998 of the doctors who qualified in the United Kingdom in 1993. Med Educ, 2002. 36: p. 193-198.

36. Cooper, R.A., Impact of trends in primary, secondary, and postsecondary education on applications to medical school. I: gender considerations. Acad Med, 2003. 78(9): p. 855-63.

37. McKinstry, B., et al., The feminization of the medical work force, implications for Scottish primary care: a survey of Scottish general practitioners. BMC Health Services Research, 2006. 6: p. 56.

38. Young, R., B. Leese, and B. Sibbald, Imbalances in the GP labour market in the UK: evidence from a postal survey and interviews with GP leavers. Work Employment and Society, 2001. 15: p. 699-719.

39. Lawrence, J., P. Poole, and S. Diener, Critical factors in career decision making for women medical graduates. Med Educ, 2003. 37(4): p. 319-27.

40. Morrison, J. and T. Murray, Career preferences of medical students: influence of a new four-week attachment in general practice. Br J of Gen Prac, 1996. 46: p. 721-5. 


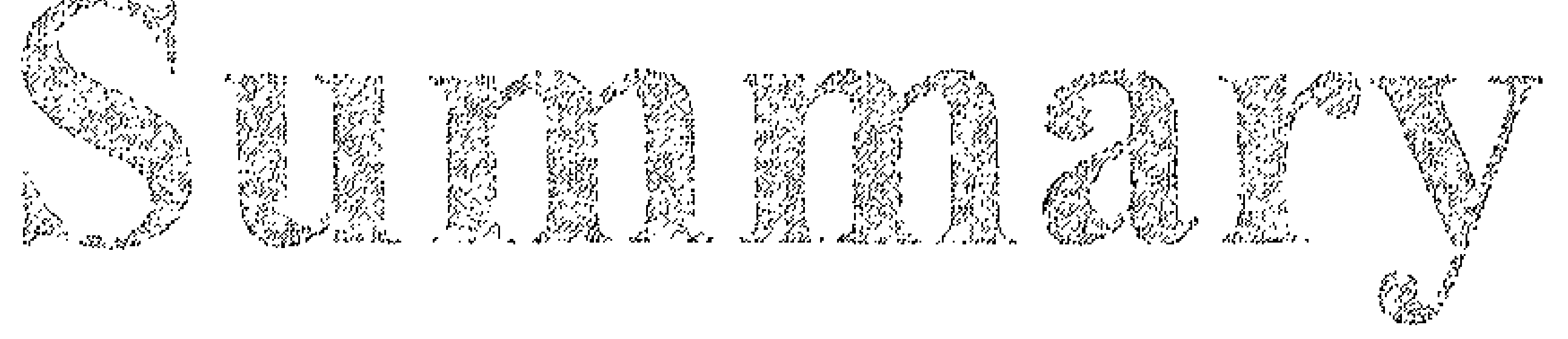

The central theme of this thesis is the educational continuum leading from undergraduate medical training to a position as a general practitioner (GPs) in the Netherlands. The research conducted consists of two separate studies and one study linking the data from these two studies. The first study is a retrospective study examining data from almost the entire population of GPs in the Netherlands who after completing postgraduate training were seeking a position in general practice during the period 1980-2005. The second study focuses on recent graduates from the eight Dutch faculties of medicine who entered general practice vocational training and on three separate cohorts of undergraduate medical students at Maastricht University undertaking their clinical clerkships in 20022003 and 2004-2005.

In all these studies the emphasis is on the effect of gender differences on students' and young GPs' choices with regard to a career in general practice. The trends in career preferences and the actual realization of these preferences were compared for male and female GPs separately. Career choices of male and female undergraduate students at Maastricht University were compared before and after their clerkship rotations in general practice, surgery and internal medicine. It was explored how several decisive factors, gender 'in itself' in particular, impact on specialty preferences.

The major focus of this thesis was on: (1) trends in practice preferences expressed by young male and female GPs and the extent to which they managed to realize them and (2) factors impacting on the preferences for general practice among Maastricht medical students during their clinical clerkships.

Chapter 1 presents the introduction to this thesis. The theme of this thesis will be addressed from the perspective of demand and supply in the medical workforce, notably in 
general practice. The emphasis is on the supply side of the GP workforce as determined by the numbers of available GPs and medical students entering vocational training for general practice. The demand side in health care is mainly determined by societal and demographic developments. There are three important societal changes that are expected to be particularly relevant to the demand for primary care. These are the feminization of the medical profession, the increasing numbers of elderly patients and the democratization of society leading to more egalitarian doctor-patient relationships.

A rising trend in the percentage of female doctors in the medical work force can be observed all over Europe and in the US too. In general practice, in particular, the majority of young doctors are female. The advent of more women has been accompanied by a trend in working conditions towards part-time work and flexible working hours, which allows doctors to balance career and family life. Men have also become more interested in working part-time. With increasing numbers of women and the concomitant changes in preferences for job conditions the question is whether there will be enough GP positions to accommodate the new doctors' wishes.

Doctor-patient relationships have also changed over the years. There has been increasing involvement of patients in decision making about their own health care. Moreover, the larger presence of women in the medical work force appears to foster a more democratic style of communication and collaborative relationships. As the content of the demand for health care changes, the content of the doctor's work and work experiences should also be expected to change. Still further change is related to the emergence of several new tasks of GPs. The ageing population, more patients with chronic illnesses and more emphasis on preventative measures have contributed to a shift from cure to care. The increasing demand for health services and the growing complexity of the provision of primary health care pose new challenges to GPs. This will reflect on the content and organization of work in primary care and the general practice labour force.

The changes in health care may also be reflected in the work preferences of young GPs and the career choices of medical students, particularly those related to general practice. Primary care is a popular career choice among female GPs. However, despite the expectation that increasing numbers of female medical students would boost the number of career choices in general practice, recruitment of general practice trainees continues to be problematic. The question we were interested in answering is what is the role of gender in this respect.

Insights into current developments in the medical work force are important to health policy making. Career pathways and preferences of new GPs help to make forecasts about the primary care labour market. Research into students' specialty choices is expected to identify important factors underlying these choices.

In Chapter 2, the topic of interest is new GPs' preferences with regard to a position in general practice. We investigated data on all GPs in the Netherlands who had completed postgraduate training in general practice and were looking for a position between 1982- 
2001. The results show differences between men's and women's preferences regarding their future practice setting. Solo practice has been consistently unpopular among women since 1982 culminating in almost zero preference in 2000 . In the early eighties male preference for solo practice was quite high but over the years it diminished to almost the same level as that among women. Today, both male and female GPs prefer partnerships, while the lack of interest in solo practices is likely to lead to the eventual extinction of this type of practice.

Women showed a more marked preference than men for non-principal positions, although the proportion of GPs in such positions increased among both men and women over the years.

Gender differences in relation to preferred practice size remained unchanged, with women preferring smaller practices. This preference was not related to type of practice (solo or group practice). Beside these differences, female GPs differed from their male colleagues in preferring an association with another GP to taking over an existing practice.

We found quite high drop-out rates from general practice in the eighties (30-40\%) with slightly higher rates among male than among female GPs. In the nineties the drop-out rates among young GPs looking for a particular type of practice fell to an average of $10 \%$. Among GPs who had no clear preference for a certain type of practice the dropout rate remained stable at $20-25 \%$. Surprisingly, there was a group of GPs leaving general practice who had never seriously considered practising as a GP. The majority of drop-outs, however, left general practice because they were unable to find a practice in accordance with their preferences. Women mentioned limitations due to family circumstances as an important second reason. Thus, lifestyle-friendly options and opportunities to combine work and family appear to be essential to retain GPs on the health care work force. Preferences of male and female GPs changed over the years and tended to converge. Based on these trends, we expect to see a growing interest in group practices and non-principal positions among GPs.

Chapter 3 describes a study into the practice preferences of young male and female GPs during 1980-2004 and the extent to which they managed to realise their initial preferences. Among those who were looking for a position in a group practice, $36 \%$ was able to realize this preference during the eighties and $60 \%$ during the late nineties. Women looking for a non-principal position were more successful than the men trying to find such a position.

Among those looking for a solo practice the men were more successful than the women in the period between 1980 and 1999. An increasing percentage of both men and women sought a position in a group practice and non-principal positions. Women were more successful than men in finding a principal position in group practice. During the period studied men and women became almost equally successful in matching prefer- 
ences and positions. Relatively more men than women were in solo practice and more women were in a group practice and/or worked as a non-principal.

Those who were looking for a non-principal position were increasingly successful in finding such a place: from $40 \%$ in the early eighties to $75 \%$ in the late nineties.

Over the years an increasing proportion of GPs, both male and female, were able to achieve their preferred positions in group practice and/or as a non-principal. Irrespective of their initial preference, men ended up in solo practice more frequently while more women found a position in a group practice. In recent years men have increasingly entered group practices, even if they initially preferred solo practice.

The overwhelming preference of male and female GPs for working in group practice appears to be matched by the number of available positions. We assume that the number of vacant positions in group practices is keeping pace with the increasing influx of new GPs seeking such a position.

In Chapter 4, we present a study comparing the eight Dutch faculties of medicine in the degree of general practice orientation of their undergraduate curricula. We also examined whether this difference was related to the percentage of graduates entering general practice vocational training. Our results showed that the departments of general practice of the Universities of Maastricht and Nijmegen and the University of Amsterdam made the most extensive contributions to the respective undergraduate curricula, making the medical curricula of these universities the most strongly general practice oriented ones. However, the highest percentages of graduates moving on to general practice vocational training were those from the universities of Maastricht, Nijmegen and Groningen. These faculties have in common that the curriculum is founded on the principles of problem-based learning. Another feature they share is that they are situated in non-urban areas. Finally, the study showed that the faculties of medicine did not differ greatly in the percentage of graduates who successfully completed postgraduate training in general practice. In other words, no relationship was found between the degree of general practice orientation of the undergraduate curriculum and the percentage of students entering or successfully finishing postgraduate training in general practice. Perhaps the possibility should be considered of a relationship between student-centred education and a career choice in general practice.

Chapter 5 explores determinants, gender in particular, of career preferences of Maastricht medical students during the clerkship period. A cohort study examined the career preferences of three cohorts of students before and after their clerkship rotations in surgery, internal medicine and general practice. The results confirm those of previous studies that exposure to clinical practice enhances students' interest in that particular discipline. In absolute terms, men were more likely than women to prefer surgery, and women were more likely than men to prefer general practice. Internal medicine was equally popular among the genders. 
Clerkship effects were different for female students compared to male students. The surgery clerkship effected only an increase in preference for surgery among the female students, whereas the general practice clerkship increased the preference for general practice more strongly among male than among female students.

In each of the three clerkships a positive evaluation of intrinsic work-related aspects of the specialty (type of patients, disorders, and treatments, variety of work, etc.) strongly predicted a preference for that specialty. A positive evaluation of extrinsic work-related aspects (status and income) was only related to a preference for general practice before students embarked on the clerkship. Gender was not a predictor of career preference after the clerkships.

Students wishing to work with patients with chronic illnesses and requiring palliative care were more likely to choose a career in general practice and less likely to show a preference for a surgical career. Those who liked technical work and valued prestige were attracted to surgery. Apparently, a career preference for surgery was associated with preferences for patient care that were the opposite of the preferences associated with a preference for general practice. A controllable lifestyle (part-time work, leisure time) was not considered essential by those reporting a high likelihood of becoming a surgeon and, surprisingly, showed no relationship at all with a preference for general practice.

Role models did not predict the likelihood of entering surgical or general practice training but had a positive effect for internal medicine.

Factors other than gender appeared to drive specialty choices, with work content and type of patient playing a prominent part.

Chapter 6 focuses on a cohort of students undertaking their general practice clerkship. They were followed until near graduation, several months after finishing the general practice rotation. The role of gender was explored in relation to career plans to enter general practice. A number of specific predictors of career choice and their relation to gender were explored. The main question was why increasing numbers of female students do not coincide with a similar increase in the number of graduates entering postgraduate training in general practice.

Attitudes towards medicine in general, and general practice in particular, were different for men and women. Female students were more attracted to working with patients with chronic diseases, patients requiring palliative care, and in a type of practice that offers controllable lifestyle options. Male students more strongly favoured technologyoriented work, acute patients and prestige. After the general practice clerkship, the intrinsic aspects of this discipline were valued equally by male and female students.

Bivariate analysis showed a significant gender effect but this disappeared when other factors were added to the analysis. Intrinsic work-related aspects of general practice played the most important role in choosing a career in general practice. Extrinsic work- 


\section{Summary}

related aspects (status, career) became less important after the clerkship. Choosing a career in general practice at this stage of the medical education continuum appeared to be more a question of a personal interest in this specialty than of an appreciation of the related working conditions, which probably do not come into play until later in a student's educational and training career. Being attracted to working with patients with chronic illnesses and in palliative care predicted a preference for general practice in both men and women.

Our results also showed that interest in general practice increased more among male students than among female students but decreased after a few months, especially among the female students.

The fact that students are attracted mainly by intrinsic aspects of the work and that female students who were motivated to choose general practice lost interest in this specialty after some time may explain why, despite increasing numbers of female trainees, recruitment into general practice training is not showing a similar rise.

In Chapter 7, the findings of all the studies are summarized and discussed.

The main research question was: What are the career paths of male and female GPs from medical student to the realisation of their initial practice preferences? Two separate studies were conducted to answer this question. The first study examined the career paths of Dutch GPs by mapping trends in practice preferences of young GPs and their success in realising their initial preferences. An important strength of this study is that it included the entire population of GPs looking for a position during a 25-year period, except for a small number of GPs who managed to find a practice almost straight from postgraduate training. During the period studied the preferences of male and female GPs differed but tended to converge, with both genders exhibiting an increased preference for partnerships, non-principal positions and associations. From the fact that most GPs were able to find a position in accordance with their wishes one might conclude that more positions in group practices became available as the number of GPs seeking such a position increased. However, the type of practice was not the only criterion in finding a practice. More research will be needed to identify the factors that play a role in GPs securing a position in their favoured type of general practice.

The changed interest in particular types of practice may be related to factors like the feminisation of general practice, seeing that women place more value on lifestylerelated factors. It would be interesting to take a closer look at why the medical profession and general practice became female dominated, in other words why fewer men are opting for medicine and which specialties they are turning to instead.

Male GPs are also increasingly expressing a wish to work part-time. An interesting question for future research is whether this change is due to a new generation of male doctors arriving on the scene or to a different type of men entering medicine these days. 
When we examined drop-out from general practice, the most frequent reason appeared to be the inability of finding a position in accordance with one's preferences. For women, the second reason was family strains and for men it was financial circumstances. Thus, if we want to retain more GPs in the medical work force, we should create practice types and conditions that are tailored to young GPs wishes. It should also be noted that drop-out was highest among GPs who showed no clear practice-related preference. Perhaps, it would be advisable for institutes offering postgraduate training in general practice to identify those applicants who have no preference for a specific type of practice as this could be a sign of a more general lack of interest in general practice. Furthermore, among the GPs who left general practice there was a group who never really intended to practice as a GP. Stricter admissions criteria to postgraduate training may prevent enrolment of this type of trainee thereby saving resources.

The second study addressed the career choices of medical students. Results from previous studies into the relationship between a strong primary-care orientation of the curriculum and the percentage of students likely to move on to postgraduate training in this field were not confirmed. Apparently, other factors play a decisive role in students' career choices, such as personal preferences, role models and clinical experiences. In this regard, it should be pointed out that it is the task of the departments of general practice to teach students about the role of primary care within the wider context of health care in general, in addition to teaching them the relevant clinical competences. It is important for students to be made aware of the tasks of GPs, even if, as a hospital specialist, they will only need this to be able to better cooperate with GPs. Hospital and primary care have a joint responsibility for good patient care.

Furthermore, we surveyed cohorts of medical students from Maastricht University during clerkship rotations because clinical training can be a decisive period for students' career choices. Our results showed that clerkships did indeed have a positive effect on students' motivation to enter the specialty of the most recent rotation. However, this was not a lasting effect. Based on these results, it seems advisable to continue to motivate students, for example by repeatedly stimulating their interest in general practice at various points during the clerkship period.

The drop in interest which we noted during the clerkships might explain the paradox of increasing numbers of female students, who presumably tend to favour general practice careers, without a concomitant increase in the number of entrants into postgraduate training in general practice. Another important finding is that gender alone did not affect career choice. It was mainly students' attitudes towards the specialty-related types of work and patients that determined career choices. Thus, in order to stimulate students to choose a certain specialty, they should be convinced of the attractiveness of the content of the work and the type of patients. 


\section{S}

Het centrale thema van dit proefschrift is het opleidingscontinuüm van huisartsen in Nederland, van geneeskundestudent tot gevestigd huisarts. Dit is onderzocht door middel van twee studies: een retrospectief onderzoek van de gegevens van vrijwel alle $\mathrm{Ne}$ derlandse huisartsen die na afronding van de huisartsenopleiding in de periode 19802005 bezig waren zich te vestigen, en een studie waarin de specialisatievoorkeuren zijn onderzocht van drie cohorten medisch studenten aan de Universiteit Maastricht die in 2002/2003 en 2004/2005 coschappen liepen.

De nadruk in de onderzoeken ligt op de verschillen tussen mannen en vrouwen ten aanzien van loopbaanvoorkeur en -keuze. Er is een vergelijking gemaakt tussen de voorkeuren van mannen en vrouwen, hoe deze zich ontwikkelden en in hoeverre ze gerealiseerd werden. Daarnaast zijn de beroepskeuzes van mannelijke en vrouwelijke coassistenten aan de Universiteit Maastricht in kaart gebracht direct voor en na de reguliere coschappen huisartsgeneeskunde, chirurgie en interne geneeskunde. Onderzocht is hoe verschillende factoren de beroepskeuze beïnvloedden en hoe mannen en vrouwen hierin verschilden.

Samenvattend had het onderzoek dat gepresenteerd wordt in dit proefschrift tot doel inzicht te bieden in de besluitvorming en keuzes van studenten en pas opgeleide huisartsen in Nederland ten aanzien van het huisartsenvak. Hierbij is gekeken naar: (1) ontwikkelingen in praktijkvoorkeuren van huisartsen en de realisatie van hun wensen; en (2) factoren die een rol spelen bij de ontwikkeling van een voorkeur voor het huisartsenberoep bij coassistenten.

Hoofdstuk 1 geeft een inleiding op het thema van dit proefschrift. Het thema wordt benaderd in het licht van vraag en aanbod van artsen, met name huisartsen, op de ar- 
beidsmarkt. Het aanbod van huisartsen en praktijken is onder andere afhankelijk van het aantal huisartsen dat beschikbaar is op de arbeidsmarkt en het aantal studenten dat de huisartsopleiding gaat volgen. De vraag naar gezondheidszorg wordt voornamelijk bepaald door maatschappelijke en demografische ontwikkelingen, zoals de feminisering van het medisch beroep, de toename van oudere patiënten en, daarmee samenhangend, van chronische aandoeningen en de democratisering van de maatschappij, waardoor de arts-patiëntrelatie een meer egalitair karakter heeft gekregen.

Het percentage vrouwelijke artsen blijft stijgen. Deze ontwikkeling doet zich ook voor in andere Europese landen en in de VS. Onder jonge huisartsen is op dit moment de meerderheid vrouw. De komst van vrouwen op de medische arbeidsmarkt heeft geleid tot veranderingen in werkomstandigheden. Er zijn meer deeltijdbanen met flexibele werkuren die het makkelijker maken om loopbaan en gezinsleven te combineren. Mannelijke artsen tonen echter ook steeds meer voorkeur voor werken in deeltijd. Het toenemende aantal vrouwelijke artsen en de daarmee samenhangende veranderende werkomstandigheden en -voorkeuren roepen de vraag op of het op termijn mogelijk zal zijn de vraag naar zorg en de werkvoorkeuren van artsen met elkaar in overeenstemming te brengen.

Ook de arts-patiëntrelatie is veranderd in de afgelopen decennia. Patiënten worden vaker en intensiever betrokken bij het nemen van medische beslissingen. Voorts heeft de toename van vrouwelijke artsen een positieve invloed gehad op de communicatie tussen arts en patiënt. Met de veranderende vraag naar zorg zal ook de inhoud van het medisch beroep veranderen. Daarnaast heeft de huisartsgeneeskunde er een antal nieuwe taken bij gekregen. Zo hebben de vergrijzing van de bevolking, de daarmee samenhangende toename van chronische aandoeningen, en een sterkere nadruk op preventie bijgedragen aan een verschuiving van behandeling naar zorg. Te verwachten is dat de stijgende vraag naar zorg en de toenemende complexiteit van de eerstelijnszorg de behoefte aan huisartsen zal vergroten. Dit kan gevolgen hebben voor inhoud en organisatie van de eerstelijnszorg en de huisartsgeneeskunde.

Er zijn ook veranderingen in de organisatie van de huisartsgeneeskunde, zoals het groeiende aantal groepspraktijken en parttime functies. Op de langere termijn betekent dit dat vrijkomende vacatures opgevuld zullen worden met in deeltijd werkende huisartsen. Inzicht in de praktijkvoorkeuren van beginnende huisartsen en in de aantallen studenten die de huisartsopleiding willen volgen, kan bijdragen aan betere planning van het huisartsenaanbod en het voorkomen van tekorten.

Veranderingen in de huisartsgeneeskunde kunnen ook van invloed zijn op de praktijkvoorkeuren van jonge huisartsen en de specialisatiekeuze van medisch studenten. Eerstelijnszorg is een populaire specialisatiekeuze bij vrouwelijke studenten. Niettemin stijgt de populariteit van dit specialisme minder snel dan werd verwacht op grond van 
de toename van het aantal vrouwelijke artsen. De vraag is daarom welke rol 'gender' speelt bij de beroepskeuze. Inzicht in loopbanen en voorkeuren van jonge huisartsen kunnen helpen bij het voorspellen van de situatie op de arbeidsmarkt op de langere termijn. Onderzoek naar specialisatievoorkeuren van medisch studenten kan belangrijke factoren belichten die een rol spelen in hun loopbaanplanning. Meer aandacht voor deze factoren kan studenten helpen bij het maken van een keuze.

In Hoofdstuk 2 is een onderzoek beschreven naar de praktijkvoorkeuren van jonge huisartsen die zich gingen vestigen. We onderzochten gegevens van alle huisartsen in Nederland die de huisartsenopleiding hadden voltooid en in de periode 1982-2001 op zoek waren naar een praktijk. De resultaten laten verschillen zien tussen mannen en vrouwen in voorkeuren ten aanzien van praktijkvormen. Weinig vrouwen gaven de voorkeur aan een solopraktijk en na 2000 is dit aantal tot vrijwel nihil gereduceerd. De voorkeur van mannen voor een solopraktijk nam eveneens af in de loop der jaren en belandde op vrijwel hetzelfde niveau als de voorkeur van vrouwen. Zowel mannelijke als vrouwelijke huisartsen prefereren nu een groepspraktijk. Gezien de uiterst geringe voorkeur voor een solopraktijk, ligt het voor de hand dat deze praktijkvorm op termijn zal verdwijnen.

Vrouwen bleken ook vaker dan mannen een voorkeur te hebben voor vestiging als nietzelfstandige huisarts, dat wil zeggen, als huisarts in dienst van een andere huisarts (HIDHA). Het aandeel van mannen en vrouwen gevestigd als HIDHA is gestegen.

Het man-vrouwverschil ten aanzien van voorkeur aangaande praktijkgrootte is in de onderzoeksperiode onveranderd gebleven. Vrouwen lieten een sterkere voorkeur zien voor een kleinere praktijk dan mannen. Voorkeuren aangaande praktijkomvang hielden geen verband met het type praktijk (solo- of groepspraktijk) Op basis van de bevindingen verwachten we dan ook dat er met de toename van vrouwelijke huisartsen meer vraag zal zijn naar kleinere praktijken en naar groepspraktijken.

Een vrij aanzienlijk percentage van de huisartsen (30-40\%) die in de jaren tachtig een praktijk zochten, heeft het huisartsenberoep vaarwel gezegd. Dit betrof meer mannen dan vrouwen. In de jaren negentig daalde dit percentage onder de huisartsen die gericht op zoek waren naar een bepaald soort praktijk (gemiddeld 10\%). Onder de huisartsen zonder uitgesproken praktijkvoorkeur bleef het percentage uitvallers door de jaren heen stabiel (20-25\%). Een opvallende bevinding is dat $15 \%$ van de mannen en $19 \%$ van de vrouwen die de huisartsenopleiding afrondden nooit serieus van plan waren geweest zich als huisarts te vestigen. De meeste huisartsen zijn gestopt met zoeken omdat ze geen praktijk konden vinden die overeenkwam met hun voorkeur. Vrouwen noemden familieomstandigheden als belangrijke tweede reden. We concluderen hieruit dat levensstijl, relationele factoren en mogelijkheden om werk en gezin goed te kunnen combineren van groot belang zijn om (twijfelende) huisartsen voor het beroep te behouden. De voorkeuren van mannelijke en vrouwelijke huisartsen zijn door de jaren heen veranderd en naar elkaar toe gegroeid. Wij verwachten dan ook dat de vraag naar groepspraktijken en HIDHA-posities zal stijgen. 
In Hoofdstuk 3 zijn de praktijkvoorkeuren van mannelijke en vrouwelijke huisartsen en de realisatie hiervan in de periode 1980-2004 beschreven. Van de huisartsen die een groepspraktijk zochten, slaagde in de jaren tachtig $36 \%$ en in de jaren negentig $60 \%$ er in om deze wens te verwezenlijken. Vrouwen slaagden er vaker in dan mannen om een gewenste plaats als HIDHA te vinden.

Onder de huisartsen die zich zelfstandig wilden vestigen in een solopraktijk slaagden in de periode 1980-1999 de mannen er gemiddeld beter in dan de vrouwen om hun wens te realiseren. Een toenemend percentage van zowel de mannelijke als de vrouwelijke huisartsen gaf de voorkeur aan een groepspraktijk of een HIDHA positie.

Vrouwen slaagden er vaker in een zelfstandige positie in een groepspraktijk te vinden dan mannen. Het percentage mannelijke en vrouwelijke huisartsen dat erin slaagde hun voorkeur te realiseren is bijna even groot geworden. Relatief meer mannen dan vrouwen werkten in een solopraktijk en meer vrouwen dan mannen werkten in een groepspraktijk en/of als HIDHA. In de loop der jaren nam het percentage huisartsen dat een HIDHA plaats vond toe van $40 \%$ in de jaren tachtig tot $75 \%$ in de jaren negentig.

Tijdens de onderzoeksperiode konden steeds meer huisartsen hun voorkeur realiseren in een groepspraktijk en/of als HIDHA. Los van hun oorspronkelijke voorkeur vestigden mannen zich vaker in een solopraktijk en traden meer vrouwen toe tot een groepspraktijk. In de afgelopen jaren hebben ook steeds meer mannen zich gevestigd in een groepspraktijk, zelfs als ze aanvankelijk de voorkeur gaven aan een solopraktijk.

In Hoofdstuk 4 is een vergelijking gemaakt tussen de acht Nederlandse geneeskundefaculteiten betreffende de hoeveelheid aandacht voor de huisartsgeneeskunde in het basisartscurriculum. Vervolgens is gekeken of deze verschillen in verband staan met op het percentage afgestudeerde studenten dat de huisartsopleiding ging volgen. Onze resultaten laten zien dat huisartsgeneeskunde de grootste bijdrage leverde aan de curricula van Maastricht, Nijmegen en de Universiteit van Amsterdam. Deze curricula vertoonden dus de grootste mate van gerichtheid op de huisartsgeneeskunde. Echter onder de studenten die aan de huisartsopleiding begonnen, waren de grootste percentages afkomstig van de faculteiten van Maastricht, Nijmegen en Groningen. Deze universiteiten hebben gemeen dat ze studentgericht onderwijs bieden. Bovendien, zijn ze gevestigd in minder sterk verstedelijkte gebieden. Er was weinig verschil in universitaire achtergrond bij de huisartsen die hun opleiding niet afrondden. We hebben hieruit geconcludeerd dat er geen verband bestaat tussen het volgen en/of succesvol afronden van de huisartsopleiding en de mate van aandacht voor de huisartsgeneeskunde in het basiscurriculum. Nader onderzoek moet uitwijzen of de studentgerichtheid van het onderwijs (bijvoorbeeld probleem gestuurd onderwijs) bepalend is voor een voorkeur voor het beroep van huisarts.

In het onderzoek dat beschreven wordt in Hoofdstuk $\mathbf{5}$ is onderzocht welke gendergebonden factoren een rol spelen bij de loopbaanvoorkeuren van medisch studenten tijdens de coschappen. In een longitudinaal cohort onderzoek zijn drie studentencohor- 
ten aan de Universiteit Maastricht voor en na de coschappen chirurgie, interne geneeskunde en huisartsgeneeskunde gevraagd naar hun voorkeur voor een toekomstige specialisatie.

Onze resultaten bevestigen dat het contact met de klinische praktijk studenten stimuleert en motiveert om het specialisme van het betreffende coschap te kiezen. De effecten van de coschappen waren verschillend voor mannen en vrouwen. Na het coschap chirurgie was de gerapporteerde sterkere waarschijnlijkheid om chirurg te worden alleen significant bij de vrouwen. Tijdens het coschap huisartsgeneeskunde was de toename in belangstelling bij de mannen groter dan bij de vrouwen.

Gender alleen was geen voorspeller van specialisme voorkeur. Weliswaar gaven de bivariate analyses een relatie te zien tussen gender en beroepskeuze, maar na toevoeging in de regressieanalyse van andere factoren zoals voorkeur voor een bepaald soort zorg en patiëntentype bleek gender geen afzonderlijk effect meer te hebben. Blijkbaar weerspiegelt gender ook andere factoren die van belang zijn voor de beroepskeuze.

$\mathrm{Bij}$ alle drie de coschappen was een positieve waardering van de intrinsieke aspecten van het werk (zoals inhoud van het werk en soort patiënten, aandoeningen en handelingen) de beste voorspeller van beroepsvoorkeur. Een positieve waardering voor extrinsieke aspecten van het specialisme, zoals status en inkomensverwachting, voorspelde alleen de beroepsvoorkeur voorafgaand aan het coschap. $\mathrm{Na}$ afloop van het coschap waren de effecten van extrinsieke werkgebonden factoren verdwenen ten gunste van de effecten van intrinsieke factoren.

Studenten die een voorkeur aangaven voor werken met patiënten met chronische aandoeningen en palliatieve zorg hadden vaker een voorkeur voor huisartsgeneeskunde. Studenten die liever niet met dit type patiënten wilden werken, vertoonden vaker een voorkeur voor een loopbaan als chirurg. Technische kenmerken van het werk en prestige waren belangrijke motivaties voor deze keuze. Kennelijk hebben studenten met een voorkeur voor chirurgie voorkeuren voor aspecten van de geneeskunde die tegenovergesteld zijn aan de voorkeuren van studenten die huisartsgeneeskunde kiezen. Voor studenten die chirurg wilden worden was een beheersbare levensstijl, met een voorkeur voor deeltijdwerk en vrije tijd, niet van essentieel belang. Verrassend genoeg, was een voorkeur voor het kunnen bepalen van de persoonlijke levensstijl niet gerelateerd aan een voorkeur voor huisartsgeneeskunde.

Het veronderstelde effect van een rolmodel als voorspeller van de keuze om chirurg of huisarts te worden werd niet gevonden. Rolmodellen hadden wel een positief effect op de motivatie om interne geneeskunde te kiezen. We leiden hieruit af dat het belang van rolmodellen voor de beroepskeuze kan variëren per specialisme.

In Hoofdstuk 6 is nader onderzoek beschreven rondom het coschap huisartsgeneeskunde. Een cohort studenten is onderzocht op drie tijdstippen: voor het coschap huisartsgeneeskunde, na het coschap en een paar maanden later, rondom het afstuderen. Een aan- 


\section{Samenvatting}

tal factoren dat gender-gebonden beroepsvoorkeuren zou kunnen beïnvloeden, is nader onderzocht. Aan de hand hiervan hebben we tevens gepoogd de paradox te verklaren van de stijgende aantallen vrouwen in de geneeskunde zonder een toename in belangstelling voor de huisartsenopleiding, die te verwachten zou zijn op grond van de sterkere voorkeur van vrouwen voor de eerstelijnszorg.

Uit het onderzoek bleek dat de attitudes van mannen en vrouwen ten aanzien van de (huisarts)geneeskunde verschilden. Vrouwelijke studenten werden meer dan mannelijke studenten aangetrokken tot werken met chronische patiënten, palliatieve zorg en een beheersbare levensstijl. Mannelijke studenten waren meer geïnteresseerd in de technische aspecten van het werk, acute patiëntenzorg en het prestige van het artsenberoep. $\mathrm{Na}$ het coschap werden de intrinsieke aspecten van het huisartsenberoep even sterk gewaardeerd door de mannelijke en de vrouwelijke studenten.

De regressieanalyse liet zien dat een positieve waardering voor de intrinsieke aspecten van het werk van de huisarts voorspellend was voor een sterkere waarschijnlijkheid na het coschap om huisarts te willen worden. Levensstijlfactoren bleken minder belangrijk te zijn dan de inhoud van het werk. We concluderen hieruit dat de voorkeur voor het huisartsenvak in deze fase van het opleidingscontinuüm gebaseerd is op een individuele keuze, voornamelijk bepaald door een initiële interesse in het vak en minder door levensstijlfactoren, die vermoedelijk pas later een rol gaan spelen. Zowel voor mannen als voor vrouwen waren interesse in chronische en palliatieve zorg belangrijke determinanten van de voorkeur voor de huisartsgeneeskunde. Mannen en vrouwen verschilden weliswaar in hun voorkeur voor het huisartsenvak, maar in de multivariate analyses verdween het effect van gender ten gunste van andere factoren.

Verder hebben onze resultaten laten zien dat het coschap de studenten, mannen meer dan vrouwen, motiveerde om huisarts te worden. Dit enthousiasme verflauwde echter na verloop van tijd met name onder de vrouwen.

Het feit dat zowel de mannelijke als de vrouwelijke studenten vooral aangetrokken werden door intrinsieke aspecten van het vak en dat gemotiveerde vrouwelijke studenten na verloop van tijde hun interesse verloren, kan mogelijk verklaren waarom de toename van het aantal vrouwelijke studenten niet gepaard gaat met een stijging in populariteit van de huisartsgeneeskunde.

In Hoofdstuk 7 zijn de belangrijkste resultaten van de bovengenoemde studies samengevat en besproken. Het belangrijkste sterke punt van dit onderzoek is dat de volledige populatie huisartsen is onderzocht (met uitzondering van een relatief kleine groep die zich onmiddellijk na het voltooien van de opleiding vestigde).

In de onderzoeksperiode van 25 jaar zijn de verschillen tussen de voorkeuren van mannen en vrouwen steeds kleiner geworden. Zowel mannen als vrouwen hebben steeds vaker een voorkeur voor een groepspraktijk, voor niet-zelfstandige posities (HIDHA) en voor associaties. De meeste huisartsen in ons onderzoek hebben hun voorkeur kunnen realiseren. Kennelijk is, tegelijk met de toegenomen vraag ernaar, het aantal plaatsen in 
groepspraktijken gestegen. Dit komt waarschijnlijk doordat vrijkomende solopraktijken meestal worden omgezet in een groepspraktijk. Praktijksoort is niet het enige criterium dat de voorkeur bepaalt. Nader onderzoek is gewenst naar het samenspel van factoren en wensen dat een rol speelt als jonge huisartsen zich gaan vestigen.

De toegenomen interesse in groepspraktijken en in HIDHA-posities kan veroorzaakt zijn door een aantal factoren waaronder de feminisering van de (huisarts)geneeskunde en de daarmee gepaard gaande veranderende attitude ten opzichte van werk en loopbaan. Vrouwen vinden flexibele levensstijlopties belangrijk om werk met gezin te kunnen combineren. Het zou daarom interessant zijn om nader te onderzoeken wat de oorzaken zijn van de feminisering van de geneeskunde, met andere woorden waarom minder mannen geneeskunde kiezen en welke alternatieven daarvoor in de plaats zijn gekomen.

Ook mannelijke huisartsen willen steeds vaker in deeltijd werken. Een interessante vraag voor toekomstig onderzoek is derhalve of deze verandering/ontwikkeling toegeschreven kan worden aan het opkomen van een nieuwe generatie mannelijke artsen of aan het feit dat een ander type mannen de huisartsenopleiding gaat volgen.

De groep huisartsen die afziet van vestiging is eveneens nader onderzocht. De meest voorkomende reden om te stoppen met zoeken was dat men geen praktijk vond die aan de wensen voldeed. Voor vrouwen speelden bovendien gezinsomstandigheden een rol en voor mannen financiële overwegingen. De groep die afziet van vestiging is vrij omvangrijk. Daarom is het belangrijk om faciliteiten te creëren die ertoe kunnen bijdragen om huisartsen voor het beroep te behouden. Huisartsen die geen voorkeur voor een bepaalde praktijkvorm aangaven, hadden de grootste kans zich niet te vestigen. Daarom verdient deze groep aandacht. Het ontbreken van een praktijkvoorkeur zou een teken kunnen zijn van een geringere interesse in het beroep. Bovendien is gebleken dat een deel van de huisartsen die zich niet vestigden ook niet van plan was dit te doen. Wellicht zouden opleidingsinstituten hierop attent moeten zijn bij het aannamebeleid voor de opleiding.

De tweede studie betrof de beroepskeuzes van medisch studenten. We konden geen verband vinden tussen de mate van aandacht voor huisartsgeneeskunde in het basiscurriculum en het percentage studenten dat huisartsgeneeskunde kiest. Er zijn waarschijnlijk andere factoren die deze keuze bepalen, zoals individuele voorkeuren, rolmodellen en klinische ervaringen. Het ontbreken van een verband tussen de huisartsgeneeskundige inbreng in het basiscurriculum en de keuze van een vervolgopleiding is verrassend, maar niet problematisch. Het is belangrijk om vast te stellen dat vakgroepen huisartsgeneeskunde, naast het onderwijs betreffende medisch inhoudelijke aspecten, vooral de taak hebben om studenten te laten kennismaken met de rol van de huisartsgeneeskunde in de gezondheidszorg. Ook toekomstige ziekenhuisspecialisten moeten op de hoogte 


\section{Samenvatting}

zijn van de taken van de huisarts om in de toekomst goed met de eerstelijnszorg te kunnen samenwerken.

Tot slot bleek uit ons onderzoek naar de motivatie van coassistenten om een bepaald specialisme te kiezen dat klinische ervaringen hierin een belangrijke rol kunnen vervullen, hoewel de belangstelling na verloop van tijd ook weer kan afnemen. Om de eenmaal gewekte belangstelling voor een bepaald vak vast te houden zouden studenten wellicht veelvuldiger dan nu het geval is in contact gebracht moeten worden met het betreffende vak. 


\section{Dankwoord}

Dit onderzoek is met een student-assistentschap begonnen en tot een proefschrift uitgegroeid. Het is een lang traject geworden waar veel mensen aan gewerkt hebben. Zonder hun bijdrage en steun was het zeker niet tot stand gekomen. Hierbij wil ik iedereen bedanken die met mij samen op dit pad gelopen heeft.

Ten eerste, een bijzondere dank aan Lud van de Velden. Beste Lud, je bent geen officiële promotor, maar door alle moeite en werk die je aan onze gezamenlijke stukken besteed hebt, ben je dat natuurlijk wel. Zonder jouw hulp en kennis waren we nooit zo ver gekomen. Van jouw nauwkeurigheid en precisie kan ik zeker leren. Heel erg bedankt voor alles wat je gedaan hebt! Het is echt een hele grote bijdrage geweest.

Mijn (co) promotoren, Jouke van der Zee, Fred Stevens en Albert Scherpbier: ik vond onze bijeenkomsten altijd nuttig en gezellig tegelijk. Het werd ook steeds leuker naarmate ik meer Nederlands kon verstaan. Jullie hebben altijd voor mij klaar gestaan, me gesteund en, vooral veel geduld met me gehad. Door jullie kennis en kunde is het uiteindelijk toch gelukt om een proefschrift te maken. Ik merkte dat jullie in mij geloofden en dat heeft mij gestimuleerd om door te zetten.

Beste Fred, jij hebt als niemand anders veel werk aan mij gehad. Ik heb grote waardering voor alle moeite, begeleiding en aandacht die je me door de jaren heen geschonken hebt. Niet alleen voor mijn proefschrift, maar ook voor mijn studie en werk. Beste Jouke, jouw brede kijk en kritische commentaar hebben de stukken altijd aangescherpt. Je wist steeds net vanuit een andere hoek te kijken en er de juiste draai aan te geven. Beste Albert, wat een positieve energie en enthousiasme! Dat heeft mij altijd goed gemotiveerd. Zulke snelle reacties op mijn mails krijg ik waarschijnlijk van niemand meer! Bedankt dat je het hele traject voor mij mogelijk hebt gemaakt.

Paul Zwietering, beste Paul, dank voor de samenwerking. Het is geen gemakkelijke opgave geweest, maar met je hulp is het artikel (hoofdstuk 4) toch tot stand gekomen.

Beste Mereke, je hebt heel erg geholpen met het taalgedeelte! Het heeft mij veel moeite en tijd bespaard. Bedankt voor het vertalen, corrigeren en voor de nuttige suggesties.

Beppie Boode, bedankt voor het organiseren van de vragenlijsten en het meedenken.

Bedankt NIVEL medewerkers voor het beoordelen van mijn artikelen en voor de data die ik mocht gebruiken. Lammert Hingstman, bedankt voor het helpen met de data verzamelen van hoofdstukken 2 en 3 .

Dank aan onderwijssecriatariaat van interne en chirurgie voor helpen met de vragenlijsten. 


\section{Dankwoord}

Linda Schilder, bedankt voor de hulp bij het uitdelen, printen en organiseren van de vragenlijsten. Het is een grote klus geweest! Dank aan alle huisartsopleiders die mee geholpen hebben met de vragenlijsten.

Arno Muijtjens en Jos Diederiks, bedankt voor de hulp bij de statistiek. Zelf opzoeken werkt ook wel maar van de discussies leer je altijd meer.

Beste leden van de leescommissie: prof.dr. J.A. Knottnerus, prof.dr. J. CohenSchotanus, prof. dr. T. Lagro- Janssen, prof. dr. A.C. Nieuwenhuijzen Kruseman, prof. dr. C.P.M. van der Vleuten bedankt voor het beoordelen en goedkeuren van het manuscript.

Beste Marjoke en Sylvia, jullie ken ik sinds mijn eerste dag in Maastricht. Door jullie warmte en vriendelijkheid voelde ik mij altijd welkom op de afdeling. Bedankt voor de hulp en gezelligheid! Marjoke's "Theeee!!!" over de hele gang zal ik nooit vergeten.

Mijn kamergenootjes: Gonnie, Lonneke en Jeantine. Fijn dat jullie er waren voor het gezellige kletsen en ook voor jullie inhoudelijke hulp. Staf $O \& O$, het was leuk om een onderdeel van jullie afdeling te zijn geweest. Kees van der Vleuten, bedankt dat je me hier welkom hebt laten voelen. Beste Lilian, bedankt voor het regelwerk en hulp bij de laatste loodjes.

Mijn ex-collega's uit Sittard, jullie hebben niet veel te maken gehad met mijn proefschrift, maar ik wil jullie hierbij toch nog eens bedanken voor de leerzame en gezellige tijd bij kindergeneeskunde! Jelleke, Nicky, Vicky, Jeanine en Agnes: ik hoop dat wij nog wel door blijven gaan met onze avondjes van de ex-Sittard club!

Beste George, Wilbert en Annemiek, ik ben heel blij om jullie als huisartsopleiders te hebben. Jullie hebben er zeker toe bijgedragen dat ik huisartsgeneeskunde zo leuk vindt. Het is erg fijn om iedere dag met plezier naar het werk te gaan!

Ik wil mijn lieve vrienden bedanken voor de steun en gezelligheid. Jullie zijn allemaal heel kostbaar voor mij. Ook al zien we elkaar soms maar zelden, ben ik heel blij met jullie. Mijn paranimfen, Helen, mijn eerste vriendin in Nederland, bij jou voel ik mij net als thuis, je weet mij goed op mij gemak te stellen. Casper, het is begonnen met een gebroken been en uitgegroeid tot een waardevolle vriendschap. Ik heb altijd een beetje een "familiebezoek" gevoel als ik bij jou en Carijn ben.

Beste Michael, de allerlaatste loodjes zijn wat zwaar gevallen. Dank je dat je me geholpen hebt met die grote bagage aan promotie ervaring van jou! Die heeft mijn laatste loodjes lichter gemaakt. 
Lieve Timo, jij hebt veel van mijn traject meegekregen. Dank je voor je begrip, goede gesprekken, je motivatie en alle hulp. Het heeft veel voor mij betekend.

My dear mama, thank you always being there for me. I have learned from you to work hard, which was very helpful for me to get where I am now. My dear mama, papa, Gena and Vera, thank you for helping me to become the person I am now. It is not always easy for you to understand what I am doing here in the Netherlands and how things proceed in another country, but your emotional support and advice are all that I could wish for!

Vanja, my brother, we live a long distance from each other. Nevertheless, I am very happy to have you. When I left, you were a sweet little boy and now you have grown into a strong charming man. I hope we will be able to see each other more often. 


\section{Curriculum Vitae}

Tanja Maiorova was born on the 8th of October 1979 in Moscow, Russia. She obtained her secondary school diploma at the Lyceum of Computer Technologies N1533 in Moscow in 1996. From 1996 to 1999 she studied medicine at Moscow State University. In 1999 she won a Nuffic scholarship and came to Maastricht University, the Netherlands to study the organisation of health care systems in Europe at the department of Medical Sociology, and also attended $4^{\text {th }}$ year units of the medicine curriculum 1999/2000. After this, she returned to Russia and completed another semester at the medical faculty in Moscow. Following this, in 2001 she came to Maastricht more permanently. In 2001 2002 she studied Psychology at Maastricht University. During this year she started her research on the career choices of medical students. In 2002 she started studying medicine at the Maastricht University. In 2004 she obtained her Master's degree cum laude and in 2006 she graduated as a medical doctor. In 2007-2008 she worked as a physician not in training for specialist (ANIO) at the department of paediatrics of the Maasland Hospital in Sittard. Subsequently, she worked on her thesis at the department of Educational Development and Research, University of Maastricht. Since September 2008 she participates in the training program for general practice at the Julius Centrum, University of Utrecht. 